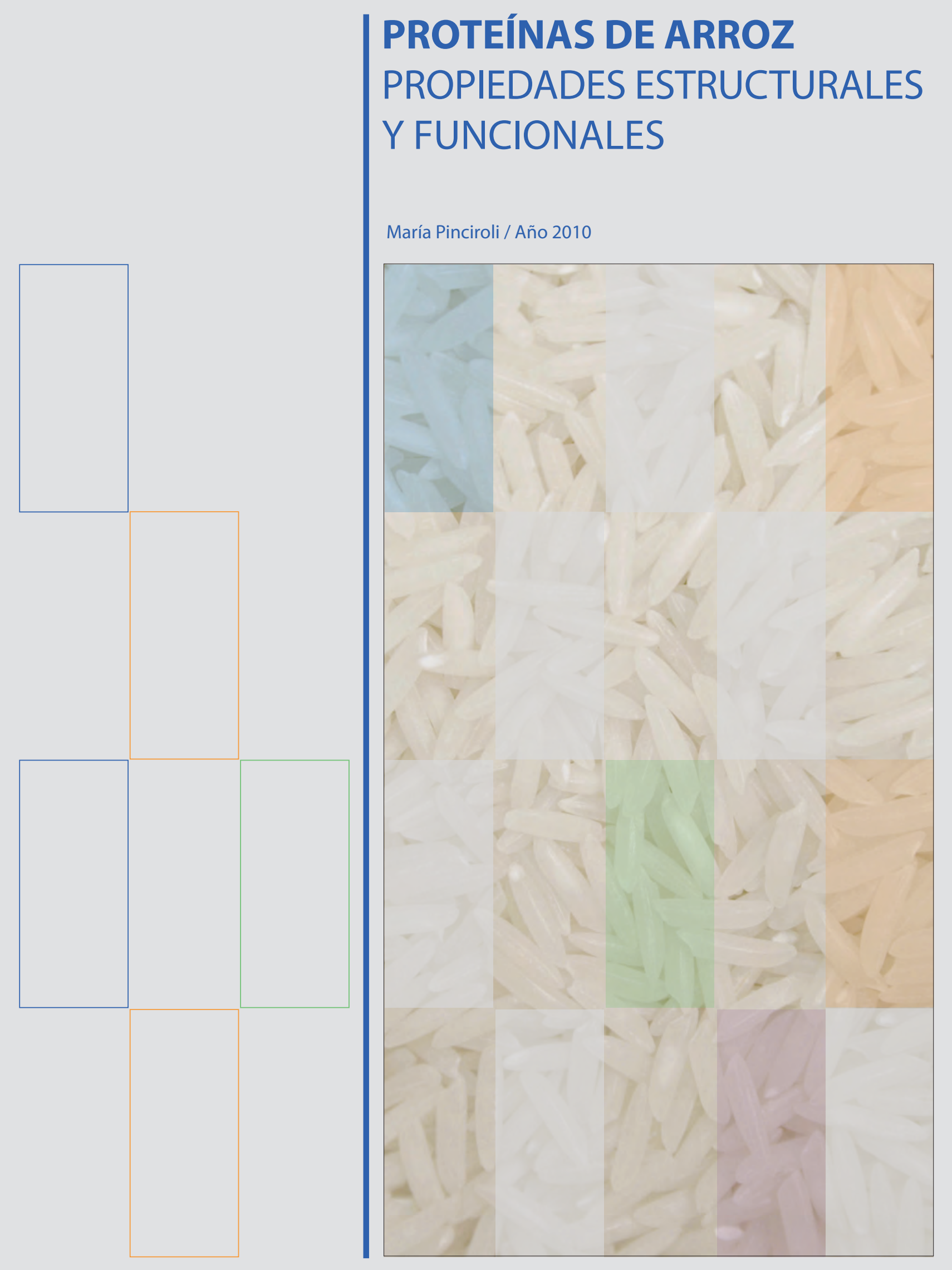




\section{PROTEÍNAS DE ARROZ PROPIEDADES ESTRUCTURALES Y FUNCIONALES}

Ingeniero Agrónomo: María Pinciroli²

Director: Dra. Estela Nora Martínez ${ }^{1}$

Co-Director: Ing. Agr. Alfonso Andrés Vidal2

(1) Centro de Investigación y Desarrollo en Tecnología de Alimentos (CIDCA). Calle 47 y 116, La Plata, Buenos Aires.

(2) Programa Arroz, Universidad Nacional de La Plata.

Calle 66 y 167, Los Hornos - La Plata, Buenos Aires, Argentina.

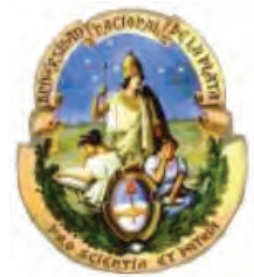

UNIVERSIDAD NACIONAL DE LA PLATA Magister en Tecnología e Higiene de los Alimentos Programa Arroz

Facultad de Ciencias Agrarias y Forestales Centro de Investigación y Desarrollo en Criotecnología de Alimentos

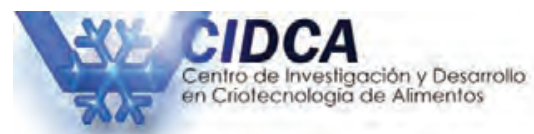


Cuando creíamos que teníamos todas las respuestas de pronto cambiaron todas las preguntas.

Mario Benedetti 
Quiero expresar mi más sincero agradecimiento a mi Directora, quien me ha guiado con un dedicado y exhaustivo seguimiento de todas las tareas de laboratorio y de gabinete realizadas.

A todo el cuerpo jerárquico y docente del Magister en Tecnología e Higiene de los Alimentos, en especial, a su Directora y Secretario quienes en el año 2004 me impulsaron a realizarlo y a los integrantes del Programa Arroz de la Facultad de Ciencias Agrarias y Forestales por permitirme completar la tesis.

Asimismo no tengo palabras para agradecerles de corazón a todos los queridos jóvenes del laboratorio de proteínas por su alegría permanente y su generosidad sin límites.

María.

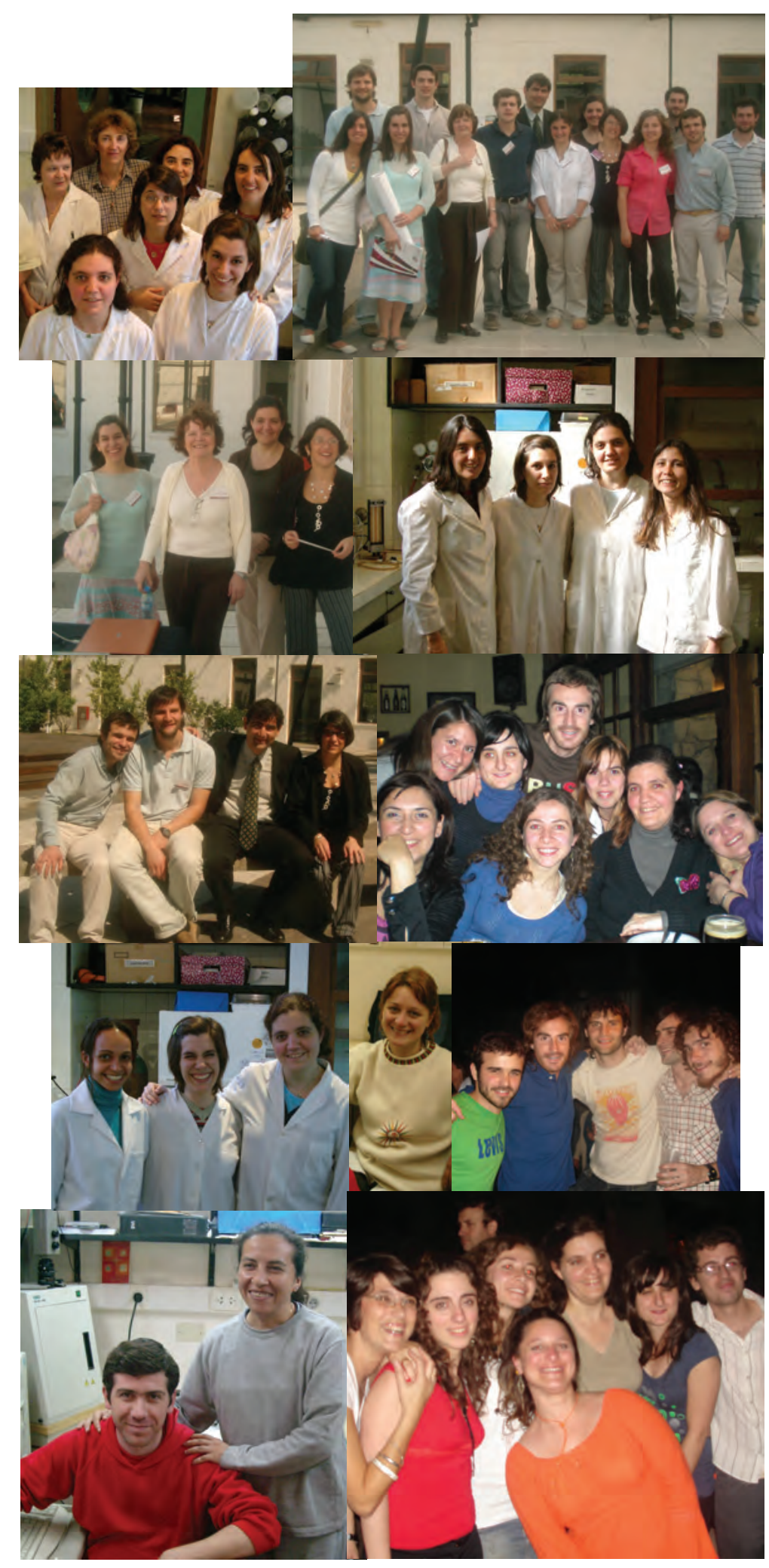


ÍNDICE 


\section{Í NDI CE}

\section{1 / INTRODUCCIÓN}

1.1 Generalidades del cultivo de arroz

1.1.1 I mportancia mundial de cultivo de arroz. Comercialización ........ 1

1.1.2 Importancia del cultivo en Argentina ............................. 2

1.1.3 Morfología del grano ............................................. 2

1.1.4 Industrialización (molinado). Fracciones de molino .................. 3

1.2 Composición química de los cereales. Composición química del grano de arroz 2 2 3

1.3 Proteínas de almacenamiento en las semillas de los cereales en general

1.3.1 Definición - Generalidades ..................................... 6

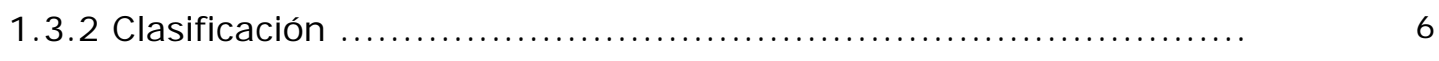

1.3.3 Síntesis, transporte y acumulación ............................. 8

1.4. Proteínas de reserva del grano arroz

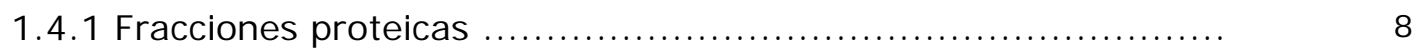

1.4.1.a Albúminas ............................................. 8

1.4.1.b Globulinas ......................................... 9

1.4.1.c Prolaminas .............................................. 10

1.4.1.d Glutelinas ............................................ 10

1.4.2 Síntesis, transporte y almacenamiento de las proteínas del

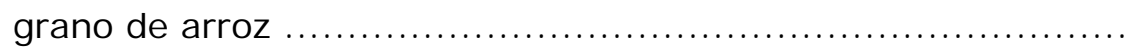

1.4.3 Composición aminoacídica. Valor nutricional y metabolismo

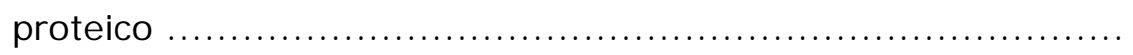

1.5. Concentrados y aislados proteicos

1.5 .1 Generalidades ........................................... 15

1.5.2 Concentrados y aislados proteicos de arroz ..................... 15

1.5.2a Obtención de aislados y concentrados proteicos a partir

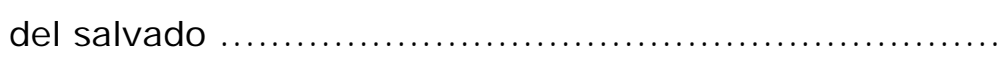

1.5.2b Obtención de aislados y concentrados proteicos a partir del endosperma ........................................ 17

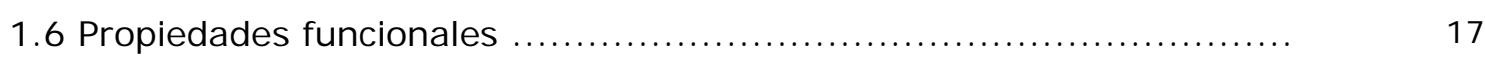

1.6.1 Propiedades dependientes de la interacción agua-proteína ....... 18

1.6.1a Solubilidad ............................................. 20

1.6.1b Capacidad de retención de agua (WHC) .................... 21 
1.6.1c Capacidad de imbibición de agua (WIC) .................. 21

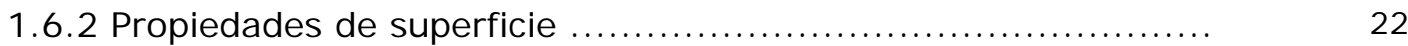

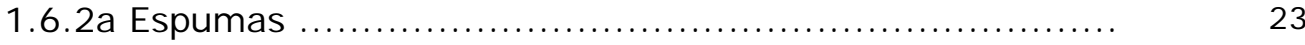

1.6.2b Emulsiones ........................................... 24

1.6.3. Propiedades dependientes de la interacción proteínas - lípidos 1.6.3a Absorción de aceite

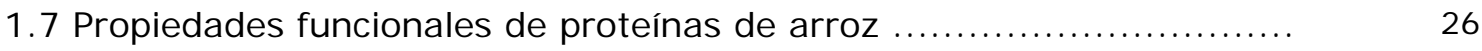

1.8 Hipótesis de trabajo y objetivos .................................... 27

\section{2 / MATERI ALES Y MÉTODOS}

2.1 Materiales: Semillas y harinas

2.2 Preparación de muestras

2.2.1 Extracción de las fracciones y subfracciones proteicas ........... 30

2.2.2 Extracción de proteínas totales ................................ 30

2.2.3 Preparación de aislados proteicos .............................. 31

2.3 Electroforesis

2.3.1 Reactivos generales ....................................... 31

2.3.2 Preparación de las muestras ............................... 32

2.3.3 SDS-PAGE. Desarrollo ..................................... 32

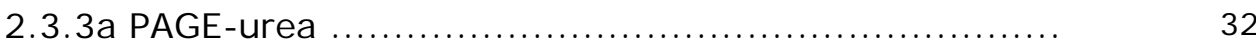

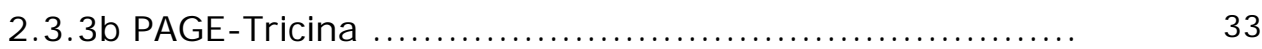

2.3.3c Electroforesis bidimensionales (SDS-PAGE $\rightarrow$ SDS-

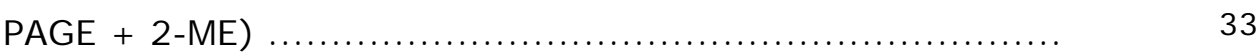

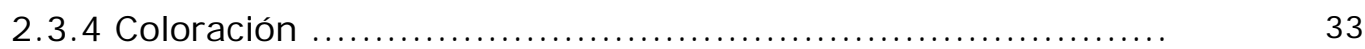

2.3.5 Obtención de las imágenes ............................... 33

2.4 Determinación de la composición aminoacídica ......................... 33

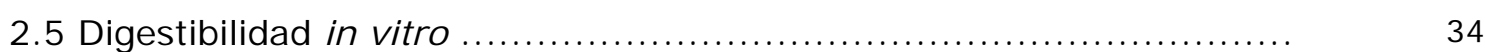

2.6 Solubilidad de las subfracciones y de los aislados proteicos ............. 35

2.7 Capacidad de absorción de agua (WIC) .............................. 35

2.8 Capacidad de retención de agua (WHC) ............................. 36

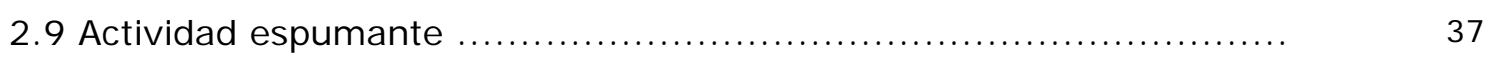

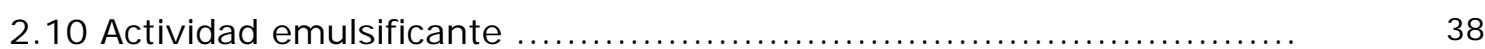

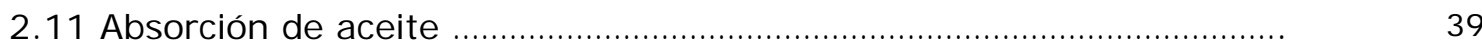

2.12 Análisis estadístico de los resultados y programas utilizados ........... 39 


\section{3 / RESULTADOS Y DISCUSIÓN}

CAPI TULO I. Caracterización estructural de las proteínas de las variedades Nutriar y El Paso 144

I.1 Caracterización polipeptídica

I.2 Análisis cuantitativo de las fracciones proteicas en harinas de grano integral y pulido

I.3 Preparación de aislados proteicos y elección del método a utilizar

I.4 Estructura de aislados extraídos a diferentes pHs

I.5 Rendimiento en la extracción de los aislados a diferentes pHs

I. 6 Conclusiones

CAPITULO II. Caracterización nutricional y funcional de los aislados pulido e integral extraídos a pH 12

II.A Caracterización nutricional de los aislados pulido e integral extraídos a pH 12

II.A. 1 Contenido proteico

II.A.2 Determinación de la composición aminoacídica de los aislados

II.A.3 Digestibilidad in vitro

II.B. Caracterización funcional de los aislados proteicos extraídos a $\mathrm{pH} 12$

II.B.1 Propiedades de hidratación

II.B.1a Solubilidad proteica de los aislados

II.B.1b Solubilidad en agua. Capacidad de retención e imbibición de agua (WHC y WIC)

II.B.1c Capacidad de retención de agua a pHs 3, 6 y 9 ..

II.B.2 Propiedades de superficie

II.B.2a Actividad espumante

II.B.2b Actividad emulsificante

II.B.3 Absorción de aceite

II.B.4 Correlación entre propiedades funcionales evaluadas 
1 INTRODUCCIÓN 


\section{I / I NTRODUCCIÓN}

\subsection{Generalidades del cultivo de ARROZ}

\subsubsection{I mportancia mundial del cultivo de arroz. Comercialización}

El arroz (Oryza sativa L.) es cultivado y consumido por la humanidad desde hace más de 5000 años y en la actualidad es producido en 112 países cubriendo todos los continentes. Constituye uno de los principales alimentos para el $60 \%$ de la población mundial, siendo la base de la alimentación en los países asiáticos donde la población tiene una tasa de crecimiento del 1,8\% anual (Katsube-Tanaka et al., 2004 a).

Tabla 1 : Principales productores mundiales de arroz elaborado

\begin{tabular}{|lcc|}
\hline $\begin{array}{c}\text { Países } \\
\text { Productores }\end{array}$ & Producción (TN) & $\begin{array}{c}\text { Porcentaje del } \\
\text { Total Mundial }\end{array}$ \\
\hline China & 125.363 .000 & 31,17 \\
India & 85.310 .000 & 21,21 \\
Indonesia & 34.250 .000 & 8,52 \\
Vietnam & 22.716 .000 & 5,65 \\
Tailandia & 17.070 .000 & 4,24 \\
Filipinas & 9.445 .000 & 2,35 \\
Japón & 7.944 .000 & 1,98 \\
Brasil & 8.996 .000 & 2,24 \\
Resto del mundo & 91.115 .000 & 22,65 \\
Total Mundial & $\mathbf{4 0 2 . 2 0 9 . 0 0 0}$ & $\mathbf{1 0 0}$ \\
\hline
\end{tabular}

Fuente: USDA; Marzo 2006.

La producción total mundial de arroz es de aproximadamente 400 millones de toneladas de arroz elaborado (SAGPyA, 2008) siendo el segundo cereal después del trigo en producción y uso para la alimentación. El 95\% del total de la producción mundial de arroz se lleva a cabo en los países en desarrollo, y China e India, juntos, son responsables de más de la mitad de esta producción. China es el principal productor, participando con un 31\% de la producción, seguida de India, Indonesia, Vietnam y Tailandia (Tabla 1). La producción del MERCOSUR es de 
aproximadamente 11 millones de toneladas de las cuales un millón es producido por nuestro país lo que representa un $0,25 \%$ de la producción mundial (SAGPyA, 2008).

\subsubsection{I mportancia del cultivo en Argentina}

En Argentina, la producción de arroz se concentra en el litoral. Entre Ríos y Corrientes son las provincias de mayor producción, según datos de la última campaña representan el 38 y el $48 \%$ respectivamente. Entre ambas representan el $87-88 \%$ de la superficie total de cultivo de arroz del país; el $12 \%$ restante se reparte entre las provincias de Santa Fe, Chaco, Formosa y Misiones.

\subsubsection{Morfología del grano}

El grano de arroz, comunmente llamado semilla, recién cosechado está formado por el fruto cariopse y por la cáscara, está última compuesta por las glumelas (palea y lema). Industrialmente se considera al arroz cáscara aquel comprendido por el conjunto de cariopse y glumelas (Figura 1).

A su vez el cariopse, está formado por el embrión, el endosperma, capas de aleurona (tejido rico en proteínas), tegmen (cubierta seminal), y el pericarpio (cubierta del fruto).

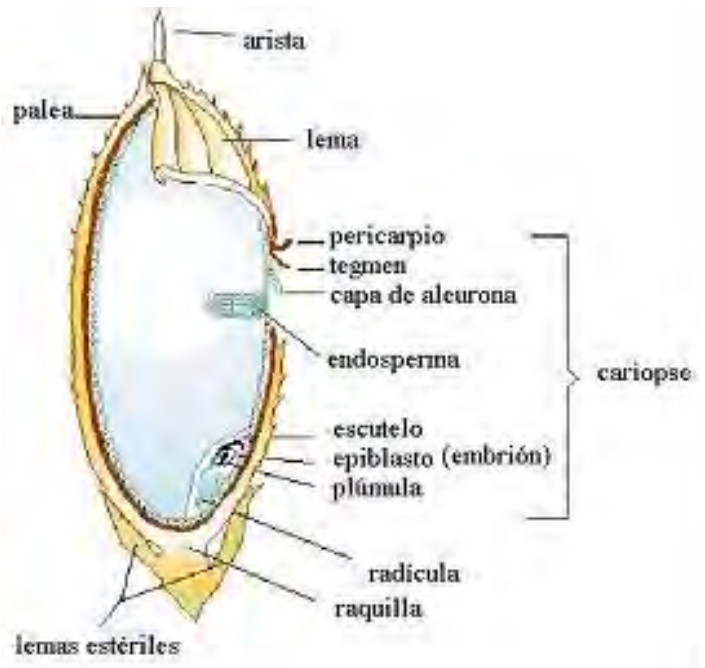

Figura 1. Partes constitutivas del grano de arroz
El pericarpio es piloso y tiene un espesor de aproximadamente $10 \mu \mathrm{m}$. Las capas de aleurona están compuestas por 1 a 7 capas de células de parénquima cuadrangular o rectangular, de 1-3 $\mu \mathrm{m}$ de espesor. El embrión es extremadamente pequeño, localizado en la zona ventral del cariopse. El endosperma consiste en células de parénquima que se elongan en forma radial y está compuesto por gránulos de almidón y algunos cuerpos proteicos

(Juliano, 1980; Juliano, 1985). La representatividad de estas capas del grano es importante dado que influyen en el rendimiento industrial. 


\subsubsection{I ndustrialización (molinado). Fracciones de molino}

El destino principal de la producción total es el consumo interno. Sobre una producción de 1.027.000 toneladas, el 84,5\% corresponde al tipo comercial largo fino (LF) y el $15,5 \%$ restante al tipo largo ancho o doble carolina (LA) (SAGPyA, 2008). El número de molinos arroceros ha decrecido en los últimos años debido a las distintas crisis que atravesó el sector arrocero en particular y el país en general. Actualmente se cita la existencia de 49 molinos arroceros, distribuidos de la siguiente manera: 35 en la provincia de Entre Ríos, 9 en Corrientes, 3 en Santa Fe, 1 en Misiones y 1 en Buenos Aires.

El proceso de industrialización tradicional del arroz, involucra las actividades que transforman el arroz cáscara (materia prima) en arroz elaborado (blanco o

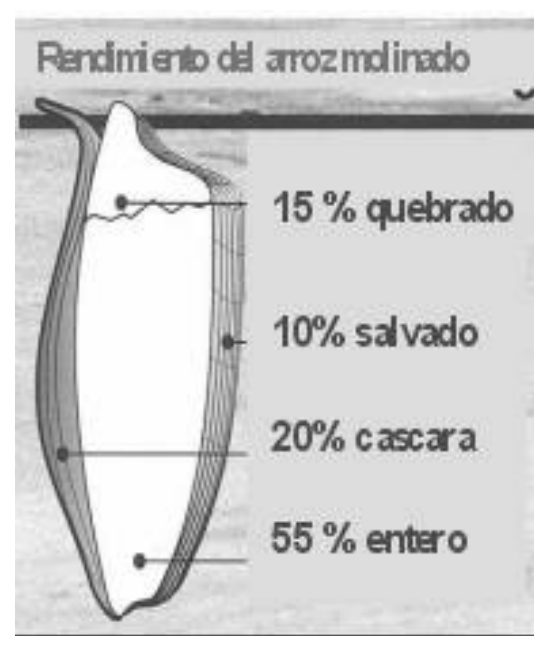

Figura 2. Productos y rendimiento del arroz en molino (Shih, 2003) pulido), con el objetivo de hacer el producto apto para el consumo humano (Figura 2). A diferencia de los otros cereales, en donde el grano es molido para convertirlo en harina, en la elaboración de arroz el objetivo consiste en mantener la mayor cantidad posible de granos intactos como arroz entero. La eficacia técnica del proceso de elaboración, o sea, el rendimiento industrial, se juzga por la cantidad de arroz entero obtenido a partir de una cantidad determinada de arroz cáscara.

Del arroz cosechado, aproximadamente $20 \%$ es cáscara, y 10 $\%$ es salvado, ambos elementos se eliminan en los procesos de descascarado y pulido respectivamente. El resto (70\%), está formado por granos de arroz blanco o pulido, entero y partido (o quebrado). El arroz pulido está constituido fundamentalmente por el endosperma, el salvado por el embrión y las capas externas (aleurona, tegmen, y pericarpio) y el arroz integral por ambos (endosperma y salvado).

En Argentina, como en la gran mayoría de los países consumidores, el uso más difundido de este cereal es como grano pulido constituido fundamentalmente por el endosperma, aunque en la actualidad se está incentivando el consumo de arroz integral (solamente descascarado, endosperma más aleurona, embrión y 
pericarpio). Los granos enteros son ricos en fibra, vitaminas del complejo B, minerales, tocoles y fitonutrientes. Estudios epidemiológicos demuestran una relación inversa entre las raciones ingeridas diariamente de granos enteros o de alimentos que los contienen y el riesgo de desarrollar enfermedades crónicas no transmisibles como la enfermedad cardiovascular, diabetes tipo 2 y cáncer (Nelina y Ruíz, 2005). El efecto protector parece estar mediado por la acción combinada y sinérgica de los diferentes compuestos encontrados en los granos enteros. La ingesta de granos enteros puede contribuir a elevar la capacidad antioxidante corporal por lo que posiblemente sea uno de los mecanismos a través de los cuales los granos enteros prevengan tales enfermedades. Entre los antioxidantes encontrados en los granos se cuentan los ácidos fenólicos, flavonoides, tocoferol, tocotrienoles, selenio, zinc, fibra soluble y ácido fítico (Nelina y Ruíz, 2005).

Más allá de la amplia utilización del grano entero de arroz existen subproductos industriales como el arroz partido y el salvado de arroz, de bajo valor comercial por su escasa funcionalidad. A partir de estos productos se pueden obtener ingredientes que, presentando buenas propiedades nutricionales y funcionales, constituyan un aporte para la industria alimentaria. Es así como la industria procesa el arroz partido y la harina de arroz para la obtención de almidón quedando la proteína como subproducto no aprovechado.

\subsection{Composición química de los cereales. Composición química del grano de arroz}

En la Tabla 2 se puede observar comparativamente la composición química del arroz con respecto a la de otros cereales.

Si bien su contenido de proteína es bajo (7-9\% promedio en peso) el grano de arroz es la mayor fuente proteica en los países consumidores de este cereal aportando el $60 \%$ de la proteína total de la dieta en Asia (Shih, 2003). Se conocen variedades de arroz salvaje en China y Estados Unidos con 12,0 y $15,2 \%$ de proteína en grano integral (Zhai et al., 2001).

El contenido de proteína del arroz es diferente según la fracción de molino que se considere como podemos observar en la Tabla 3. El mayor contenido proteico corresponde al embrión pero su tamaño es muy pequeño. 
Tabla 2. Composición y balance de energía de cereales*

\begin{tabular}{|c|c|c|c|c|c|c|c|}
\hline Propiedad & $\begin{array}{c}\text { Arroz } \\
\text { integral }\end{array}$ & trigo & maíz & cebada & sorgo & centeno & avena \\
\hline $\begin{array}{l}\text { Proteína }^{a} \\
(N \times 6,25)\end{array}$ & 7,3 & 10,6 & 9,8 & 11,0 & 8,3 & 8,7 & 9,3 \\
\hline Lípidos $^{a}$ & 2,2 & 1,9 & 4,9 & 3,4 & 3,9 & 1,5 & 5,9 \\
\hline Carbohidratos $^{a}$ & 64,3 & 69,7 & 63,6 & 55,8 & 58,0 & 71,8 & 62,9 \\
\hline Fibra cruda $^{a}$ & 0,8 & 1,0 & 2,0 & 3,7 & 4,1 & 2,2 & 5,6 \\
\hline Cenizas $^{a}$ & 1,4 & 1,4 & 1,4 & 1,9 & 2,6 & 1,8 & 2,3 \\
\hline $\begin{array}{l}\text { Digestibilidad } \\
\text { verdadera }^{a}\end{array}$ & 99,7 & 96,0 & 95,0 & 88,0 & 84,8 & 77,0 & 84,1 \\
\hline $\begin{array}{l}\text { Utilización neta } \\
\text { de la proteína }{ }^{a}\end{array}$ & 73,8 & 53,0 & 58,0 & 62,0 & 50,0 & 59,0 & 59,1 \\
\hline $\begin{array}{l}\text { Energía } \\
\text { digestible }^{b}\end{array}$ & 1550 & 1360 & 1450 & 1320 & 1290 & 1330 & 1160 \\
\hline
\end{tabular}

Fuente: Juliano, 1985. *Datos calculados a $14 \% \mathrm{H} ;{ }^{a}$ valores expresados en $\%$; ${ }^{b}$ valores expresados en $\mathrm{kJ} \cdot 100^{-1}$.

Tabla 3. Composición aproximada del grano de arroz y sus fracciones*

\begin{tabular}{|l|c|c|c|c|c|c|}
\hline & $\begin{array}{c}\text { Arroz } \\
\text { cáscara }\end{array}$ & $\begin{array}{c}\text { Grano } \\
\text { integral }\end{array}$ & $\begin{array}{c}\text { Grano } \\
\text { pulido }\end{array}$ & cáscara & salvado & embrión \\
\hline Proteína & $6,7-8,3$ & $8,3-9,6$ & $7,3-8,3$ & $2,3-3,2$ & $13,2-17,3$ & $17,7-23,9$ \\
\hline Lípidos & $2,1-2,7$ & $2,1-3,3$ & $0,4-0,6$ & $0,4-0,7$ & $17,0-22,9$ & $19,3-23,8$ \\
\hline Fibra cruda & $8,4-12,1$ & $0,7-1,2$ & $0,3-0,6$ & $40,1-53,4$ & $9,5-13,2$ & $2,8-4,1$ \\
\hline Cenizas & $3,4-6,0$ & $1,2-1,8$ & $0,4-0,9$ & $15,3-24,4$ & $9,2-11,5$ & $6,8-10,1$ \\
\hline Almidón & 62,1 & 77,2 & 90,2 & 1,8 & 16,1 & 2,4 \\
\hline $\begin{array}{l}\text { Fibra } \\
\text { dietaria }\end{array}$ & 19,1 & 4,5 & 2,7 & 77,3 & $27,6-33,3$ & - \\
\hline
\end{tabular}

Fuente: Pomeranz and Ory, 1982.* Datos calculados en base seca.

\section{Características de las variedades Nutriar FCyF y El Paso 144}

El Programa Arroz de la Facultad de Ciencias Agrarias de la Universidad Nacional de La Plata es un programa de mejoramiento que tiene entre sus objetivos no solo, obtener variedades con mayores rendimientos, sino también mejorar la tolerancia a bajas temperaturas, y acentuar caracteres especiales entre ellos el contenido proteico. Entre sus logros se destaca el cultivar Nutriar inscripto en el año 2003. Esta variedad se caracteriza por poseer valores de proteína en grano que superan en un 25 a $30 \%$ el promedio de las variedades cultivadas en la actualidad (Bezus et al., 2002). Es una variedad de tipo semi-enano, con alta capacidad de 
macollaje que ha mostrado altos rendimientos. El grano es de tipo comercial largo fino, con una relación largo/ancho de 3 para grano elaborado y un peso de $26 \mathrm{~g} / \mathrm{mil}$ granos cáscara. Posee buenos valores de rendimiento industrial con un $63 \%$ de grano entero. (Bezus et al., 2002). Su calidad culinaria está caracterizada por valores bajos de amilosa e intermedios de temperatura de gelatinización.

El cultivar El Paso 144 fue lanzado por la Estación Experimental del Este (República Oriental del Uruguay) en 1986. En Argentina fue inscripto como introducción en el año 1994. Es de origen tropical, de tipo semienano, con alto potencial de rendimiento, alta capacidad de macollaje y hojas erectas, pubescentes, de color verde claro. Su altura media es de $87 \mathrm{~cm}$ dependiendo de las condiciones de crecimiento. Posee grano tipo largo fino, con cáscara color pajizo, pubescente, con aristas de tamaño variable, una relación largo/ancho mayor de 3 para grano elaborado y un peso de $26,5 \mathrm{~g} /$ mil granos cáscara. Su calidad molinera presenta valores de grano entero superiores a la base de comercialización (57\%). Su calidad culinaria está caracterizada por un alto porcentaje de amilosa, una temperatura de gelatinización baja que le imprime un comportamiento de arroz suelto después de la cocción (Libore, 2006).

\subsection{Proteínas de almacenamiento en las semillas de los cereales en general}

\subsubsection{Definición - Generalidades}

Si bien en las semillas existen tres grupos de proteínas: las estructurales, las biológicamente activas llamadas "housekeeping" y las de reserva o almacenamiento, estas últimas constituyen más del $80 \%$ y son por lo tanto las que más influyen en la calidad nutricional proteica de la semilla. Las proteínas de almacenamiento son aquéllas cuya velocidad de síntesis se incrementa notablemente durante el desarrollo de la semilla y se acumulan en vesículas rodeadas de membrana denominadas cuerpos proteicos. Posteriormente, durante la germinación, estas proteínas son degradadas para proveer, principalmente, nitrógeno reducido y secundariamente carbono, con el fin de sostener el crecimiento del brote y el desarrollo inmediato luego de la germinación.

\subsubsection{Clasificación}

Los trabajos de Osborne fueron pioneros en la sistematización del estudio de las proteínas de plantas e introdujeron una clasificación, ampliamente utilizada, que 
se basa en la solubilidad mostrada por las proteínas en diferentes medios a lo largo de una extracción secuencial (Osborne, 1924). Los grupos proteicos extraídos en cada etapa de la serie de extracciones se denominan "fracciones de Osborne" y son los siguientes: albúminas, solubles en agua; globulinas, solubles en soluciones salinas diluidas y neutras; prolaminas, solubles en alcohol o en mezclas de alcoholagua y glutelinas, solubles en soluciones alcalinas o ácidas. Esta clasificación fue introducida antes de que se posea un detallado conocimiento de la estructura y características genéticas de las diferentes proteínas, por lo que con el correr del tiempo se han desarrollado otras clasificaciones.

Posteriormente se elaboró una clasificación basada en la estructura de los genes, la homología de las secuencias de aminoácidos y su mecanismo de acumulación en los cuerpos proteicos (Fukushima, 1991). Esta clasificación divide a las proteínas de reserva en dos tipos, las globulinas y las prolaminas.

Tabla 4. Clasificación de las proteínas de almacenamiento de vegetales en base a sus características moleculares y genéticas

\begin{tabular}{lcc}
\cline { 2 - 3 } & GLOBULI NAS & PROLAMI NAS \\
\hline $\begin{array}{l}\text { Mecanismos de } \\
\text { acumulación en los } \\
\text { cuerpos proteicos }\end{array}$ & Acumulación en vacuolas & Acumulación directa \\
\hline Estructura genética & Con intrones & Sin intrones \\
\hline $\begin{array}{l}\text { Secuencia de } \\
\text { aminoácidos }\end{array}$ & Sin secuencias que se & Con secuencias que se \\
repiten & repiten \\
\hline Proteínas de & Glutelina de arroz & $\begin{array}{c}\text { Prolamina de arroz } \\
\text { almacenamiente maíz }\end{array}$ \\
& Glicinina de soja & Hordenina de cebada \\
& Conglicinina de soja & Glutenina APM de trigo \\
& Legumina de arveja & Gliadina de trigo \\
& Vicilina de arveja & Glutenina APM de centeno \\
& Faseolina de poroto & Secalina de centeno \\
\hline
\end{tabular}

Fuente: Fukushima, 1991.

Las primeras se caracterizan por acumularse en cuerpos proteicos o vacuolas derivadas del aparato de Golgi, sus genes contienen varios intrones y la estructura primaria de la proteína no presenta secuencias repetitivas. Por otro lado las prolaminas se acumulan dentro de cuerpos proteicos derivados del retículo endoplásmico, sus genes a pesar de ser eucariotas llamativamente no presentan intrones y presentan secuencias de aminoácidos repetitivas en determinadas zonas 
de la molécula. En la Tabla 4 se muestra el agrupamiento de diferentes proteínas de almacenamiento de origen vegetal de acuerdo a esta última clasificación realizada en base a datos compilados por Fukushima (1991).

\subsubsection{Síntesis, transporte y acumulación}

Las proteínas de los cereales se caracterizan en su conjunto por acumularse en el endosperma en lugar de hacerlo en el embrión como en leguminosas. Estas diferencias se reflejan en algunas propiedades fisicoquímicas y van acompañadas por modificaciones en los mecanismos de síntesis, transporte y/o almacenamiento en las semillas. Las especies de cereales más estudiadas son el trigo, cebada, centeno, maíz, arroz y avena.

\subsection{Proteínas de reserva del grano de arroz}

La calidad nutricional de las proteínas de arroz es sólo inferior a la avena y supera a la del trigo y maíz. Son hipoalergérnicas y poseen propiedades anticancerígenas (Tang et al., 2003). Por lo que el arroz es considerado un alimento funcional.

\subsubsection{Fracciones proteicas}

El componente proteico mayoritario del grano de arroz lo constituyen las glutelinas en proporción de $75-90 \%$ con respecto a la proteína total. Son las únicas proteínas de cereales ricas en glutelinas y pobres en prolaminas (J uliano, 1985). En la Tabla 5 se presenta la proporción de las diferentes fracciones proteicas en el grano de arroz según los diferentes autores.

\subsection{1a Albúminas}

Electroforéticamente responde a un patrón muy heterogéneo. En SDS-Page aparecen 12 bandas de peso moleculares que van desde 8,5 a $95 \mathrm{kDa}$, con tres polipéptidos principales de 8,5; 11 y 16 kDa (Juliano, 1980). Se localizan fundamentalmente en la aleurona (Juliano, 1985). 


\subsection{1b Globulinas}

Esta fracción proteica se extrae del residuo de harina resultante de la extracción de las albúminas con soluciones de $\mathrm{pH}$ cercano a la neutralidad y concentraciones salinas elevadas (en general fuerza iónica entre 0,4 y 1,1).

Presentan una banda característica que corresponde a polipéptidos de 25-26 kDa (Krishnan et al., 1992; Komatsu and Hirano, 1992; Furukawa et al., 2003; Kumagai et al., 2006) y otra a los 16-18 (Juliano, 1980; Krishnan et al., 1992). Estudios realizados en el endosperma del grano establecen que ambos polipéptidos ( 25 y $16 \mathrm{kDa}$ ) se localizan en zonas discretas dentro de los cuerpos proteicos irregulares (Krishnan et al., 1992), fundamentalmente en las capas externas del pericarpio del grano (Juliano, 1980) y en el embrión (Sawai and Morita, 1970).

Estudios inmunológicos realizados por Robert et al. (1985) revelan que esta fracción tiene gran similitud con las glutelinas.

Tabla 5. Abundancia relativa de las diferentes fracciones proteicas del grano de arroz pulido e integral

\begin{tabular}{|c|c|c|c|c|}
\hline $\begin{array}{l}\text { Fracción } \\
\text { proteica }\end{array}$ & $\begin{array}{l}\text { Abundancia } \\
\text { Arroz pulido }\end{array}$ & Referencia & $\begin{array}{l}\text { Abundancia }{ }^{a} \\
\text { Arroz integral }\end{array}$ & Referencia \\
\hline Albúminas & $\begin{array}{l}2-5 \\
8 \\
1-5 \\
5 \\
9,7-14,2\end{array}$ & $\begin{array}{l}(1) \\
(5) \\
(6) \\
(8) \\
(7)\end{array}$ & $\begin{array}{l}5-17 \\
11\end{array}$ & $\begin{array}{l}(2) \\
(3) \text { y (4) }\end{array}$ \\
\hline Globulinas & $\begin{array}{l}2-10 \\
10 \\
4-15 \\
13,5-18,9 \\
12\end{array}$ & $\begin{array}{l}(1) \\
(5) \\
(6) \\
(7) \\
(8)\end{array}$ & $\begin{array}{l}4-12 \\
15 \\
10\end{array}$ & $\begin{array}{l}(2) \\
(3) \\
(4)\end{array}$ \\
\hline Glutelinas & $\begin{array}{l}75-90 \\
70 \\
80 \\
63,8-73,4\end{array}$ & $\begin{array}{l}(1) \\
(5) \\
(6) \text { y (8) } \\
(7)\end{array}$ & $\begin{array}{l}73-86 \\
71 \\
77 \\
66-67,7\end{array}$ & $\begin{array}{l}(2) \\
(3) \\
(4) \\
(7)\end{array}$ \\
\hline Prolaminas & $\begin{array}{l}1-5 \\
3-5,4 \\
2-8 \\
3\end{array}$ & $\begin{array}{l}(1) \\
(7) \\
(6) \\
(8)\end{array}$ & $\begin{array}{l}2-5 \\
3 \\
2 \\
12,5-14,5\end{array}$ & $\begin{array}{l}(2) \\
(3) \\
(4) \\
(7)\end{array}$ \\
\hline
\end{tabular}

aAbundancia como \% respecto al total de proteína. (1) Juliano, 1985; (2) Mitra and Das, 1975; (3) Chavan and Duggal, 1978; (4) Wieser et al., 1980; (5) Padhye and Salunkhe, 1979; (6) Krishnan and Withe, 1997; (7) Zhou et al., 2002; (8) Juliano, 1994. 


\subsection{1c Prolaminas}

Las prolaminas constituyen polipéptidos heterogéneos con masas moleculares variables entre 10 y 23 kDa, según los diferentes autores.

Las bandas más marcadas corresponden a los 17 y 23 kDa según Juliano (1980) y a los 10, 13 y 16 kDa según estudios más actuales (Furukawa et al., 2003, Kumagai et al., 2006).

\subsection{1d Glutelinas}

Constituyen la fracción mayoritaria de las proteínas de reserva del arroz. Esta fracción es la que determina el valor nutricional de la proteína de arroz que la convierte en una de las mejores proteínas vegetales (Qu et al., 2001).

El contenido de proteína total se correlaciona positivamente con el de glutelinas (Villareal and Juliano, 1978; Udaka et al., 2000). Se localizan en el endosperma del grano (Villareal and Juliano, 1978). Se caracterizan por su gran insolubilidad que se debe fundamentalmente a la abundancia de puentes disulfuro formando agregados de alto peso molecular (Juliano, 1985). Las glutelinas son prácticamente insolubles excepto en ácidos o álcalis diluidos. A pesar de su insolubilidad en soluciones salinas neutras las glutelinas presentan una estructura general y propiedades fisicoquímicas similares a las globulinas 11S (leguminas) de las leguminosas (Robert et al., 1985). Según Utsumi (1992), existe una homología con la familia de las globulinas por su composición en aminoácidos, y su similar biosíntesis y proceso de acumulación, por lo cual en la clasificación, de Fukushima (1991) integrarían dicha fracción.

Al igual que las leguminas, la fracción glutelina está constituida por dos polipéptidos alfa y beta, ambos unidos por puentes disulfuro (Utsumi, 1992) y por la proglutelina, un polipeptido de $55 \mathrm{kDa}$ no procesado, todos estos polipéptidos estarían formando agregados mediante uniones disulfuro.

Actualmente se han identificado seis genes que las codifican y permiten establecer una clasificación en dos subfamilias: GluA y GluB de acuerdo a la secuencia de nucleótidos que generan. Estas diferencias se trasladan a sus propiedades nutricionales ya que GluB contiene mayor cantidad del aminoácido esencial lisina (Katsube-Tanaka et al., 2004b) y a sus propiedades estructurales ya que presentan diferencias en su grado de polimerización. Estas últimas se reflejan en la solubilidad y estabilidad estructural afectando procesos alimentarios como gelación, formación de espumas y emulsiones (Katsube-Tanaka et al., 2004a). 


\subsubsection{Síntesis, transporte y almacenamiento de las proteínas del grano de arroz}

Las glutelinas son sintetizadas en la membrana del retículo endoplásmatico como preproglutelina de $59 \mathrm{kDa}$. Luego pasan al aparato de Golgi formando el grupo de proglutelinas con una masa molecular de 55-59 kDa (57 kDa). Finalmente son procesadas en subunidades alfa y beta o ácidas y básicas con pesos moleculares de 37-39 kDa y 20-22 kDa respectivamente. Poseen diferente punto isoeléctrico y son depositadas en vacuolas o cuerpos proteicos (Yamagata et al., 1982; Qu et al., 2001).

Por otro lado las prolaminas, son sintetizadas y se depositan en cuerpos

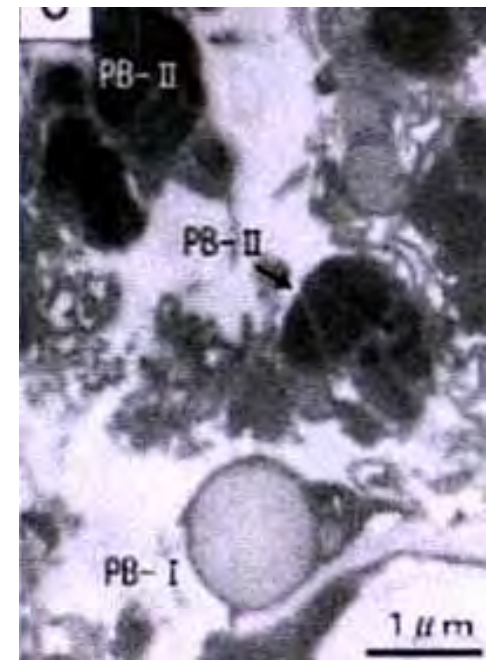

Figura 3. Micrografía electrónica de harina de arroz. PB-I: cuerpos proteicos tipo I y PB-II: cuerpos proteicos tipo II (Kumagai et al., 2006). proteicos en el retículo endoplásmico.

En arroz, el almacenamiento de las proteínas tiene lugar en dos tipos de cuerpos proteicos diferentes, característica que lo distingue del resto de los cereales y leguminosas (Figura 3).

Los cuerpos proteicos tipo I (PB-I), son claros y esféricos en el microscopio electrónico, se encuentran asociados con el REr (retículo endoplamático) y están rodeados de una membrana con ribosomas. Los cuerpos proteicos tipo II (PB-II), se observan opacos y de forma irregular al microscopio electrónico, se encuentran depositados en vacuolas y se los asocia con el aparato de Golgi.

Estudios posteriores determinaron que los PB-I están constituidos fundamentalmente por prolaminas (debido a que los pesos moleculares oscilan entre 10-16 kDa) y los PB-II por glutelinas (Yamagata, 1982; Juliano, 1985, Furukawa et al., 2003; Kumagai et al., 2006; Nishimura et al., 2009). Ambos tipos de cuerpos proteicos se hayan distribuidos a lo largo del endosperma y un aumento en el contenido proteico del grano resulta en un incremento en el número de cuerpos proteicos (Juliano, 1972).

La distribución de las proteínas en los cuerpos proteicos del endosperma es variable según los cultivares. Los PB-II contienen el 60-65\% de las proteínas de almacenaje del endosperma, los PB-I el 20-25\% y los restantes 10-15\% serían 
albúminas y globulinas presentes en el citoplasma (Zhou et al., 2002). Según Furukawa et al. (2003) los PB-I pueden presentar entre 20 y $42 \%$ de las proteínas totales y los PB-II entre 36 y $59 \%$.

Durante el periodo de llenado del grano, las proteínas se van acumulando en diferente orden. A los 5 días después de la floración (antesis) aparecen las subunidades básicas y ácidas (22-23 y 37-39 kDa) de las glutelinas, 10 días después aparecen los polipéptidos de bajo peso molecular correspondiente a las prolaminas 10-16 kDa. Más tarde, en el desarrollo del cariopse, aparecen los polipeptidos de 76-57 kDa y se acumulan en los PB-II junto con las globulinas (Yamagata et al., 1982).

\subsubsection{Composición aminoacídica. Valor nutricional y metabolismo proteico}

Tabla 6. Aminoácidos en proteínas de distintos orígenes

\begin{tabular}{|l|l|l|l|l|l|l|l|l|l|}
\hline $\begin{array}{l}\text { Origen de la } \\
\text { proteína }\end{array}$ & Ile * & Leu & Thr & Lys & Met & Val & Arg & Tyr & Phe \\
\hline Animales & 5,5 & 8,2 & 4,4 & $\mathbf{8 , 4}$ & 2,9 & 6,0 & 4,8 & 1,5 & 4,5 \\
Cereales & 4,4 & 8,5 & 3,4 & $\mathbf{2 , 7}$ & 2,2 & 5,7 & 4,8 & 1,1 & 4,8 \\
Leguminosas & 4,4 & 7,9 & 4,2 & $\mathbf{7 , 3}$ & 1,3 & 4,7 & 7,6 & 1,3 & 5,4 \\
\hline
\end{tabular}

*Aminoácidos, expresados en $\mathrm{g} / 16 \mathrm{~g} \mathrm{~N}$, mediante su símbolo de tres letras.

La función fundamental de la proteína en la dieta es la de proporcionar aminoácidos esenciales y nitrógeno aminoacídico para la síntesis de las proteínas y otras sustancias nitrogenadas que intervienen en la composición corporal (Cheftel et al., 1993).

La calidad nutricional está gobernada fundamentalmente por la composición aminoacídica.

La proteína del salvado de arroz contiene abundante ácido glutámico y aspártico (FAO, 2004) y aunque en menor proporción, aminoácidos esenciales como treonina, valina, tirosina, histidina y arginina (Tang et al., 2003). La Organización Mundial de la Salud de las Naciones Unidas propone el patrón ideal de los aminoácidos que conforman la proteína (FAO/WHO, 1973). Esta establece como buena una proporción de aminoácidos esenciales con respecto a aminoácidos totales de $36 \%$. La proteína total del arroz pulido según los trabajos realizados por Padhye and Salunkhe (1979) excederían este valor (41,0\%). La proteína de arroz 
pulido está integrada por un 40,1\% de aminoácidos hidrofóbicos, 21,8 de polares, 12,2 de básicos y 26\% de aminoácidos ácidos (Padhye and Salunkhe, 1979).

Si bien en los cereales, la lisina es un aminoácido limitante como podemos observar en la Tabla 6; el arroz contiene cantidades considerables de este aminoácido esencial (Juliano, 1985; Chandi and Sogi, 2007a). Las cantidades en salvado oscilan entre 3,99 y 5,3 g de lisina/100g de proteína (Wang et al., 1999 y Tang et al., 2003 respectivamente), se localiza fundamentalmente en las capas externas por este motivo la proteína del arroz integral tiene mayor contenido de lisina que el pulido (Baldi et al., 1976; Cagampang et al., 1976; Villareal and Juliano, 1978) y dentro de la fracción glutelina la subunidad ácida es la de mayor contenido (Juliano, 1980). Mientras que las albúminas y glutelinas son ricas en lisina, las prolaminas al igual que en otros cereales, presentan bajos niveles de este aminoácido.

Las prolaminas poseen altos contenidos de glutamina, histidina, cisteína y metionina (Mandac and Juliano, 1978; Padhye and Salunkhe, 1979; Shyur et al., 1994). Esta fracción es rica en leucina, tirosina, fenilalanina pero es la que presenta menor contenido de arginina y glicina (Juliano, 1980). Se diferencian de las prolaminas de maíz, trigo, cebada y centeno, ya que no presentan secuencias repetitivas ricas en prolina.

La fracción globulinas es rica en aminoácidos azufrados cisteína y metionina (Juliano, 1985).

Los aminoácidos más abundantes en fracción glutelinas son ácido glutámico/glutamina, ácido aspártico/asparagina, arginina, glicina alanina y treonina (Wen and Luthe, 1985; Juliano, 1985). Esta composición influye en gran medida sobre su solubilidad. Los grupos aminos en las cadenas de glutamina y asparagina juegan un importante rol promoviendo la asociación de las moléculas de glutelinas mendiante puentes hidrógeno (Anderson et al., 2001). No obstante las subunidades tienen diferente composición aminoacídica, la subunidad básica tiene más leucina, tirosina, ácido aspártico y menos glutámico que la subunidad ácida (Villareal and Juliano, 1978).

Para que estos aminoácidos sean aprovechados es necesario que los mismos puedan ingresar al torrente sanguíneo para lo cual las proteínas deben ser adecuadamente digeridas.

Esta digestión es realizada por las enzimas proteolíticas del tracto intestinal, primero por la pepsina, presente en el jugo gástrico, y luego por las proteasas segregadas por el páncreas (tripsina, quimiotripsina, caboxipeptidasas A y B y 
elastasa) y por las células de la mucosa intestinal (aminopeptidasas y dipeptidasas). La mayor parte de estas enzimas catalizan la hidrólisis de enlaces peptídicos específicos. Los aminoácidos libres y los pequeños péptidos se absorben a través de las células en cepillo y de borde estriado de la mucosa intestinal. Existen mecanismos específicos de absorción de péptidos de aminoácidos neutros, ácidos y básicos. La mayor parte de los péptidos absorbidos son hidrolizados en el interior de las células intestinales. Los aminoácidos absorbidos pasan luego a la vena porta para su transporte al hígado.

Algunos factores como el calor, pueden incrementar la digestibilidad al modificar la estructura terciaria y secundaria o sea al desnaturalizar la proteína (Cheftel et al., 1993).

La digestibilidad resulta un factor muy importante, determinante de la capacidad de la proteína de ser utilizada en mezclas dietarias.

Como podemos observar en la Tabla 2, la digestibilidad del nitrógeno en arroz así como la proteína neta utilizable es la mayor de los 7 cereales comparados (Juliano, 1985). Estudios realizados sugieren que la proteína producida mediante extracción alcalina presenta mayor digestibilidad que la de la harina (Kumagai et al., 2006) y que la obtenida por degradación del almidón (Morita and Kiriyama, 1993; Kumagai et al., 2006). Morita and Kiriyama (1993) han encontrado que dietas con un $40-50 \%$ de aislado proteico de harina de arroz tiene digestibilidad similar a formulaciones con un $25 \%$ de caseina.

Si bien los cuerpos PB-I son prácticamente indigeribles (Furukawa et al., 2003; Nishimura et al., 2009), la digestibilidad de la proteína de arroz cocido en humanos oscila entre un $80-87 \%$ (FAO, 2008) y un 85-90\% (FAO/WHO/UNU, 1985). La digestibilidad varía según las fracciones proteicas, estudios realizados por Steenson and Sathe (1995) indican que las prolaminas son más resistentes a la digestión enzimática in vitro que las albúminas y globulinas.

La proteína de arroz es fácilmente extraída por tratamiento alcalino de tipo industrial y por su alta calidad puede ser utilizada en manufactura de alimentos (Kumagai et al., 2006). Posiblemente la preparación de concentrados y aislados proteicos estaría potenciando la posibilidad de obtener ingredientes proteicos con mejorada digestibilidad. 


\subsection{Concentrados y aislados proteicos}

\subsubsection{Generalidades}

La disponibilidad de fuentes proteicas vegetales junto con la tendencia a reducir la ingesta de proteínas animales, hace que en los últimos años se esté produciendo un gran desarrollo en los procesos de extracción y mejora de proteínas vegetales para su uso en la alimentación humana.

Se denominan concentrados proteicos a productos alimenticios sólidos 0 semisólidos conteniendo entre 60 y $80 \%$ de proteína, mientras que un aislado es un ingrediente con un contenido proteico superior al $80 \%$.

La mejora de la nutrición es la razón primera para el uso de los concentrados y aislados proteicos en fórmulas infantiles, bebidas nutritivas para adultos y suplementos (Vioque et al., 2001). Las ventajas de estos ingredientes proteicos es que permite su inclusión en formulaciones adecuadas a distintos requerimientos, ya sea para personas con alteraciones de salud específicas o proporcionando beneficios a personas con un alto nivel de colesterol o triglicéridos en sangre (Vioque et al., 2001). En los últimos años se han producido aislados proteicos de otros cultivos como colza (Mahajan and Dua, 1995), trigo (Hettiarachchy et al., 1996; Ahmedna et al., 1999), maíz (Lin and Zayas, 1987), garbanzo (Sánchez-Vioque et al., 1999), girasol (Saeed and Cheryan, 1988), Phaseolus (Apostolatos, 1984) y amaranto (Martínez and Añón, 1996).

En arroz, la vía más conveniente y simple para obtener productos de alto contenido proteico resulta ser la extracción alcalina seguida de una precipitación ácida (Shih, 2003). No obstante se han estudiados diversos métodos enzimáticos y físicos con el propósito de conservar o mejorar las propiedades nutricionales y funcionales del producto obtenido.

\subsubsection{Concentrados y aislados proteicos de arroz}

Con la finalidad de utilizar la proteína del arroz a partir de los co-productos del molinado se han propuestos diferentes procesos de obtención de concentrados y aislados proteicos. Los co-productos más utilizados para tal fin han sido el salvado de arroz y el grano pulido o quebrado. Las principales metodologías pueden agruparse en: extracción alcalina, métodos enzimáticos y físicos. Los trabajos se iniciaron en 1966 con Cagampang et al. quienes realizaron una extracción del 97\% de la proteína del endosperma del grano de arroz con $\mathrm{NaOH} \mathrm{0,1} \mathrm{N} \mathrm{durante} 6$ hs. 
Los estudios realizados para la obtención de aislados y concentrados proteicos pueden ordenarse según la extracción se haya realizado a partir del a) salvado o b) endosperma y por medio de solventes alcalinos, métodos enzimáticos o métodos físicos.

\subsection{2a Obtención de aislados y concentrados proteicos a partir del salvado}

Extracción alcalina. Los trabajos a partir de salvado de arroz comenzaron en 1969 con Lynn, Chen and Houston (1970); Desikachar and Parpia (1970); Barber and Barber (1974), Lew et al. (1975); le siguió Connor et al. (1976) quienes propusieron una extracción con hidróxido diluido a $24^{\circ} \mathrm{C}$ obteniendo concentrados de 33-38\% de proteína en peso, Betschart et al. (1977); Maki and Misao (1983); Bera and Mukherjee (1989). Posteriormente, Prakash and Ramnatham (1995) propusieron extracción a pH 11 obteniendo concentrados de $71-73 \%, 39,5$ y 54,5\% de proteína en peso según se partiera de salvado de arroz no estabilizado, estabilizado con calor o parbolizado. En forma similar, Gnanasambandam and Hettiarachchy (1995) a partir de un producto comercial de salvado de arroz estabilizado y no estabilizado con calor sugirieron extraer a pH 9,5 durante 30 min obteniendo concentrados de 71,5 y $50,9 \%$ de proteína en peso respectivamente. En la actualidad, Chandi and Sogi (2007a) estudiaron aislados proteicos extraídos de diferentes variedades de arroz a pH 9 durante 1 lh logrando concentraciones entre 52,5 y $90,6 \%$ de proteína según variedad.

Métodos enzimáticos. En esta metodología las enzimas actúan sobre extracciones acuosas. En general las proteasas resultan más efectivas que las carbohidrasas. Los estudios se iniciaron con Ansharullah et al. (1997) removiendo la pared celular con carbohidrasas como celulasas, pectinasas, hemicelulasa y xilanasas. Posteriormente, Hamada en 1999 y 2000 obtuvo aislados a partir de hidrólisis con proteasas alcalinas. Wang et al. (1999) obtuvieron aislados con un $92 \%$ de proteína en peso utilizando glicosidasas y en la actualidad aparecen los trabajos de Shih and Daigle (2000) y Tang et al. (2003) utilizando en forma combinada proteasas y carbohidrasas.

Métodos físicos. Si bien son más deseables porque no producen alteraciones en las proteínas, son más costosos. Anderson and Guraya (2001) proponen la extracción con agua a partir de salvado de arroz formando primero una suspensión coloidal que se somete a homogeneización y se separa por centrifugación. 


\subsection{2b Obtención de aislados y concentrados proteicos a partir del endosperma}

Extracción alcalina. Hasta un $97 \%$ de proteína básicamente glutelina puede ser extraída con una solución de hidróxido de sodio o de potasio 0,1 N (Cagampang et al., 1966; Tecson et al., 1971).

Métodos enzimáticos. Debido a que el endosperma es mayoritariamente almidón se utilizan enzimas como amilasa, glucoamilasas y pululanasas para separar la proteína de la harina de arroz por solubilización y remoción del almidón. Morita and Kiryama (1993) han recuperado hasta un 90\% de la proteína mediante la utilización de $\alpha$-amilasa a $97^{\circ} \mathrm{C}$ durante 2 horas. Shih and Daigle (1997) logran concentrados de $47-65 \%$ de proteína mediante un tratamiento con $\alpha$-amilasa a 90 ㅇ C durante 45 minutos.

Métodos físicos. Kung et al. (1987) han separado por centrifugación una emulsión de harina de arroz en presencia de esteroil lactilato de sodio.

\subsection{Propiedades funcionales}

Se puede definir como toda propiedad no nutricional que imparte a un alimento o ingrediente determinadas características sensoriales o determinado comportamiento físico, durante su preparación, procesamiento, almacenamiento o consumo (Cheftel et al., 1989, Schwenke, 2001). No solo son importantes en definir la calidad del producto final, sino también en facilitar el proceso de producción.

Las propiedades funcionales son un reflejo de las propiedades intrínsecas de la proteína per se. Estas dependen del tamaño molecular, forma, composición aminoacídica, secuencia, carga y distribución de la misma, estructura secundaria ( $\alpha$-hélice, $\beta$-plegada y estructuras aperiódicas), ordenamientos terciarios y cuaternarios de los segmentos peptídicos, cross-linking intra e inter caternarios, relación hidrofobicidad/hidrofilicidad y relación rigidez/flexibilidad en respuesta a las condiciones externas. Estas propiedades pueden ser alteradas por diversos factores tales como condiciones de procesos, métodos de aislamiento, factores ambientales ( $\mathrm{pH}$, temperatura, fuerza iónica, constante dieléctrica del medio), interacción con otros componentes (agua, iones, lípidos, hidratos de carbono, proteínas), concentración de la proteína, modificaciones sufridas por métodos físicos, químicos y enzimáticos, entre otros. 
Las propiedades funcionales se pueden clasificar en tres grupos según la interacción que predomine en el proceso (Cheftel et al., 1989 y Bourgeois and Le Roux 1986):

- Propiedades dependientes de la interacción agua-proteína (hidratación, solubilidad, capacidad de retención de agua, capacidad de imbibición de agua)

- Propiedades superficiales (habilidad para formar espumas y emulsiones)

- Propiedades dependientes de la interacción proteínas-lípidos

- Propiedades dependientes de la interacción proteína-proteína (gelificación, texturización: formación de películas por coagulación térmica, formación de fibras).

\subsubsection{Propiedades dependientes de la interacción agua-proteína}

El agua es un ingrediente universal en los sistemas alimentarios. La interacción proteína-agua determina las propiedades de hidratación que influyen en aquellos aspectos inherentes a la formulación, procesamiento y almacenamiento de los alimentos (Pilosof, 2000). La base de la interacción fisicoquímica del agua con los ingredientes alimenticios es una materia de investigación extensa. Las propiedades de hidratación de las proteínas son consecuencia de su capacidad para interaccionar con las moléculas de agua a través de grupos polares y no polares presentes en su estructura. Los grupos polares interactúan con el agua a través de puentes de hidrógeno, enlaces dipolo-dipolo e interacción con grupos ionizados, en tanto que los no polares lo hacen mediante el proceso, termodinamicamente favorable, denominado hidratación hidrofóbica. Cuando el agua es agregada en exceso a un alimento, parte del agua interactúa con los sólidos y constituye el agua ligada y el resto es agua libre. Las proteínas que contienen numerosas cadenas polares laterales junto con las uniones peptídicas, resultan hidrofílicas. Por lo tanto, tienden a absorber y retener agua cuando están presentes en sistemas de alimentos. En el caso de los grupos ionizables la polaridad es afectada por las condiciones de $\mathrm{pH}$. La retención de agua está a un mínimo cuando el pH está cercano al punto isoeléctrico y se incrementa rápidamente cuando el $\mathrm{pH}$ aumenta o disminuye (Wijeratne, 2005). 


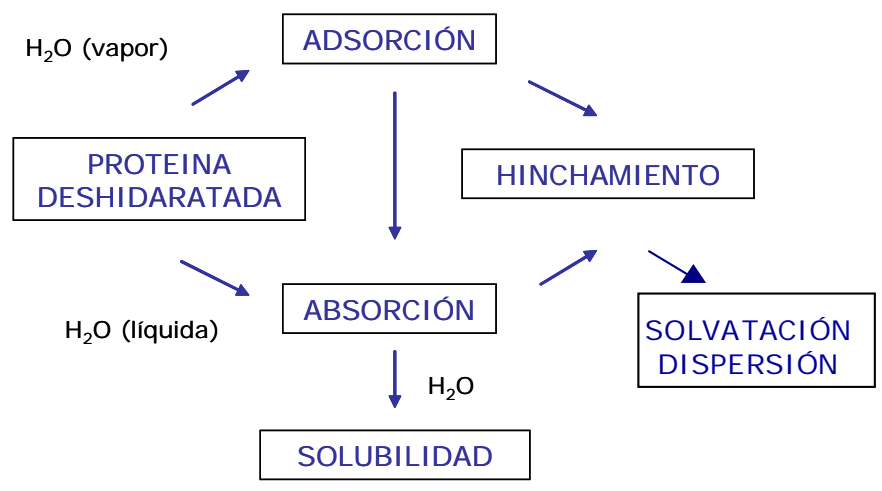

Figura 4. Etapas de la hidratación y propiedades funcionales involucradas (Pilosof, 2000).

En la Figura 4 se ve representado el esquema del proceso de hidratación de una proteína. De acuerdo a Hardy et al. (2002) y Pilosof (2000) en el mismo se pueden reconocer diversas etapas:

a) Adsorción de agua es la capacidad de un alimento de adsorber agua espontáneamente cuando se lo coloca en una atmósfera con un porcentaje de humedad relativa mayor a la que posee.

b) Absorción de agua indica la aptitud de un material de embeber agua espontáneamente en su estructura por inmersión o cuando se lo pone en contacto con una superficie que se mantiene húmeda. Este es un parámetro importante desde el punto de vista tecnológico. En productos horneados, una alta capacidad de absorción de agua contribuye a reducir la pérdida de humedad de los productos envasados, lo que permite que se mantengan frescos (Chandi and Sogi, 2007a). Por otro lado, es una propiedad fundamental vinculada a la práctica de rehidratación que normalmente se realiza antes de la utilización de cualquier ingrediente proteico.

c) Hinchamiento o "swelling" se refiere al cambio de volumen que acompaña a la hidratación.

d) Solvatación o dispersabilidad es la propiedad de un aislado proteico deshidratado en polvo que permite que el mismo se disperse uniformemente al ponerse en contacto con el agua.

e) Solubilidad en proteínas alimentarias representa la capacidad de una miscela proteica de formar una solución coloidal. Este proceso involucra, simultáneamente, humectación, hinchamiento, solvatación y disolución. 


\subsection{1a Solubilidad}

Desde un punto de vista termodinámico, la solubilidad supone: separación de moléculas del disolvente, separación de moléculas de proteína y dispersión de estas últimas en las primeras con máxima interacción entre proteína y disolvente. Para ser soluble, la proteína debe, por consiguiente, interaccionar tanto cuanto sea posible con el disolvente (puentes de hidrógeno, dipolo-dipolo, e interacciones iónicas). La solubilidad depende de factores como el pH, la fuerza iónica y la temperatura, entre otros.

Influencia del pH: A valores de pH superiores o inferiores al punto isoeléctrico, la proteína arrastra una carga eléctrica negativa o positiva y las moléculas de agua pueden interaccionar con estas cargas contribuyendo así, a la solubilización. Además, las cadenas proteicas que llevan cargas eléctricas del mismo signo tienen una tendencia a repelerse y a disociarse o desplegarse. Si se representa la solubilidad de una determinada proteína en función del $\mathrm{pH}$, suele obtenerse una gráfica en forma de $\mathrm{V}$ o de $\mathrm{U}$, cuyo mínimo se corresponde con el punto isoeléctrico. Esta característica es utilizada para la extracción de numerosas proteínas, especialmente las procedentes de semillas. A valores del pH no alejados del punto isoeléctrico, las cargas netas son lo suficientemente bajas como para permitir que las cadenas polipeptídicas se aproximen y se formen algunos agregados, lo que puede conducir a la precipitación proteica. La velocidad de la precipitación proteica aumenta cuando la densidad global de los agregados difiere considerablemente de la del disolvente y cuando el diámetro de los agregados neoformados es considerable.

I nfluencia de la fuerza iónica: a concentraciones salinas elevadas, la solubilidad de la proteína desciende, lo que puede conducir a la precipitación. Este efecto (precipitación por salado) es consecuencia de la competencia entre la proteína y los iones salinos por las moléculas de agua necesarias para sus respectivas solvataciones. A altas concentraciones salinas no hay suficientes moléculas de agua disponibles para la solvatación de la proteína, puesto que la mayor parte de las moléculas de agua están fuertemente ligadas a las sales. Así, las interacciones proteína-proteína dominan sobre las interacciones proteína-agua, lo que puede conducir a la formación de agregados seguida por la precipitación de las moléculas proteicas.

Influencia de la temperatura (a pH y fuerza iónica constantes): En general, la solubilidad de las proteínas aumenta con la temperatura, entre 0 y $40-50{ }^{\circ} \mathrm{C}$. 
Cada una de las etapas de hidratación proteica tendrá relevancia de acuerdo al sistema alimentario que se trate. La adsorción es importante en productos de bajo contenido de agua y en procesos de secado y almacenamiento; la absorciónhinchamiento-retención en productos semisólidos como embutidos, masas, geles por la influencia que tiene sobre la textura de los mismos (Cheftel et al., 1993) y la solubilidad en bebidas y productos emulsionados o espumados.

\subsection{1b Capacidad de retención de agua (WHC)}

La capacidad de retención de agua (WHC) se define como la capacidad de un alimento hidratado para retener agua en la matriz proteica, cuando es sometida a fuerzas externas como la centrifugación, compresión, vacío o presión osmótica. Esta fracción de agua puede ser asimilable a la suma del agua capilar y el agua unida por puentes de hidrógeno a los grupos de la proteína. Esta propiedad funcional depende no solo del tamaño de los poros y de los capilares sino también de las características de las moléculas proteicas como interacciones hidrofóbicas, puentes hidrogeno, puentes disulfuro, ácidos, bases y de fuerzas de Van der Waalls presentes. Asimismo se ve influida por parámetros del medio como fuerza iónica especies iónicas, $\mathrm{pH}$, temperatura y el tiempo consumido en alcanzar el equilibrio (Kneifel et al., 1991). La capacidad de los ingredientes proteicos de absorber y retener agua juega un importante papel en la textura de diversos alimentos especialmente en masas horneadas (Cheftel et al., 1993) y en la viscosidad intrínseca, importante especialmente, en la elaboración de quesos, masas dulces y variados productos no alimenticios (Kneifel et al., 1991).

Esta propiedad está vinculada directamente con la solubilidad; Were et al. (1997) encontraron relación entre WHC y solubilidad en aislados proteicos de soja.

\subsection{1c Capacidad de imbibición de agua (WIC)}

La capacidad de imbibición de agua (WIC) se define como la capacidad de un alimento deshidratado para absorber agua espontáneamente contra la fuerza de gravedad. Según Chou and Morr (1979) el proceso de hidratación de una proteína deshidratada consta de las siguientes etapas: adsorción de las moléculas de agua por fijación en zonas polares, adsorción multicapa de agua; condensación de agua liquida; hinchamiento y solvatación o dispersión. 


\subsubsection{Propiedades de superficie}

Las espumas y emulsiones están presentes en la mayoría de los alimentos procesados. Existe una gran variedad de espumas o batidos en alimentos de consistencias muy diversas, tales como merengues, malvaviscos, productos de pastelería-confitería, cremas batidas, aderezos, algunas pastas, helados, suflés, espuma de cerveza, incluso en el pan.

Las propiedades superficiales requieren un grado de hidratación y de solubilización proteica elevado (Chandi and Sogi, 2007a). En los alimentos basados en emulsiones y espumas, las proteínas desempeñan un rol fundamental como agentes tensioactivos (Cheftel et al., 1989; Wilde and Clark, 1996; Damodaran, 1997).

Una espuma o una emulsión alimenticia es una dispersión de burbujas de gas o de gotitas en una fase continua líquida o semilíquida, ambas fases no miscibles. La proteína, como agente tensioactivo, es la principal responsable de esta propiedad ya que forma una barrera protectora conteniendo las burbujas o gotitas. La habilidad de las proteínas para actuar como agentes tensioactivos y estabilizar espumas y emulsiones depende de su habilidad para adsorberse a las interfases, reducir la tensión interfasial y formar un film cohesivo. Las proteínas, contribuyen tanto a la formación como a la estabilidad de la emulsión (Cheftel et al., 1993). Estas son buenos agentes espumantes o emulsionantes debido a que por su naturaleza anfifílica, tienen acción tensioactiva, y por su tendencia a desnaturalizarse y agregarse en interfases, forman películas de rigidez y elasticidad variables (Wagner, 2000). Se supone que una vez que una zona de una molécula proteica ha hecho contacto con la interfase los restos aminoacídicos apolares se orientan hacia la fase no acuosa, la energía libre del sistema disminuye y el resto de la proteína se adsorbe espontáneamente. Durante la adsorción, la mayor parte de las proteínas sufren un acusado desplegamiento y si se halla disponible una superficie grande, se extiende formando en ella una capa monomolecular $\left(1 \mathrm{mg} / \mathrm{m}^{2}\right.$, 10-20 A de espesor) (Cheftel et al., 1993). La proteína se adsorbe en la interfase gotas de aceite o aire (fase dispersa)/disolución acuosa (fase continua) y contribuyen a las propiedades físicas y reológicas (espesor, viscosidad y elasticidadrigidez) que determinan la resistencia del sistema. La formación de este sistema requiere aporte de energía, proporcional a la superficie creada y a la tensión entre las fases. Es un sistema termodinámicamente inestable debido a la elevada área interfasial creada, acompañada por una alta tensión superficial, lo cual genera un aumento de la energía libre del sistema. 


\subsection{2.a Espumas}

Al estudiar las propiedades de las proteínas se debe distinguir entre la capacidad de formación de espuma que estas presenten y su capacidad para estabilizar el sistema. La primera está relacionada con la velocidad de las proteínas de migrar y adsorberse rápidamente en la interfase y formar una lamela alrededor de la burbuja, proceso que se ve representado en la Figura 5.

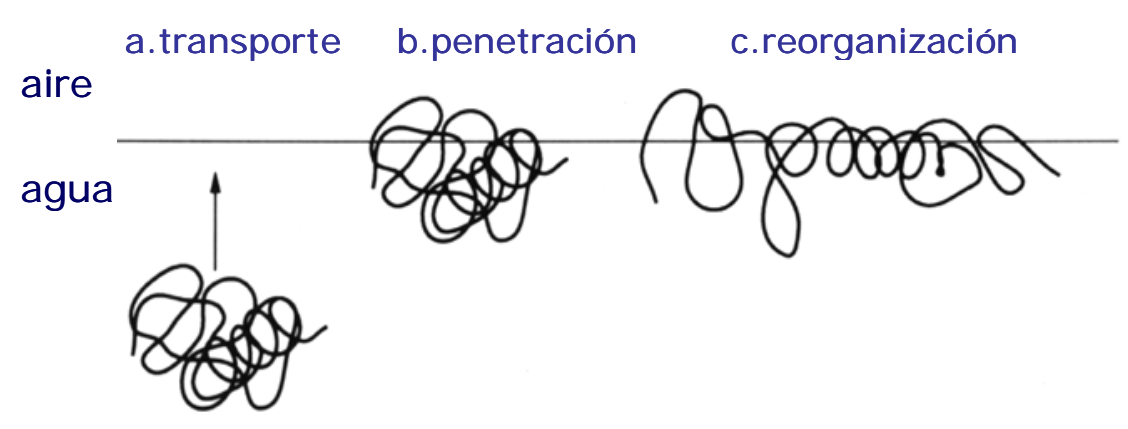

Figura 5. Proceso de adsorción de proteínas. a) difusión a la interfase b) adsorción, c) reorganización estructural (Wilde y Clark, 1996)

Para que esto ocurra, la proteína debe ser soluble, flexible, tener baja masa molecular y poseer un balance adecuado lipofílico-hidrofílico. No todas las proteínas pueden espumar, y aquellas que lo hacen varían ampliamente en su capacidad espumante (MacRitchie, 1998). Paralelamente, para que el sistema resulte estable, esta película creada debe mantenerse en el tiempo; para lo cual, debe poseer determinadas propiedades reológicas que le confieran resistencia, cierta rigidez y flexibilidad e involucran las estructura secundaria y terciaria de la proteína (Tang et al., 2003). Las moléculas de proteína tienen que asociarse entre sí ya sea por interacciones hidrofóbicas o por puentes disulfuro para formar agregados de gran tamaño, mínima carga superficial y alta capacidad de absorción de agua (Wagner, 2000). Debido a que el sistema es termodinámicamente inestable se produce la destabilización de la espuma. Este proceso involucra mecanismos como: drenaje de líquido por efecto de la fuerza de gravedad; acumulación de burbujas en la parte superior del recipiente por flotación y maduración de Ostwald, las burbujas grandes crecen a expensas de las pequeñas (Figura 6). 


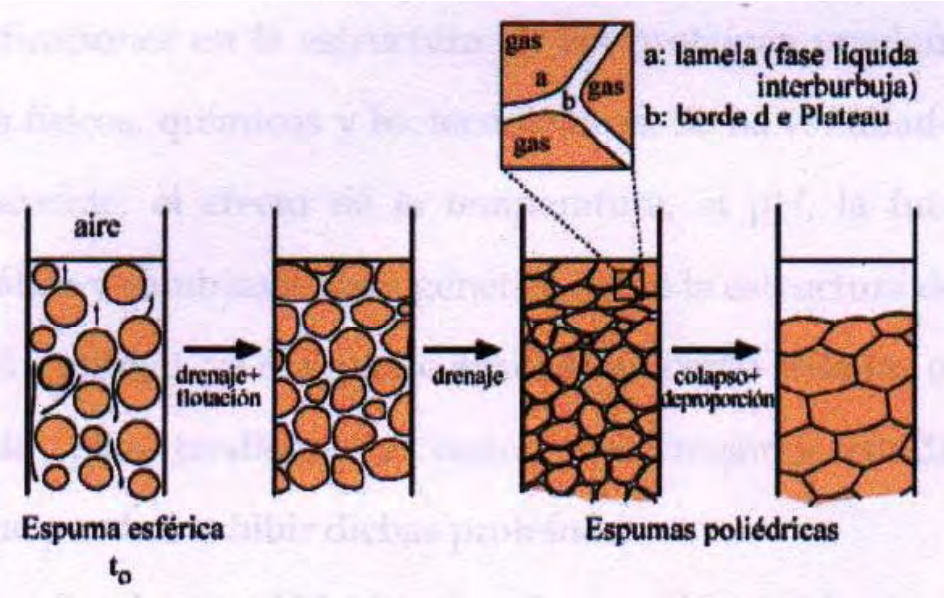

Figura 6. Representación esquemática de los procesos de desestabilización de una espuma (Wagner, 2000)

Se puede observar que con el pasar del tiempo las espumas pueden colapsar por ruptura de las películas creadas por las proteínas y las burbujas adoptan una forma poliédrica (Wagner, 2000).

Las propiedades espumantes se ven afectadas por factores dependientes del medio como son la concentración y solubilidad proteica, el $\mathrm{pH}$, la concentración y tipo de sales e hidratos de carbono presente en la solución o suspensión considerada.

\subsection{2.b Emulsiones}

Las emulsiones son dispersiones de dos líquidos no miscibles, uno se encuentra bajo la forma de pequeñas gotitas dispersas y el otro es la fase continua dispersante. La mayor parte de las emulsiones alimenticias son emulsiones de aceite en agua o bien agua en aceite. La estabilidad de una emulsión está entonces determinada o afectada por distintos factores como son la distribución del tamaño de gota (generalmente en el rango de 0,1-100 $\mathrm{m}$ ), la viscosidad de la fase continua, la temperatura, la diferencia de densidad entre fases, la relación volumétrica entre fase, las propiedades de la película interfacial y el trabajo mecánico (agitación, batido) al que se somete la emulsión (Wagner, 2000).

El proceso de emulsificación involucra la formación estabilización y desestabilización de la emulsión. Semejante al proceso descripto en las espumas, la formación de una emulsión depende de la rápida adsorción, desenrollamiento en la interfase y reorientación de las proteínas. Desde el momento en que se forma una emulsión, por dispersión de una fase en otra, comienza simultáneamente el proceso 
de desestabilización, que tiende a una disminución del área interfacial y origina finalmente la separación parcial o total de las dos fases inmiscibles. Según Halling (1981), los mecanismos que contribuyen simultánea y sinérgicamente a la desestabilización de una emulsión son la desproporción, la floculación, el cremado, la coalescencia y la inversión de fase. La desproporción es el crecimiento de las gotas de mayor tamaño a expensas de las más pequeñas. La floculación es la aproximación e interacción de las gotas entre sí, que conduce a la formación de agregados o "floculos"; la velocidad de este proceso depende de la naturaleza de los grupos constitutivos (provenientes de los residuos polares de las cadenas polipeptídicas, de fosfolípidos, de sales). El cremado es la separación de la dispersión en una emulsión "concentrada" superior y una emulsión "diluida" inferior, debido a la diferencia de densidad entre la fase continua y la dispersa. La emulsión "concentrada" esta constituida mayoritariamente por la fase dispersa y se denomina fase cremada. El proceso de cremado esta favorecido por el mayor tamaño de la gota y por la floculación, ya que los agregados "creman" más rápidamente que las gotas aisladas. Estos dos procesos, floculación y cremado, se pueden revertir generalmente con una agitación más o menos vigorosa. Ambos procesos, junto a la desproporción, son los precursores de la coalescencia, la cual es irreversible. La coalescencia resulta de la ruptura del film interfacial, fusión de las gotas y separación final de las dos fases. La resistencia a la coalescencia depende de numerosos parámetros como son las propiedades reológicas del film proteico interfacial, la viscosidad de la fase continua, la distribución de tamaño de gota, la temperatura y la relación entre fases. La inversión de fase es la transformación de una emulsión aceite/agua en agua/aceite, o a la inversa, ocurre generalmente en emulsiones con alta relación fase dispersa-fase continua cuando es sometida a un trabajo mecánico enérgico.

La capacidad de formar y estabilizar una emulsión está altamente relacionada con la solubilidad de la proteína (Bera and Mukherjee, 1989; Cheftel et al., 1993) y con la flexibilidad de las moléculas (Paranam et al., 2007). Las proteínas no disueltas contribuyen muy poco a la emulsión (Cheftel et al., 1993). El $\mathrm{pH}$ también influye sobre esta propiedad ya que en sus puntos isoeléctricos son escasamente solubles (Cheftel et al., 1993). 


\subsubsection{Propiedades dependientes de la interacción proteínas - lípidos}

\subsection{3a Absorción de aceite}

A veces resulta conveniente que los ingredientes proteicos deshidratados adsorban cierta cantidad de aceite y la retengan (Cheftel et al., 1993). Esta propiedad es esencial en la formulación de sistemas alimentarios como salchichas, batidos, mayonesas o aderezos salados. La materia grasa en un alimento es fundamental para aumentar la palatabilidad del mismo.

En numerosos alimentos son frecuentes las interacciones entre proteínas y lípidos, sobre todo fosfolípidos y triacilgliceroles. En estas interacciones no participan enlaces covalentes sino interacciones hidrofóbicas entre cadenas alifáticas apolares de los lípidos y regiones apolares de las proteínas. Los triacilgliceroles neutros se ligan a las proteínas a través de interacciones hidrofóbicas y pueden eliminarse mediante solventes apolares; los fosfolípidos en cambio, se ligan aun más intensamente a través de enlaces polares y para separarlos se necesita recurrir a disolventes polares. La interacción proteína-lípido esta relacionada con la solubilidad: las proteínas insolubles son las que mayor cantidad de aceite fijan y tanto más cuanto más hidrófobas sean (Cheftel et al., 1993). Las lipoproteínas de baja densidad, en polvo, con tamaño de partícula pequeño adsorben o atrapan más aceite que las de alta densidad (Cheftel et al., 1993).

\subsection{Propiedades funcionales de proteínas de arroz}

El estudio de las propiedades funcionales de las proteínas de arroz se inició sobre concentrados y aislados de salvado de arroz con evaluaciones de solubilidad (Chen and Houston, 1970), posteriormente se estudió la capacidad espumante y su relación con la estructura (Kinsella, 1981) y la variación de la capacidad espumante y emulsificante con el pH y la fuerza iónica (Bera and Mukherjee, 1989) continuando hasta la actualidad con estudios más detallados evaluando, además, propiedades de hidratación y absorción de aceite (Chandi and Sogi, 2007a).

A partir del año 2000 y hasta nuestros días la investigación se ha centrado en el estudio de las propiedades funcionales de hidrolizados proteicos: Hamada (2000) estudia solubilidad y capacidad emulsificante, Tang et al. (2003) agregan capacidad espumante e hidrofobicidad superficial y en nuestros días Bandyopadhyay et al. (2008) estudian solubilidad, capacidad espumante y 
emulsificante a partir de hidrolizados de arroz pero con diferente grado de hidrólisis.

Solo unos pocos trabajos evalúan las propiedades funcionales de las fracciones proteicas (Ju et al., 2001) o solamente de las glutelinas (Anderson et al., 2001; Tang et al., 2002; Agboola et al., 2005). Menor aún es la cantidad de trabajos que estudian las diferencias de las propiedades funcionales entre variedades diferentes de arroz (Agboola et al., 2005).

Si bien la proteína de arroz es valorada por su sabor suave, la ausencia de color, su riqueza en aminoácidos esenciales, y por ser hipoalergénica, es escasa y fragmentaria la información con que se cuenta hasta el momento sobre diferentes modos de preparación de aislados proteicos provenientes de grano integral ó pulido, y la diferente funcionalidad que estos aislados puedan presentar al obtenerse a partir de variedades específicas. Como fuera mencionado en la Estación Experimental "Julio Hirschhorn", La Plata, Buenos Aires, Argentina y en el marco del Programa de Incentivos Docentes, el Programa Arroz de la Facultad de Ciencias Agrarias y Forestales ha desarrollado la variedad Nutriar con un 30\% más de proteína que los cultivares normales. Dependiendo de la ubicación y la fracción proteica a la que pertenezca, esta proteína extra podría presentar propiedades que permitan un mejoramiento en la obtención de aislados proteicos con buenas propiedades funcionales.

\subsection{Hipótesis de trabajo y objetivos}

Por todo lo anterior se ha elaborado la siguiente hipótesis de trabajo:

A partir de la variedad de arroz Nutriar, de alto contenido en proteínas, se podrían obtener aislados proteicos de buena calidad nutricional y funcional.

En el marco de esta hipótesis nos hemos propuesto los siguientes objetivos:

\section{Objetivo general}

- Estudiar las proteínas de arroz de la variedad Nutriar desde el punto de vista estructural y funcional provenientes de grano pulido e integral. Compararlas con las de una variedad de amplio uso local, de calidad tropical. 


\section{Objetivos particulares}

- Determinar la composición proteica, cuali y cuantitativamente de la variedad Nutriar en comparación con la variedad de referencia.

- Explorar distintos métodos de preparación de aislados proteicos mediante la variación del pH de extracción de proteínas. Elección del método más adecuado.

- Caracterización estructural, nutricional y funcional de los aislados obtenidos con la metodología de elección. 
2 MATERIALES Y MÉTODOS 


\section{I - MATERI ALES Y MÉTODOS}

\subsection{Materiales: Semillas y harinas}

Se utilizaron granos de arroz cáscara de las variedades Nutriar FCAyF (Facultad de Ciencias Agrarias y Forestales, Universidad Nacional de La Plata) de alto contenido proteico y El Paso 144 ROU, variedad de amplia difusión local (Figuras 1 y 2 ).

El material se obtuvo de los ensayos que se condujeron en la Estación

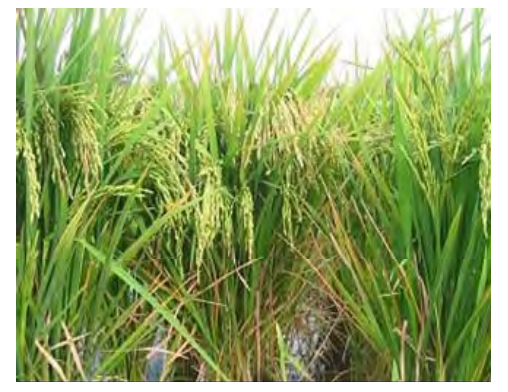

Nutriar

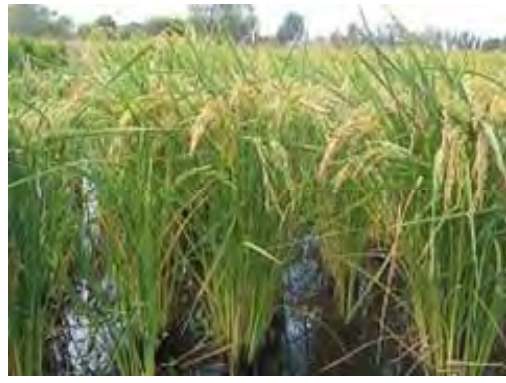

El Paso 144

Figura 1: variedades Nutriar y El Paso 144 cultivadas en la Estación Experimental Julio Hirschhorn, La Plata, Bs. As.

Experimental Julio Hirschhorn (Lat.: 34은'S y Long.:

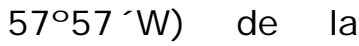
Facultad de

Ciencias Agrarias y Forestales de la Universidad Nacional de La Plata.

Los granos

fueron cosechados

maduros, trillados en forma manual y secados en estufa a $40^{\circ} \mathrm{C}$ hasta humedad de $13,5 \%$. Se obtuvieron las fracciones de grano integral y pulido por medio de un molino experimental (tipo universal Giudetti y Artioli, USA).

Las harinas de grano integral y pulido fueron molidas en la cátedra de Cerealicultura de la Facultad antes mencionada utilizando un molino Udy, de $1 \mathrm{~mm}$ de mesh y tamizadas a través de un cedazo de mesh 10xx. Las harinas así obtenidas, se almacenaron a $4{ }^{\circ} \mathrm{C}$.

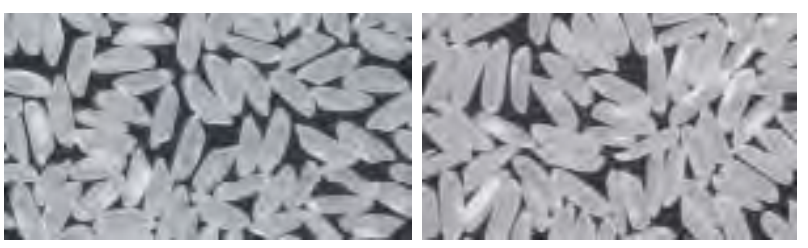

Nutriar

Figura 2: grano pulido de las variedades Nutriar y El Paso 144 


\subsection{Preparación de muestras}

\subsubsection{Extracción de las fracciones y subfracciones proteicas}

A partir de harina integral de las variedades Nutriar y El Paso 144 se realizó una extracción secuencial de las distintas fracciones proteicas según el método de Osborne modificado. La relación "harina/solvente de extracción ( $\mathrm{gr} / \mathrm{ml})$ " fue de 1/10 en todos los casos. En primera instancia se extrajo la fracción albúminas utilizando agua destilada como solvente. Luego de 60 minutos de agitación constante la suspensión harina/agua se centrifugó a $15.000 \mathrm{rpm}$ durante 20 minutos a $20{ }^{\circ} \mathrm{C}$ y se separó el sobrenadante. Con el residuo precipitado se procedió a la extracción de las globulinas utilizando Buffer $A: K_{2} \mathrm{HPO}_{4} 32,5 \mathrm{mM}$, $\mathrm{KH}_{2} \mathrm{PO}_{4}$ 2,6 mM (pH 7,5) conteniendo $\mathrm{NaCl}$ 0,4 M. Después de 60 minutos de agitación se centrifugó, se separó el sobrenadante y a partir del precipitado se realizó la extracción de glutelinas $(\mathrm{NaOH} 0,1 \mathrm{~N})$. Por último a partir de este residuo se extrajo la fracción prolamina con etanol al $70 \%$.

En una preparación independiente se obtuvieron las subfracciones Gt0,01 y Gt0,1 a partir del residuo remanente luego de la extracción de globulinas. La subfracción Gt0,01 se extrajo utilizando $\mathrm{NaOH}$ 0,01N con agitación constante durante 60 minutos a $25^{\circ} \mathrm{C}$. Se centrifugó a $15000 \mathrm{rpm}$, durante 20 minutos, a $20^{\circ} \mathrm{C}$. El precipitado se re-suspendió con $\mathrm{NaOH} 0,1 \mathrm{~N}$ y se extrajo la subfracción Gt0,1 en forma similar a la anterior.

\subsubsection{Extracción de proteínas totales}

Se realizó la extracción de proteínas a pHs 2, 9, 10, 11 y 12 a partir de harina de arroz pulido e integral de las variedades Nutriar y El Paso 144 con una relación final harina/solución de extracción de 1:10 p/v. En el caso de pH 2 se disolvió la harina en agua destilada y se mantuvo el $\mathrm{pH}$ con $\mathrm{HCl} 0,1 \mathrm{~N}$ durante 60 minutos con agitación constante, a temperatura ambiente. En los casos de extracción alcalina se procedió del mismo modo pero manteniendo el $\mathrm{pH}$ con $\mathrm{NaOH}$ $0,1 \mathrm{~N}$. Después de cada extracción se centrifugó a 15.000 rpm, durante 20 minutos, a $20^{\circ} \mathrm{C}$ y se conservó el sobrenadante.

En todos los casos se cuantificó el contenido proteico o rendimiento en la extracción del sobrenadante mediante el método de Lowry (Lowry et al., 1951). 


\subsubsection{Preparación de aislados proteicos}

En el caso de las subfracciones (Gt0,01 y Gt0,1) y los aislados a pH 12 a partir de los sobrenadantes obtenidos en la forma descripta se obtuvieron los liofilizados proteicos de la siguiente manera:

En cada caso el sobrenadante se llevó a pH 6. El precipitado proteico obtenido se separó por centrifugación a $12.000 \mathrm{rpm}$, durante 20 minutos, a $8{ }^{\circ} \mathrm{C}$. El mismo se re-resuspendió en agua destilada ajustando el $\mathrm{pH}$ a 7,0 . Se congeló a - 80 ${ }^{\circ} \mathrm{C}$ y se liofilizó en un equipo Heto modelo FD4. Los liofilizados se mantuvieron en cámara $\left(4^{\circ} \mathrm{C}\right)$.

El contenido proteico de los aislados se cuantificó por el método de microKjeldahl de acuerdo con la AOAC (1970). El factor de conversión utilizado fue 5,95 (Juliano, 1985).

\subsection{Electroforesis}

\subsubsection{Reactivos generales}

Buffer de electrodo: hidroximetil aminometano- $\mathrm{HCl}$ (Tris- $\mathrm{HCl}$ ) 0,025 M, glicina $0,192 \mathrm{M}(\mathrm{pH} 8,3)$, con o sin dodecil sulfato de sodio (SDS) $0,1 \% \mathrm{p} / \mathrm{v}$, para electroforesis desnaturalizante o nativa respectivamente.

Buffer de gel apilador o de concentración: Tris- $\mathrm{HCl} 0,125 \mathrm{M}(\mathrm{pH} \mathrm{6,8)}$ con o sin SDS $0,1 \% \mathrm{p} / \mathrm{v}$.

Buffer de gel separador: Tris- $\mathrm{HCl} 0,375 \mathrm{M}(\mathrm{pH} 8,8)$ con o sin SDS 0,1\% p/v. $\mathrm{N}^{\prime}, \mathrm{N}^{\prime}, \mathrm{N}^{\prime}, \mathrm{N}^{\prime}$, tetrametiletilendiamina (TEMED): en ambos buffers (separador $\mathrm{o}$ apilador) se utilizó una concentración $0,1 \% \mathrm{v} / \mathrm{v}$.

Buffer de tratamiento para electroforesis bidimensional: Tris- $\mathrm{HCl} 0,0625 \mathrm{M}(\mathrm{pH}$ $6,8)$, SDS $0,1 \% \mathrm{p} / \mathrm{v}$, sacarosa $20 \% \mathrm{p} / \mathrm{v}$, con o sin 2 -ME $0,2 \mathrm{M}$.

Buffer de muestra para geles:

desnaturalizantes (SDS-PAGE): Tris- $\mathrm{HCl} \mathrm{0,185} \mathrm{M} \mathrm{(pH} \mathrm{8,8),} \mathrm{glicerol} \mathrm{12,5 \%}$ $\mathrm{v} / \mathrm{v}$, azul de bromofenol $0,05 \% \mathrm{p} / \mathrm{v}$ y $\operatorname{SDS} 0,1 \% \mathrm{p} / \mathrm{v}$, con o sin 2mercaptoetanol (2-ME) $5 \% \mathrm{v} / \mathrm{v}$, para obtener condiciones reductoras o no reductoras, respectivamente.

no desnaturalizantes (PAGE-nativo): similar al anterior pero sin el agregado de SDS $0,1 \% \mathrm{p} / \mathrm{v}$

en presencia de urea (PAGE-urea): similar al anterior pero con el agregado de urea $6 \mathrm{M}$. 
Electroforesis con tricina: buffer anódico (colocado fuera del contenedor de electrodos) Tris- $\mathrm{HCl} \mathrm{0,2} \mathrm{M} \mathrm{(pH} \mathrm{8,9);} \mathrm{buffer} \mathrm{catódico} \mathrm{(colocado} \mathrm{dentro} \mathrm{del} \mathrm{contenedor}$ de electrodos) Tris- $\mathrm{HCl} 0,2 \mathrm{M}(\mathrm{pH} 8,25)$ Tricina 0,1M, SDS 0,1\% p/v; gel buffer Tris$\mathrm{HCl} 3 \mathrm{M}(\mathrm{pH} 8,45)$, SDS 0,3\% p/v (Schägger and Jagow, 1987).

\subsubsection{Preparación de las muestras}

Las muestras se prepararon disolviendo la proteína liofilizada en buffer de muestra o, cuando se trataba de soluciones proteicas, agregando 3 volúmenes de las mismas a 1 volumen de buffer de muestra $4 x$. En las electroforesis en condiciones desnaturalizantes y reductoras las muestras fueron tratadas con 2-mercaptoetanol al $5 \% \mathrm{v} / \mathrm{v}$, durante un minuto, a $100{ }^{\circ} \mathrm{C}$. Todas las muestras, antes de ser cargadas en el gel correspondiente, se centrifugaron a $15.000 \mathrm{rpm}$ durante 15 minutos a $20^{\circ} \mathrm{C}$ en una microcentrífuga IEC (Centra MP4R, International Equipment Company), y los sobrenadantes se sembraron a razón de 30-50 $\mu$ g de proteína/calle.

\subsubsection{SDS-PAGE. Desarrollo}

Las electroforesis se realizaron en miniplacas con un equipo BIO-RAD, modelo Mini Protean II.

Se utilizó el sistema de buffers descripto por Laemmli (1970), que se detalló previamente. Las electroforesis se llevaron a cabo a un voltaje constante de $200 \mathrm{~V}$ (aproximadamente 1,5 horas). Se utilizaron geles de concentración constante de acrilamida $14 \%$ p/v con gel apilador en su parte superior, con una concentración de acrilamida de $4 \% \mathrm{p} / \mathrm{v}$.

La mezcla de proteínas patrón utilizadas para la estimación de las masas moleculares de los polipéptidos fueron suministradas por Pharmacia en un único vial y son: fosforilasa b (94.000 Da); seroalbúmina bovina (67.000 Da); ovoalbúmina (45.000 Da); anhidrasa carbónica (30.000 Da); inhibidor de tripsina (20.100 Da) y $\alpha$-lactoalbúmina (14.400 Da).

2.3.3a PAGE-urea. Para estas electroforesis se empleó el mismo sistema buffer que para las no-desnaturalizantes pero con el agregado de urea $6 \mathrm{M}$ y en remplazo de SDS se empleó Chaps 0,005M. Se utilizaron geles de acrilamida de 7,5\% p/v. Se llevaron a cabo a un voltaje constante de $200 \mathrm{~V}$ durante aproximadamente 2 horas. 
2.3.3b PAGE-Tricina. Con la finalidad de obtener mayor resolución en muestras de menor peso molecular, se utilizó el sistema de buffers descripto por Schägger and Jagow, (1987). Se utilizaron geles de acrilamida de $16 \% \mathrm{p} / \mathrm{v}$ para el separador, $10 \%$ para el spacer y $4 \% \mathrm{p} / \mathrm{v}$ en el stacking. Las electroforesis se llevaron a cabo a un voltaje inicial de 30V, una vez atravesado el stacking se continuó la corrida a $90 \mathrm{~V}$ durante 2,5 horas aproximadamente.

\subsection{3c Electroforesis bidimensionales (SDS-PAGE $\rightarrow$ SDS-PAGE + 2-ME).} Luego de correr la primera dimensión (geles de 0,75 mm de espesor) se cortó la porción del gel correspondiente a dos calles con la proteína a analizar, y se la sumergió en $30 \mathrm{ml}$ de buffer de tratamiento (descripto previamente en el punto 23-1), manteniéndola a $55{ }^{\circ} \mathrm{C}$ durante 30 minutos con dos cambios de la solución. La porción de gel tratada se colocó sobre el gel de la segunda dimensión de $1 \mathrm{~mm}$ de espesor (SDS-PAGE o SDS-PAGE + 2-ME según correspondiera). En este mismo gel, en una calle aparte y como referencia, se sembró la mezcla de proteínas patrón de masa molecular conocida. La electroforesis se desarrolló de la misma manera que las anteriores.

\subsubsection{Coloración}

Los geles fueron fijados y teñidos al mismo tiempo con Coomasie Brilliant Blue R-250 al 0,192\% p/v en agua/metanol/ácido acético (10:10:4) durante 12 horas y desteñidos con metanol $25 \%$ p/v y ácido acético $10 \%$ p/v.

\subsubsection{Obtención de las imágenes}

Las imágenes de las electroforesis fueron digitalizadas mediante un equipo BIO-RAD (Gel Doc 1000).

\subsection{Determinación de la composición aminoacídica}

Previo el análisis de aminoácidos, la proteína de los aislados $\mathrm{Ni}$ y Ei fue purificada según el método descripto por Mooney and Thelen (2004).

La determinación de la composición aminoácidica fue realizada en el Laboratorio Nacional de Investigación y Servicios en Péptidos y Proteínas (LanaisPro, CONICET-UBA) perteneciente al departamento de Química Biológica de la Facultad de Farmacia y Bioquímica de la Universidad de Buenos Aires. 


\subsection{Digestibilidad in vitro}

Se determinó la digestibilidad in vitro de los aislados $\mathrm{Ei}, \mathrm{Ni}$, Ep y $\mathrm{Np}$ por simulación gástrica e intestinal (Nakano et al., 1994).

Las enzimas utilizadas fueron: Pancreatina: (Sigma Chemical Co., St. Louis, MO) y Pepsina (Sigma Chemical Co., St. Louis, MO).

Se prepararon suspensiones con los aislados proteicos $(25 \mathrm{mg} / \mathrm{ml}$ ) ajustadas a pH 2 con $\mathrm{HCl} 1 \mathrm{~N}$. Se preincubaron durante 30 minutos a $37^{\circ} \mathrm{C}$ con agitación constante. Se agregó pepsina al $1 \%$ en $\mathrm{HCl} 0,1 \mathrm{~N}$; $\mathrm{NaCl} 0,03 \mathrm{M}$, solución que simula el fluido gástrico, se incubaron durante 60 minutos a $37^{\circ}$. Posteriormente se llevó a pH 6 con $\mathrm{NaOH} 1 \mathrm{~N}$, se agregó pancreatina al $5 \%$ en $\mathrm{NaHCO}_{3} 0,1 \mathrm{~N}$ (solución que simula el fluido instestinal), nuevamente, se incubaron 60 minutos a $37^{\circ}$. La reacción se interrumpió sumergiendo la muestra en baño maría ( $T=80^{\circ} \mathrm{C}$ durante 10 minutos). Se centrifugó y se recuperó el sobrenadante.

Se utilizó el método TNBS propuesto por Adler-Nissen (1979) para determinar la extensión de los péptidos. Se tomó como referencia el aminoácido leucina para realizar la curva patrón y considerando que el total de grupos aminos posibles en un grado máximo de hidrólisis es de 8 meq de leucina/litro de solución.

Posteriormente luego de la hidrólisis enzimática, se calculó, en base al mencionado valor, el Grado de Hidrólisis (GH) mediante la utilización de la expresión matemática:

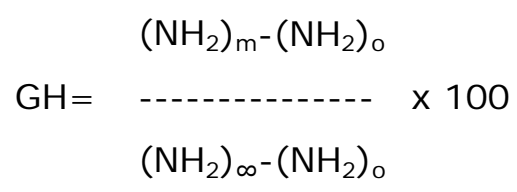

Siendo:

$\mathrm{GH}=$ Grado de hidrólisis en porcentaje

$\left(\mathrm{NH}_{2}\right)_{\mathrm{m}}=$ meq de leucina/l de la muestra digerida

$\left(\mathrm{NH}_{2}\right)_{0}=$ meq de leucina/I de la muestra sin digerir

$\left(\mathrm{NH}_{2}\right)_{\infty}=$ meq de leucina/l totales de la proteína $=8$

El número de meq de leucina/I totales de la proteína fue ajustado por el porcentaje de proteína del aislado. 


\subsection{Solubilidad de las subfracciones y de los aislados proteicos}

Para el estudio de la solubilidad de las subfracciones proteicas (Gt0,01 y Gt0,1) se utilizó buffers borato, $(\mathrm{pH} 10)$ en concentraciones de 0,030 y 0,1 M $\mathrm{H}_{3} \mathrm{BO}_{3} / \mathrm{H}_{2} \mathrm{BO}_{3}{ }^{-}$.

Para el estudio del efecto del pH sobre la solubilidad de los aislados proteicos se utilizaron distintos buffers de concentración 0,2 M:
a) ácido cítrico / citrato ( $\mathrm{pH} 2,3 ; \mathrm{pH} \mathrm{3,1;} \mathrm{pH} \mathrm{4,1;} \mathrm{pH} \mathrm{4,7} \mathrm{y} \mathrm{pH} \mathrm{5,1)}$
b) ácido fosfórico/fosfato, ( $\mathrm{pH} \mathrm{6,3} \mathrm{y} \mathrm{pH} \mathrm{7,5)}$
c) ácido bórico/borato ( $\mathrm{pH} 8,8$ y pH 9,7)
d) ácido carbónico/carbonato ( $\mathrm{pH} \mathrm{10,1} \mathrm{y} \mathrm{pH} \mathrm{11,0).}$

Se prepararon suspensiones de las muestras ( $1 \mathrm{mg} / \mathrm{ml}$ ) en agua o en las soluciones correspondientes. Se incubaron 1 hora a temperatura ambiente con agitación cada 15 minutos, se centrifugaron a 12.000 rpm, durante 20 minutos, a temperatura ambiente y se calculó el contenido de proteína del sobrenadante mediante el método de Lowry. Finalmente el porcentaje de solubilidad se calculó dividiendo la concentración proteica del sobrenadante $(\mathrm{mg} / \mathrm{ml}$, calculada por el método de Lowry) por el contenido proteico del aislado (calculada por el método Micro-kjeldahl, mg de proteína/mg de aislado).

\subsection{Capacidad de absorción de agua (WIC)}

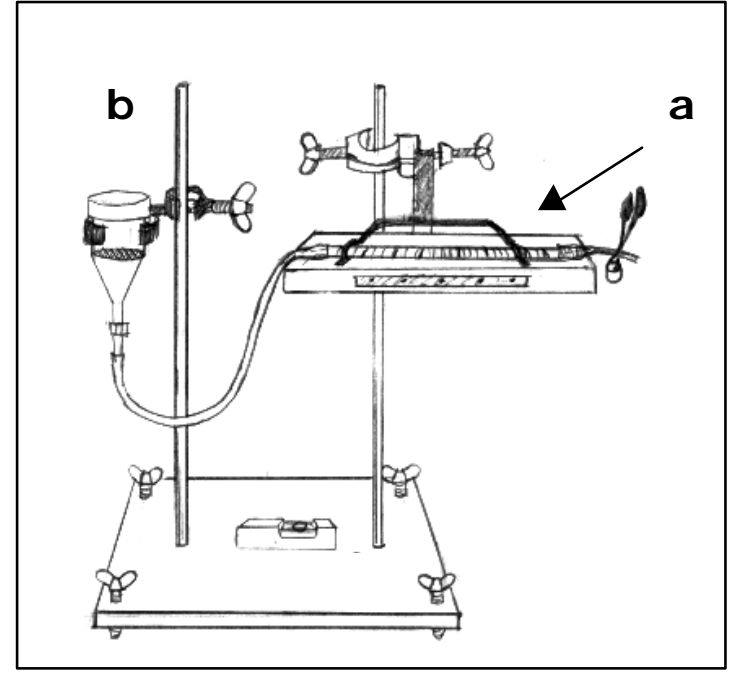

Figura 3. Esquema del equipo utilizado en la determinación de la capacidad de absorción de agua de los aislados proteicos. a) pipeta graduada, b) embudo con papel de filtro.
La capacidad de absorción de agua (WIC, water imbibing capacity) se determinó siguiendo la técnica Torgensen and Toledo (1977), utilizando un equipo similar al aparato diseñado por Baumann (Baumann, 1967) que se esquematiza en la Figura 3.

Tal como lo describiera Silingo en su Tesis doctoral 
(2000), el principio del método se basa en determinar la cantidad de agua que un polvo proteico es capaz de absorber espontáneamente a una temperatura dada, cuando se pone en contacto con una cantidad ilimitada de agua. El equipo consiste en una pipeta de pequeño volumen, graduada, cuyo eje longitudinal se encuentra al mismo nivel que la superficie de contacto entre el agua y la proteína en polvo. La proteína se coloca sobre un papel de filtro que está apoyado en una superficie plana que continua en un embudo. Ambos, la pipeta y el embudo, se conectan a través de un tubo. Para medir la WIC de los aislados, se colocó una cantidad conocida de muestra (de aproximadamente $30 \mathrm{mg}$ ) de una vez, en forma de monocapa sobre el papel de filtro húmedo luego de enrasar la pipeta y antes de tapar el embudo. Se registró el retroceso de la columna de agua en la pipeta en función del tiempo hasta que se llegó a un valor constante de absorción. Todo el proceso se llevó a cabo en un ambiente a $20 \pm 2^{\circ} \mathrm{C}$. Las curvas ideales de absorción de agua en función del tiempo tienen forma hiperbólica. Los valores obtenidos fueron graficados. La WIC se obtuvo dividiendo el volumen de agua absorbido en la región de equilibrio (saturación) por la masa de muestra empleada en la determinación. A partir la curva de cinética se obtuvo el volumen máximo de absorción y el tiempo de equilibrio que fue el necesario para alcanzar el volumen máximo de absorción

\subsection{Capacidad de retención de agua (WHC)}

Se determinó la capacidad de retención de agua aproximada (WHC, water holding capacity) por el método de Quinn and Paton (1979). Se prepararon dispersiones de los aislados al $1 \%(p / v)$ en agua destilada se mantuvieron con agitación durante $1 \mathrm{~h}$ a temperatura ambiente. Las muestras fueron centrifugadas a $14.000 \mathrm{rpm}$ durante 30 minutos a $15^{\circ} \mathrm{C}$. Luego de separar el sobrenadante los tubos de centrifuga fueron invertidos y colocados sobre papel absorbente por 1 minuto antes de pesarlos. Se determinó la masa húmeda de los sedimentos y el contenido de proteína soluble en los sobrenadantes obtenidos por el método de Lowry. WHC es expresado como mililitros de agua retenida por la fracción insoluble de la proteína total (Petruccelli and Añón, 1994).

La capacidad de retención de agua se calculó de acuerdo a la siguiente expresión:

$W H C=(m h-m d+m p) / m d x \delta$

Siendo WHC: capacidad de retención de agua, en $\mathrm{ml}$ de agua/g de muestra 
md: masa del aislado proteico deshidratado

mh: masa del pellets hidratado (proteína insoluble)

mp: masa de proteína soluble

$\delta$ : densidad del agua a $20^{\circ} \mathrm{C}(1 \mathrm{~g} / \mathrm{ml})$

\subsection{Actividad espumante}

La actividad espumante de los aislados se determinó utilizando un equipo similar al diseñado por Loisel et al. (1993). El equipo genera espuma por burbujeo de $\mathrm{N}_{2}$ y registra la conductividad eléctrica del líquido (en nuestro caso solución proteica). Este equipo permite el seguimiento del proceso de formación de espuma y el registro de la variación del volumen de la solución en función del tiempo, según el principio propuesto por Wagner et al. (1996). A partir de la planilla generada por el mismo, se pueden calcular diferentes parámetros que dan cuenta de las propiedades espumantes de la proteína (Wilde and Clark, 1996; Wagner, 2000). Este método tiene numerosas ventajas ya que permite trabajar con bajas concentraciones de proteína (inferiores a 0,5\%), usar volúmenes de líquidos pequeños (inferiores a $20 \mathrm{ml}$ ), permite controlar el caudal y volumen de aire incorporado, además de obtener un volumen de burbujas homogéneo y tener una buena reproducibilidad (Wagner, 2000).

En nuestro caso particular, las espumas de los aislados se formaron por burbujeo de $\mathrm{N}_{2}$ a flujo constante (caudal $1,7 \mathrm{ml} / \mathrm{seg}$ ) a través de $6 \mathrm{ml}$ de dispersiones $1 \mathrm{mg}$ proteína total/ml en buffer $\mathrm{H}_{3} \mathrm{BO}_{3} / \mathrm{H}_{2} \mathrm{BO}_{3}{ }^{-}$a $\mathrm{pHs} 3$ y 9 y fuerza iónica $\mu=0,2 \mathrm{M}$.

Se determinó la capacidad de formar espuma como el volumen máximo de líquido incorporado a la espuma (Vmax), y la estabilidad de la espuma como el tiempo que tarda en drenar el $50 \%$ del volumen máximo $\left(t_{1 / 2}\right)$; parámetros que pueden visualizarse gráficamente en la Figura 4. 


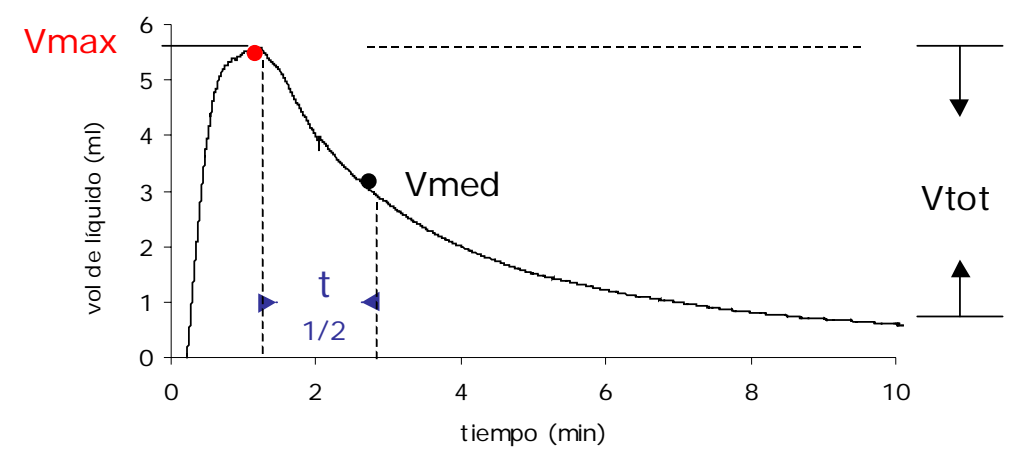

Figura 4 . Parámetros determinados a partir de la curva de volumen incorporado a la espuma en función del tiempo.

Vmax=volumen máximo del liquido incorporado a la espuma; $\mathbf{t}_{\mathbf{1 / 2}} \mathbf{2 =}$ tiempo que tarda en drenar el $50 \%$ del Vmax; Vmedio $=50 \%$ de Vmax; Vtot $=$ Volumen total de liquido incorporado a la espuma en 10 minutos.

\subsection{Actividad emulsificante}

Se prepararon suspensiones a partir de $7 \mathrm{ml}$ de aceite puro de girasol con 14 $\mathrm{ml}$ de una suspención de muestras de aislados (1,5 $\mathrm{mg}$ de muestra/ml) en buffer borato $\mathrm{pH} 3$ y 9 y fuerza iónica $\mu=0,2 \mathrm{M}$. Estas muestras fueron homogeneizadas mediante un equipo Ultraturrax (T-25, S25N10G, IKA Labortechnik, Karlsruhe, Alemania) operando a $20.000 \mathrm{rpm}$ durante 90 segundos a 25 ㄷ. La evolución de las diferentes emulsiones se determinó por medidas de dispersión de la luz en un analizador óptico vertical QuickScan (Beckman Coulter, Fullerton, USA). Este equipo permite hacer un barrido de la emulsión a lo largo del tubo de medida en diferentes instantes, obteniéndose una serie de perfiles del porcentaje de backscattering (\%BS) en función del tiempo (Pan et al., 2002).

Las muestras homogeneizadas fueron colocadas en recipientes cilíndricos o tubo de medida para determinar los perfiles de backscattering (\%BS) registrando el valor de porcentaje cada 60 segundos durante 1 hora a lo largo del tubo (altura total: $60 \mathrm{~mm}$ ).

El backscattering inicial (\%BSin) fue medido al comienzo de la determinación como promedio del barrido a $\mathrm{t}=0 \mathrm{~min}$, a lo largo de todo el tubo de medida. La cinética de cremado $\left(\% \mathrm{BS}_{10-30 \mathrm{~mm}}\right)$ fue determinada mediante los valores promedio de backscattering en la parte inferior del tubo (entre 10 y $30 \mathrm{~mm}$ ) en función del tiempo.

Los parámetros calculados para caracterizar la estabilidad de la emulsión fueron: 
$\mathrm{t}_{0,1}$ como el tiempo que tarda en disminuir en un $10 \%$ el valor de $\% \mathrm{BS}_{10-30 \mathrm{~mm}}$

y la constante cinética $\left(\mathrm{K}_{0,1}\right)$ según la expresión matemática:

$\mathrm{K}_{0,1}=\left(\% \mathrm{BSin}_{10-30 \mathrm{~mm}} \times \mathrm{t}_{0,1}\right)^{-1}$

La coalescencia ( $\% \mathrm{BS}_{50-60 \mathrm{~mm}}$ ) se midió como la variación de los promedios de backscattering en la zona superior del tubo $(50-60 \mathrm{~mm})$ en función del tiempo de estacionamiento de la emulsión.

\subsection{Absorción de aceite}

Se prepararon dispersiones de los aislados al $1 \%(p / v)$ en aceite puro de girasol, se mantuvieron con agitación durante 1 hora a temperatura ambiente. Las muestras fueron centrifugadas a $14.000 \mathrm{rpm}$ durante $30 \mathrm{~min}$ a $15^{\circ} \mathrm{C}$. Luego los tubos fueron invertidos y colocados sobre papel absorbente por 1 minuto antes de pesarlos.

\subsection{Análisis estadístico de los resultados y programas utilizados}

Los resultados numéricos obtenidos fueron analizados estadísticamente empleando el programa Statgraphics Plus 4.0, Statical Statgraphics Corp., Rockville, MD. Las determinaciones se realizaron al menos por duplicado.

Con los parámetros evaluados se realizaron análisis de varianza (ANOVA), una sola vía comparando las medias por Test de $\operatorname{LSD}(p<0,05)$. Letras iguales en las tablas representan diferencias no significativas.

Con los valores obtenidos al evaluar los diferentes parámetros que caracterizaron las propiedades funcionales estudiadas a $\mathrm{pH} 9$ y fuerza iónica $\mu=$ $0,2 \mathrm{M}$, se realizó una Matriz de Correlación de Pearson.

Se utilizaron las herramientas proporcionadas por Office Microsof 1997-2003 y el OriginPro 7. 
3 RESULTADOS Y DISCUSIÓN 


\section{3 / RESULTADOS Y DISCUSIÓN}

\section{CAPITULO I. Caracterización estructural de las fracciones proteicas de las variedades Nutriar y EI Paso 144}

\section{I.1 Caracterización polipeptídica}

Se estudiaron las proteínas de arroz de las variedades Nutriar y El Paso 144 mediante electroforesis desnaturalizante (SDS-PAGE).

En una primera instancia se observó el perfil que presentaban las harinas de

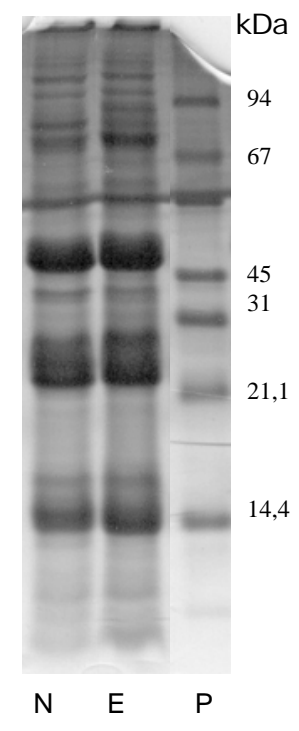

Figura 1. SDS-PAGE de harina integral de las variedades $\mathbf{N}$ : Nutriar y E: El Paso 144. P: patrón molecular. Se indican las masas de las proteínas patrones en kDa. las variedades en estudio (Figura 1). Tanto la distribución como la intensidad de las bandas muestran una gran similitud entre Nutriar y El Paso 144. Se distinguen claramente los polipéptidos de: 13-16 kDa, alrededor de 26 kDa, entre 30 y 40 kDa y 55-59 kDa correspondientes a la fracción glutelina. Ambos perfiles sólo se diferencian en la intensidad de algunas bandas, especialmente las de mayor peso molecular.

Se analizó la composición polipeptídica de las fracciones proteicas de las dos variedades en estudio.

La fracción albúminas, tanto en grano pulido como integral, presentó numerosas bandas con pesos moleculares entre 95 y 14,4 kDa conforme a lo observado por Juliano (1980). No obstante, la mayor abundancia, correspondió a 


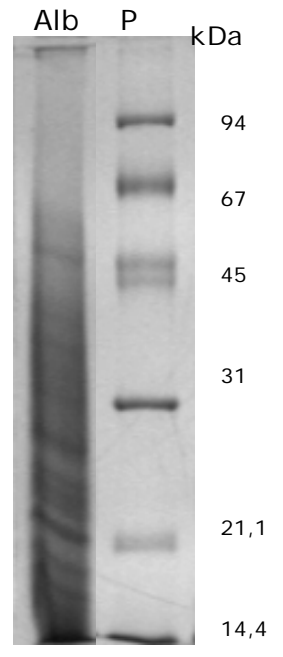

Figura 2. Perfil tipo de la fracción albúmina en condiciones no reductoras. polipéptidos de peso molecular inferior a $45 \mathrm{kDa}$. En la Figura 2 podemos ver un perfil representativo de la fracción que se encontró en las muestras estudiadas.

En cuanto a la fracción globulina, en condiciones no reductoras, su perfil presentó polipéptidos entre 45 y 67 $\mathrm{kDa}$, entre 31 y $45 \mathrm{kDa}$ y bandas de aproximadamente 26 , 21 y $14 \mathrm{kDa}$ (Figura 3 , sin $\beta$-ME). En condiciones reductoras, las bandas de pesos moleculares altos disminuyen en intensidad, mientras se distingue marcadamente la banda de 26 kDa descripta como mayoritaria de las globulinas de arroz (Komatsu and Hirano 1992; Furukawa et al., 2003; Kumagai et al., 2006; entre otros).

Como se puede observar en la Figura 4, que muestra el perfil bidimensional de globulina de la variedad Nutriar, algunos de los polipéptidos de alrededor de 50 kDa serían dimeros unidos por puentes disulfuro. Por otro lado, el polipéptido de alrededor de 26 kDa corre por encima de la diagonal en la segunda dimensión, lo que indica que en su estructura están presentes uniones disulfuro internas (intracatenarios).

$\sin \beta-M E$

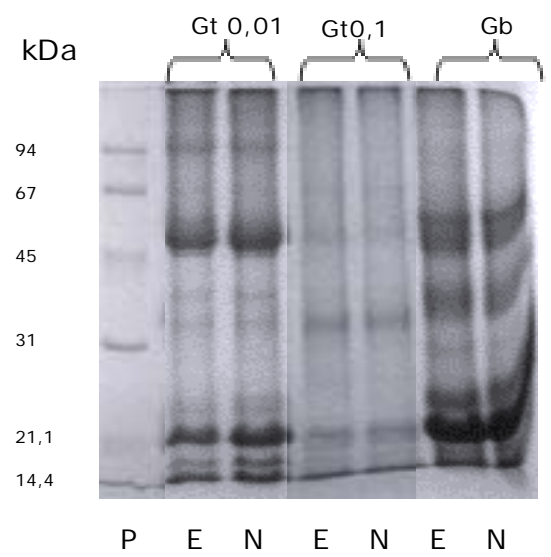

con $\beta-M E$

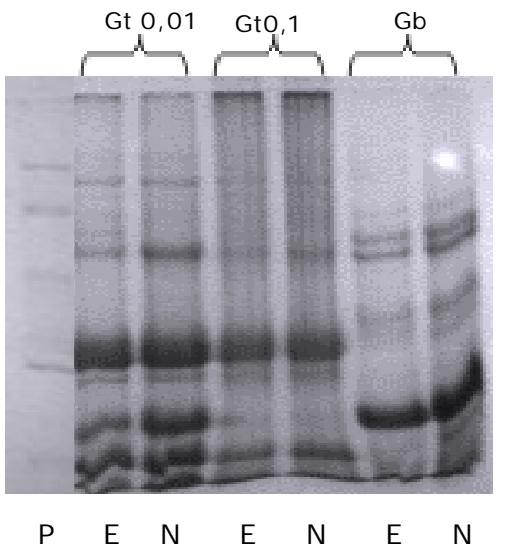

Figura 3. SDS-PAGE de las subfracciones proteicas de harina integral. Gt0,01 y Gt0,1. E: El Paso 144 y $\mathbf{N}$ : Nutriar; Gb: globulinas. P:masas de las proteínas patrones de peso molecular. 
La fracción glutelina se caracteriza por la abundancia de polipéptidos de alto peso molecular que no entran al gel o si lo hacen, se distribuyen con dificultad

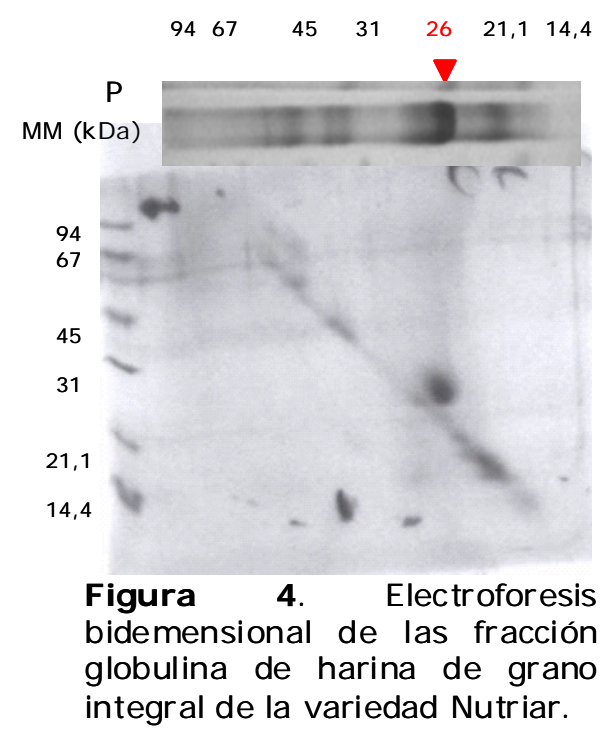
en la parte superior.

Por ser la fracción mayoritaria del arroz $y$, teniendo en cuenta los resultados de Abugoch et al. (2003) en glutelinas de amaranto, la fracción glutelinas fue extraída en dos solventes diferentes. En una primera extracción se utilizaron condiciones más suaves $(\mathrm{NaOH}$ $0,01 \mathrm{~N}$ ) con el objeto de preservar la estructura molecular, si la hubiera, y se completó la extracción mediante condiciones más drásticas con $\mathrm{NaOH}$ $0,1 \mathrm{~N}$.

En condiciones no reductoras, la subfracción Gt0,01 presentó una banda de alrededor de $94 \mathrm{kDa}$, otra más abundante de aproximadamente $57 \mathrm{kDa}$ que correspondería a dimeros y otras de 22-23 y de 16 y 14 kDa, mientras la subfracción Gt0,1 presentó una mayor proporción de los polipéptidos de aproximadamente 30 y $20 \mathrm{kDa}$ y menor del polipéptido de alrededor de 57 kDa (Figura $3, \sin \beta-M E$ ). Esto nos estaría indicando que hubo un intercambio disulfurosulfidrilos (S-S/SH) favorecido por la desnaturalización generada en condiciones alcalinas extremas. La extracción con $\mathrm{NaOH} 0,1 \mathrm{~N}$ posibilitó el desplegamiento de la estructura proteica con la consecuente exposición de los grupos SS-SH que en otras condiciones estarían ubicados en el interior de la misma.

En condiciones reductoras, se pudo observar, tanto en Gt0,01 como en Gt0,1 la presencia del polipéptido de alrededor de 57 kDa que corresponde a la proglutelina (Qu et al., 2001; Kumagai et al., 2006) y de los polipéptidos integrantes de los dímeros de 37-39 y 22-23 kDa, subunidades ácida y básica respectivamente (Figura 3, con $\beta$-ME). Este comportamiento responde a la constitución propia de la glutelina mencionada por diversos autores (Yamagata et al., 1982; Robert et al.,1985; Qu et al., 2001; Furukawa et al., 2003; Kumagai et al., 2006; entre otros). 


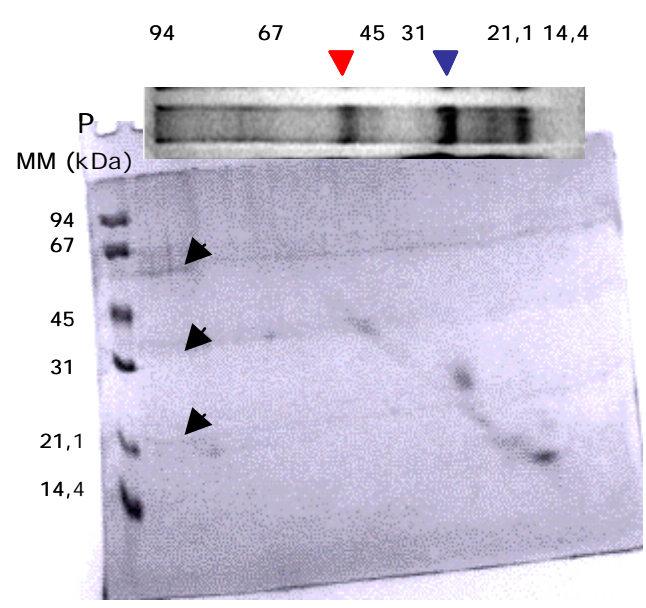

Figura $5 . \quad$ Electroforesis bidemensional de las fracción glutelina de harina de grano integral de la variedad Nutriar.
La diferencia entre ambas subfracciones pudo observarse en una banda adicional de aproximadamente 26 $\mathrm{kDa}$, solo presente en la subfracción Gt0,01 (flecha azul, figura 5).

Observando en detalle la fracción glutelina de harina integral de la variedad Nutriar, en la segunda dimensión puede verse que agregados de alto peso molecular que no entraron al gel, se estarían fraccionando en subunidades de aproximadamente 60, 32 y 21 kDa,

mientras que el polipéptido de aproximadamente $57 \mathrm{kDa}$ (flecha roja, figura 5) estaría integrado por polipéptidos de alrededor de 30 y $20 \mathrm{kDa}$, aunque la mancha del de 20 kDa no está intensa en la Figura 5.

Con posterioridad se corrió un gel desnaturalizante con urea en concentraciones 8 y 6 . presentó agregados, probablemente unidos por puentes disulfuro, debido a la exposición de los grupos SS y $\mathrm{SH}$ por el efecto desnaturalizante de la urea. Los perfiles reflejaron similar comportamiento de los

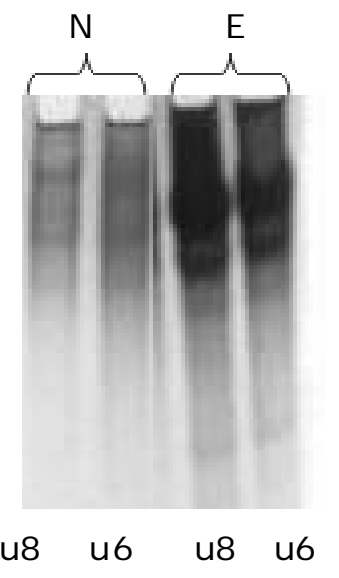

Figura 6. PAGE-nativo de la subfracción Gto,1 extraída a partir de harina integral de las variedades E: El Paso 144 y $\mathbf{N}$ : Nutriar; u6 y u8: molaridad de la urea. polipéptidos tanto en las diferentes concentraciones de urea como en las diferentes variedades estudiadas (Figura 6).

Después de realizar un detallado estudio de la composición polipeptídica de las fracciones proteicas pudimos observar escaso polimorfismo entre las variedades Nutriar y El Paso 144 (Chandi and Sogi, 2007b). 


\section{I.2 Análisis cuantitativo de las fracciones proteicas en harinas de grano integral y pulido}

En la Tabla 1 podemos observar la participación relativa de las diferentes fracciones proteicas en harina de arroz de grano pulido e integral de las variedades Nutriar y El Paso 144. En general todas las fracciones fueron más abundantes en el grano integral que en el pulido, con las excepciones de las globulinas en la variedad Nutriar con un contenido de $19 \%$ menor en integral que en pulido, y de las glutelinas en El Paso 144 con contenidos en grano integral y pulido equivalentes.

Tabla 1. Fracciones proteicas en harina de arroz de grano pulido e integral de las variedades Nutriar y El Paso 144 expresada en $\mathrm{g} / 100 \mathrm{~g}$ harina

\begin{tabular}{l|c|c|c|c|c|}
\cline { 2 - 6 } & Albúmina & Globulina & Prolamina & Glutelina & $\begin{array}{c}\text { Total de } \\
\text { proteína* }\end{array}$ \\
\hline $\begin{array}{l}\text { Nutriar } \\
\text { grano integral }\end{array}$ & $1,14 \pm 0,05 \mathrm{a}$ & $0,65 \pm 0 \mathrm{c}$ & $0,39 \pm 0,01 \mathrm{c}$ & $10,18 \pm 0,18 \mathrm{a}$ & $12,36 \pm 0,25 \mathrm{a}$ \\
\hline $\begin{array}{l}\text { Nutriar } \\
\text { grano pulido }\end{array}$ & $0,21 \pm 0,01 \mathrm{c}$ & $0,80 \pm 0,01 \mathrm{~b}$ & $0,29 \pm 0 \mathrm{~d}$ & $7,98 \pm 0,05 \mathrm{~b}$ & $9,28 \pm 0,05 \mathrm{~b}$ \\
\hline $\begin{array}{l}\text { EI Paso 144 } \\
\text { grano integral }\end{array}$ & $1,03 \pm 0,04 \mathrm{~b}$ & $0,89 \pm 0,02 \mathrm{a}$ & $0,63 \pm 0,02 \mathrm{a}$ & $7,59 \pm 0,44 \mathrm{bc}$ & $10,14 \pm 0,51 \mathrm{~b}$ \\
\hline $\begin{array}{l}\text { El Paso 144 } \\
\text { grano pulido }\end{array}$ & $0,06 \pm 0 \mathrm{~d}$ & $0,62 \pm 0,02 \mathrm{c}$ & $0,57 \pm 0,02 \mathrm{~b}$ & $6,90 \pm 0,40 \mathrm{c}$ & $8,15 \pm 0,44 \mathrm{c}$ \\
\hline
\end{tabular}

${ }^{*} \mathrm{~g} / 100 \mathrm{~g}$ harina. Letras diferentes en columnas representan diferencias significativas (LSD, $\left.p<0,05\right)$.

El contenido total de proteínas para ambas variedades fue significativamente superior ( $L S D, p<0,05$ ) en la harina de grano integral que en la de pulido (Tabla 1 ). Este resultado es consecuencia de que en la harina de grano integral, además del endosperma, se encuentran presentes las cubiertas externas del grano (aleurona, testa y pericarpio) ricas en proteínas y el embrión, especialmente rico en albúminas y globulinas (Kishrnan and Withe, 1997). Asimismo, no se puede descartar que en el proceso de pulido se haya eliminado una pequeña porción de endosperma.

Los contenidos de cada fracción expresados en porcentaje de proteínas totales oscilaron entre $0,7-10,2 \%$ en las albúminas, 5,3-8,8\% en las globulinas, 3,1-7\% en las prolaminas y entre un $74,8-86,0 \%$ en la fracción glutelina. Estos valores coinciden en uno u otro caso, con los diferentes autores que han estudiado la abundancia relativa de las fracciones proteicas sobre diferentes variedades de arroz a lo largo del tiempo como figura en Introducción (Tabla 5, página 9). 
Paralelamente, se evaluó la proporción de las subfracciones de glutelinas (Gt0,01 y Gt0,1) en las dos variedades en estudio cuyos resultados se encuentran en la Tabla 2.

Tabla 2. Contenido de las subfracciones de glutelinas en harina integral expresado en $\mathrm{g} / 100 \mathrm{~g}$ de harina

\begin{tabular}{|c|c|c|}
\hline $\begin{array}{l}\text { Fracciones } \\
\text { proteicas }\end{array}$ & Nutriar & EI Paso 144 \\
\hline Gt0,01 & $1,86 \pm 0,25$ a $A$ & $2,37 \pm 0,31 a$ \\
\hline Gt0,1 & $8,78 \pm 1,65 \quad b$ A & $5,44 \pm 0,73 \quad b A$ \\
\hline
\end{tabular}

Letras diferentes minúsculas en columna y mayúsculas en filas representan diferencias (LSD, $p<0,05)$.

El contenido de la fracción Gt0,01 en ambas variedades fue muy bajo y similar entre ambas. En la variedad El Paso 144 la proporción de Gt0,01 en el total de glutelinas es mayor $(30,34 \%)$ que en la variedad Nutriar $(17,48 \%)$. Si consideramos que la Gt0,01 corresponde a la glutelina con menor grado de agregación, este resultado nos sugiere que el contenido extra de glutelinas que presenta la variedad Nutriar se encontraría entre la proteína más agregada (Gt0,1).

El total de glutelinas fue significativamente mayor en la variedad de alto contenido proteico $(10,64$ y $7,81 \%$ para $\mathrm{N}$ y E). Esto es coincidente con lo observado por Juliano (1980) y Udaka et al. (2000) quienes sostienen que un incremento en el contenido proteico del grano de arroz se correlaciona positivamente con un incremento de la fracción glutelina.

Con posterioridad se procedió a caracterizar estas dos subfracciones, en lo que se refiere a su solubilidad, utilizando buffer borato pH 10 a diferentes fuerzas iónicas.

Tabla 3. Solubilidad de las subfracciones de glutelinas de grano integral a pH 10 y distinta fuerza iónica expresada en $\mathrm{g} / \mathrm{l00 \textrm {g }}$ de proteína

\begin{tabular}{|c|c|c|c|c|}
\hline \multirow[b]{3}{*}{ Gt 0,01} & \multicolumn{2}{|c|}{ Borato 0,03 M ( $\mathrm{pH} 10)$} & \multicolumn{2}{|c|}{ Borato 0,1 M (pH10) } \\
\hline & Nutriar & EP 144 & Nutriar & EP 144 \\
\hline & $22,7 \pm 0,52$ a $A$ & $9,35 \pm 0,89$ a $B$ & $12,5 \pm 0,98$ a $A$ & $5,81 \pm 0,71$ a $B$ \\
\hline Gt 0,1 & $2,31 \pm 0,19 \quad b$ A & $2,21 \pm 0,41 \quad b A$ & $1,44 \pm 0,13 \quad b$ A & $1,15 \pm 0,11$ \\
\hline
\end{tabular}

Letras diferentes, minúsculas en columna y mayúsculas en filas para cada uno de los solventes, representan diferencias (LSD, $\mathrm{p}<0,05)$. 
Las subfracciones mostraron diferencias en su solubilidad (Tabla 3). La fracción Gt0,1 resultó de muy escasa solubilidad siendo significativamente menor que la subfracción Gt0,01 en ambas concentraciones de solvente y ambas variedades. Este resultado responde a las características propias de las glutelinas descriptas por numerosos autores, entre ellos Agboola et al. (2005), quienes explican su insolubilidad debido al alto peso molecular y a la abundancia en puentes disulfuro (alto grado de agregación).

La solubilidad Gt0,01 de la variedad Nutriar fue significativamente superior a El Paso 144 en ambas concentraciones de solvente. Este resultado nos estaría indicando la existencia de diferencias en el grado de agregación ó en la estructura de los agregados entre las glutelinas de ambas variedades. Estas diferencias podrían reflejarse en diferencias en la funcionalidad de las proteínas de las variedades Nutriar y El Paso 144.

En términos generales, la solubilidad de las glutelinas fue mayor en el solvente de menor concentración salina (Tabla 3). El gran número de iones en solución favorecería la formación de agregados estabilizados por interacciones hidrofóbicas que la tornan más insoluble.

Podríamos decir, de acuerdo a estos resultados, que el nuevo genotipo contiene glutelinas en mayor cantidad que la variedad control y con su solubilidad mejorada.

\section{I.3 Preparación de aislados proteicos y elección del método a utilizar}

Con el fin de estudiar cual sería el método más conveniente para producir un aislado de alto rendimiento y buenas propiedades para ser utilizado como ingrediente proteico en la industria alimentaria, se realizaron extracciones de la proteína a diferentes pHs con posterior precipitación a pH 6.

Posteriormente, se realizó la caracterización estructural y el rendimiento de los aislados obtenidos para luego seleccionar el más adecuado para continuar la investigación.

\section{I.4 Estructura de aislados extraídos a diferentes pHs}

Los aislados obtenidos a partir de la extracción a diferentes pHs presentaron diferente composición polipeptídica (Figura 7). 


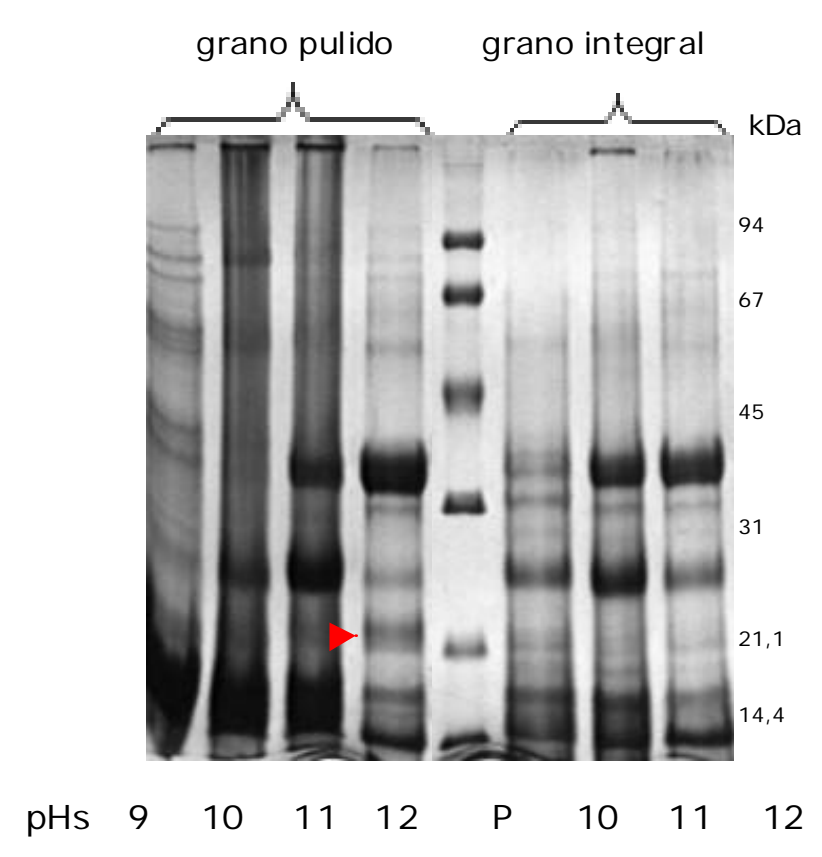

Figura 7. SDS-PAGE en condiciones reductoras de los aislados extraídos a diferentes pHs en harina de grano pulido e integral de la variedad Nutriar.
El aislado

pH 9 de grano

pulido presentó

alrededor de 12

bandas entre $95 \mathrm{y}$

14,4 kDa conforme a lo observado por Juliano (1980) para la fracción

albúminas. Si comparamos con las Figuras 2 y 3 podemos decir que este aislado estaría

compuesto

fundamentalmente por las fracciones albúminas $\mathrm{y}$

globulinas, con polipéptidos comprendidos entre 60 y 14,4 kDa (Figura 3, con $\beta$ $\mathrm{ME})$.

El aislado pH 10 en grano pulido, presentó dos bandas más importantes: una de alrededor de 26 kDa mayoritaria de la fracción globulina y presente en Gt0,01 y otra formada por polipéptidos de bajo peso molecular pertenecientes, posiblemente, a las albúminas. En menor proporción y propios de globulinas y glutelinas, se encuentran polipéptidos de alto peso molecular (alrededor de $90 \mathrm{kDa}$ ) y de 55-59 kDa correspondientes a la proglutelina. En grano integral, no se observaron polipéptidos de alto peso molecular pero se observó, con mayor intensidad, la banda de 37-39 kDa que correspondería a la subunidad ácida (Yamagata et al., 1982; Kumagai et al., 2006) de la fracción glutelina. Si bien la electroforesis bidimensional del aislado a pH 10 (grano pulido) sólo muestra las manchas de mayor intensidad sobre la diagonal, el perfil es muy similar al de la fracción globulina, con predominancia del polipéptido de alrededor de 26 kDa, lo que confirmaría que el mismo está mayoritariamente integrado por esta fracción. Asimismo los resultados nos sugieren que este aislado estaría formado además por albúminas y no se puede descartar que parte de Gt0,01 también esté presente.

Los aislados extraídos a pH 11, a partir de harina de grano pulido e integral presentaron un perfil electroforético muy similar. En la Figura 7 se pueden observar 
tres bandas bien marcadas: $37-39,26-23$ y $17-14,4 \mathrm{kDa}$, por lo que se deduce que ambos estarían constituidos fundamentalmente por las fracciones glutelinas y globulinas.

Contrariamente a los aislados de pH 11, los aislados extraídos a pH 12, presentaron diferencias en la composición polipeptídica de la proteína que se solubilizó en la harina de grano pulido e integral (Figura 7). Ambos aislados presentaron una banda más marcada entre 33-37 kD y bandas menos intensas de alrededor de 26, 23, 17 y 14 kDa. Se observó una diferencia en el perfil del aislado proveniente de grano pulido con una menor intensidad en la banda de alrededor de $26 \mathrm{kDa}$ y mayor intensidad en la de $23 \mathrm{kDa}$ (Figura 7, flecha roja). Dado que la banda de 26 kDa era más intensa en la subfracción Gt0,01 estos resultados nos indican que esta subfracción estaría mayoritariamente localizada en las capas externas del grano.

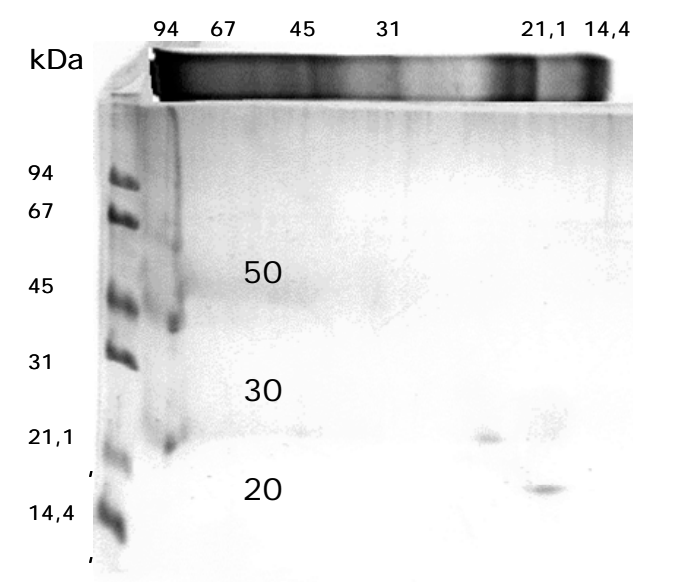

Figura $\quad 8 . \quad$ Electroforesis bidimensional del aislados $\mathrm{pH} 12$ de grano integral de variedad Nutriar.

En la segunda dimensión, en el aislado $\mathrm{pH} \mathrm{12,} \mathrm{los} \mathrm{agregados} \mathrm{de} \mathrm{alto} \mathrm{peso}$ molecular que no entran al gel, se estarían fraccionando en subunidades de aproximadamente 50, 30 y 20 kDa (Figura 8). La gran similitud con la segunda dimensión de las glutelinas (Figura 5), nos confirma la participación de esta fracción en la constitución del aislado a pH 12 presentando polipéptidos de alto peso molecular con abundantes uniones disulfuro. Paralelamente, y sobre la diagonal se pueden distinguir los polipéptidos de alrededor de $26 \mathrm{kDa}$ y entre 17-14 kDa propios de las globulinas y glutelinas respectivamente. Como hemos visto anteriormente, estos aislados también estarían constituidos fundamentalmente por estas dos fracciones. 


\section{I.5 Rendimiento en la extracción de los aislados a diferentes pHs}

Tabla 4. Rendimiento de los aislados extraídos a distintos $\mathrm{pH}$ de harinas de grano integral y pulido de las variedades Nutriar y El Paso 144 (g/100g de harina)

\begin{tabular}{l|c|c|c|c|c|}
\hline Harina & pH 9 & pH 10 & pH 11 & pH 12 & pH 2 \\
\hline $\begin{array}{l}\text { Nutriar } \\
\text { integral }\end{array}$ & $2,64 \pm 0,09 \mathrm{aD}$ & $5,23 \pm 0,69 \mathrm{aC}$ & $6,51 \pm 0,34 \mathrm{aB}$ & $12,67 \pm 0,49 \mathrm{aA}$ & $0,78 \pm 0,05 \mathrm{cE}$ \\
\hline $\begin{array}{l}\text { Nutriar } \\
\text { pulido }\end{array}$ & $0,43 \pm 0,29 \mathrm{cD}$ & $1,0 \pm 0,01 \mathrm{cD}$ & $2,67 \pm 0,25 \mathrm{bC}$ & $10,72 \pm 0,41 \mathrm{bA}$ & $3,90 \pm 0,04 \mathrm{aB}$ \\
\hline $\begin{array}{l}\text { El Paso 144 } \\
\text { integral }\end{array}$ & $1,64 \pm 0,01 \mathrm{bC}$ & $2,24 \pm 0,04 \mathrm{bC}$ & $3,01 \pm 0,10 \mathrm{bB}$ & $9,56 \pm 0,51 \mathrm{bcA}$ & $0,78 \pm 0,04 \mathrm{cD}$ \\
\hline $\begin{array}{l}\text { EI Paso 144 } \\
\text { pulido }\end{array}$ & $0,52 \pm 0,10 \mathrm{cD}$ & $1,11 \pm 0,19 \mathrm{cD}$ & $1,90 \pm 0,08 \mathrm{cC}$ & $8,26 \pm 0,58 \mathrm{cA}$ & $3,39 \pm 0,09 \mathrm{bB}$ \\
\hline
\end{tabular}

Letras diferentes minúsculas en las columnas y mayúsculas en filas, representan diferencias (LSD, $\mathrm{p}<0,05)$.

El rendimiento en proteína extraída fue diferente dependiendo del $\mathrm{pH}$ y del tipo de harina considerado (Tabla 4).

En términos generales, los mayores rendimientos en extracciones alcalinas correspondieron a las harinas de grano integral y entre estas la variedad Nutriar presentó los mayores valores. Esto está relacionado con su mayor contenido proteico y con la mayor solubilidad de la fracción glutelina expresada en la Tabla 3.

En medio alcalino, los rendimientos obtenidos en los aislados se fueron incrementando al aumentar el pH. Es sobresaliente el comportamiento de la variedad Nutriar en la que, a partir de pH 10 mostró un marcado incremento en el rendimiento, mientras que en la variedad El Paso 144 sólo se obtuvo un rendimiento aceptable en la extracción a pH 12.

También se realizaron extracciones a pH ácido (Tabla 4, pH 2). En general los rendimientos fueron inferiores a la extracción a pH 12, sin embargo los resultados mostraron un comportamiento diferente entre las harinas de grano pulido e integral. Mientras que en las harinas integrales la extracción a pH 2 mostró un rendimiento muy inferior a todas las extracciones en medio alcalino, las extracciones a $\mathrm{pH} 2$ de harinas de grano pulido mostraron un rendimiento superior a las de los pHs 9, 10 y 11 . Este comportamiento diferencial se vio reflejado en las propiedades funcionales que se desarrollaran más adelante. 


\section{I.6. Conclusiones}

Las fracciones proteicas de las variedades Nutriar y El Paso 144 presentaron una gran similitud estructural cualitativa; las estructuras observadas en las distintas fracciones concordaron con las descriptas en bibliografía.

Los resultados presentados mostraron que, al igual que las glutelinas de amaranto, las glutelinas de arroz presentan distintas características estructurales que permiten dividirlas en dos subfracciones de distinta solubilidad ó extractabilidad.

Las observaciones que muestran a la fracción globulina de similar composición a las glutelinas concuerdan con la hipótesis de Robert et al. (1985) quien mostró que esta fracción presenta reactividad inmunoquímica cruzada con glutelinas. Esta fracción se asemeja mayormente a Gt0,01 ya que, además de los polipéptidos de alrededor de 57, 30 y 20 kDa ambas contienen el polipéptido de 26 $\mathrm{kDa}$, que no forma parte de las subunidades diméricas (Figuras 4 y 5) y está prácticamente ausente en Gt0,1. Estos resultados nos permiten proponer a globulinas y glutelinas como productos de un elevado polimorfismo propio de las proteínas de almacenamiento que lleva a una heterogeneidad molecular (Robert et al., 1985). En este caso polipéptidos provenientes de genes isomorfos formarían agregados que difieren en sus características de solubilidad. También se ha observado en globulinas (Delseny and Raynal, 1999) y en especial en globulinas de amaranto (Abugoch et al., 2003; Quiroga et al., 2007) la existencia de subunidades provenientes de diferentes subfamilias genéticas intercambiables en diferentes oligómeros confiriendo particulares propiedades fisicoquímicas (Quiroga et al., 2007); inclusive se han observado variaciones entre cultivares (Drzewiecki, 2001).

En las preparaciones de aislados se demostró que los mayores rendimientos de extracción se llevan a cabo en las harinas integrales de la variedad Nutriar. Los rendimientos aumentaron con la alcalinidad del solvente de extracción lo que se correspondió con la solubilización de la fracción mayoritaria (glutelina). La preparación de aislados a pH 2 permitió detectar diferencias entre las proteínas provenientes de granos pulido e integral.

Los resultados obtenidos indicaron que las condiciones óptimas de extracción correspondían a la utilización de solvente a pH 12. 


\section{CAPITULO II. Caracterización nutricional y funcional de los aislados extraídos a pH 12}

A partir de los resultados presentados en el capítulo anterior y como consecuencia de un mayor rendimiento en la extracción, fueron seleccionados los aislados extraídos a pH 12 para un posterior y exhaustivo estudio como posibles ingredientes proteicos de alto valor alimentario.

La nomenclatura de los aislados a estudiar se encuentra en la Tabla 1.

Tabla 1. Nomenclatura de los aislados en función de la variedad y del tipo de harina utilizada en la extracción

\begin{tabular}{l|cc}
\cline { 2 - 3 } & Nutriar & El Paso 144 \\
\hline grano integral & $\mathrm{Ni}$ & $\mathrm{Ei}$ \\
grano pulido & $\mathrm{Np}$ & $\mathrm{Ep}$ \\
\hline
\end{tabular}

\section{I.A Caracterización nutricional de los aislados proteicos extraídos a pH 12}

\section{II.A.1 Contenido proteico}

En la Tabla 2 se compara el contenido proteico de los granos de los cultivares en estudio. Nutriar superó en un $27,5 \%$ en grano integral y en un $19,8 \%$ en grano pulido a la variedad El Paso 144.

Tabla 2. Contenido proteico de harinas y aislados $\mathrm{pH} 12$

\begin{tabular}{|c|c|c|}
\hline \multicolumn{3}{|c|}{ Contenido proteico de la harina ( $\%$ p/ $\mathbf{p})$} \\
\hline & $\begin{array}{c}\text { Nutriar } \\
\text { (N) }\end{array}$ & $\begin{array}{c}\text { EI Paso } 144 \\
\text { (E) }\end{array}$ \\
\hline grano integral (i) & $12,42 \pm 0,16$ & $9,74 \pm 0,05$ \\
\hline grano pulido (p) & $10,36 \pm 0,71$ & $8,65 \pm 0,03$ \\
\hline \multicolumn{3}{|c|}{ Contenido proteico del aislado (\%) } \\
\hline grano integral & $83,3 \pm 0,8$ & $77,4 \pm 0,5$ \\
\hline grano pulido & $86,1 \pm 0,9$ & $86,0 \pm 0,4$ \\
\hline
\end{tabular}


Estos resultados indican que el incremento en proteína se concentra fundamentalmente en el grano integral o sea que estaría localizada en las capas externas del grano.

Por otro lado, observando el contenido proteico de los aislados, se puede corroborar que esta proteína (la correspondiente al grano integral de la variedad Nutriar) es más soluble al pH correspondiente a la extracción (es más fácilmente extraíble) que la de El Paso 144 (Tabla 2).

\section{II.A.2 Determinación de la composición aminoacídica de los aislados}

Se estudió la composición aminoacídica de los aislados y se compararon con los valores característicos del grano de arroz y con los requerimientos dietarios de aminoácidos esenciales de adultos y niños (Tabla 3).

De acuerdo a lo informado por el Laboratorio Nacional de Investigación y Servicios en Péptidos y Proteínas (Lanais-Pro, UBA) los datos de metionina y glicina, en las muestras, no corresponden a los valores reales. La hidrólisis ácida de las proteínas ocasiona una destrucción parcial del aminoácido esencial metionina. La glicina, en cambio, se encuentra sobredimensionada por ser un gran contaminante.

El aislado Ni presentó mayores valores de glicina, tirosina, arginina y lisina que Ei. En ambos aislados, la suma de tirosina y fenilalanina resulta limitante, mientras que los valores de los aminoácidos treonina, valina e histidina se presentan cercanos a los requeridos en la dieta humana (FAO/WHO/UNU, 1985). Ambos aislados cubren los requerimientos de los adultos en los aminoácidos leucina e isoleucina, pero no el de los niños (FAO/WHO, 1973).

Tanto $\mathrm{Ni}$ como Ei poseen menores valores de algunos aminoácidos comparando con los contenidos publicados por Cagampang et al. (1976) a excepción de serina, alanina y glicina posiblemente por limitaciones del método utilizado.

Los aislados de arroz poseen elevadas proporciones de ácido glutámico y/o glutamina, ácido aspártico y/o asparagina, como ha sido observado en otras proteínas de almacenamiento (Shotwell and Larkins, 1989; Galili, 1997; FAO, 2008). Si bien la proteína de arroz es rica en aminoácidos azufrados (Juliano, 1985), por las causas antes mencionadas, los valores de metionina presentes en la tabla resultan limitantes. 
Tabla 3. Análisis de aminoácidos de los aislados $\mathrm{Ni}$ y $\mathrm{Ei}$, de grano integral de arroz y patrón de aminoácidos esenciales

\begin{tabular}{|c|c|c|c|c|c|c|}
\hline \multirow{3}{*}{ Aminoácidos } & \multirow{3}{*}{$\mathbf{N i}$} & \multirow{3}{*}{ Ei } & \multirow{3}{*}{$\begin{array}{c}\text { Grano de } \\
\text { arroz } \\
\text { integral* }\end{array}$} & \multicolumn{3}{|c|}{$\begin{array}{l}\text { Patrón ideal de algunos } \\
\text { aminoácidos esenciales }\end{array}$} \\
\hline & & & & \multicolumn{2}{|c|}{ FAO/ WHO ${ }^{a}$} & \multirow{2}{*}{$\begin{array}{c}\text { FAO/ OMS } \\
\text { UNU }\end{array}$} \\
\hline & & & & adultos & niños & \\
\hline Asp & 7,45 & 14,3 & 9,0 & & & \\
\hline Thr & 2,85 & 3,0 & 3,9 & 0,9 & 4,3 & 3,4 \\
\hline Ser & 5,85 & 7,3 & 5,8 & & & \\
\hline Glu & 11,15 & 20,0 & 16,8 & & & \\
\hline Pro & 2,4 & 2,4 & 4,9 & & & \\
\hline Gly & $35,75^{*}$ & $14,1^{*}$ & 4,8 & & & \\
\hline Ala & 6,45 & 7,2 & 5,8 & & & \\
\hline Val & 3,75 & 5,6 & 6,6 & & & 3,5 \\
\hline Met & 0,8 & 0,7 & 2,6 & & & $2,5^{c}$ \\
\hline Ile & 2,45 & 3,7 & 4,5 & 1,3 & 4,6 & 2,8 \\
\hline Leu & 4,75 & 8,1 & 8,3 & 1,9 & 9,3 & 6,6 \\
\hline Tyr & 1,35 & 0,7 & 4,0 & & & \\
\hline Phe & 2,55 & 4,3 & 5,3 & & & \\
\hline Tyr + Phe & 3,9 & 5,0 & 9,3 & & & 6,3 \\
\hline His & 1,9 & 2,0 & 2,6 & & & 1,9 \\
\hline Lys & 3,9 & 3,4 & 4,4 & 1,6 & 6,6 & 5,8 \\
\hline Arg & 6,65 & 4,6 & 9,0 & & & \\
\hline
\end{tabular}

Ref.: ${ }^{*}$ Cagampang et al., 1976. ${ }^{\mathrm{a}} \mathrm{FAO} / \mathrm{WHO}, 1973 ;{ }^{\mathrm{b}} \mathrm{FAO} / \mathrm{WHO} / \mathrm{UNU}, 1985 ;{ }^{\mathrm{c}} \mathrm{Met}+\mathrm{Cys}$.

Una forma de cuantificar la calidad nutricional es calculando el cociente E/T, relación entre aminoácidos esenciales (E) y totales $(T)$. La Organización Mundial de la Salud de las Naciones Unidas (1973) establece como buena una relación mayor o igual a 36\% (Padhye and Salunkhe, 1979). Los valores del cociente E/T fueron 38,7 y $30,95 \%$ para $\mathrm{Ei}$ y $\mathrm{Ni}$, con lo cual sólo tiene un valor bueno el aislado de la variedad El Paso 144. Debemos considerar que estos resultados pueden ser algo inferiores a los reales debido al método que subvalora aminoácidos esenciales. 
Como ya ha sido mencionado por varios autores, si bien los cereales son pobres en lisina, el grano de arroz tiene un contenido de este aminoácido esencial mayor que el resto. No obstante, tanto en Ni como en Ei resultó ser un aminoácido limitante según los requerimientos de los niños estimados por la FAO, pero no de los adultos (FAO/WHO, 1973).

El aislado Ni presentó mayores valores lisina que Ei. Los valores detectados de lisina coinciden con el valor encontrado por Wang et al. (1999) de 3,99/100g de proteína.

\section{II .A.3 Digestibilidad in vitro.}

Más allá de una composición aminoacídica balanceada, la calidad nutricional de una proteína depende de su facilidad para hidrolizarse y que los aminoácidos liberados sean asimilados e ingresen al torrente sanguíneo. Por esta razón se decidió determinar la digestibilidad in vitro de los aislados $\mathrm{Ni}, \mathrm{Ei}, \mathrm{Np}$ y $\mathrm{Ep}$ por simulación gástrica e intestinal como un aporte más a la caracterización nutricional de estos aislados.

En la Figura 1, se puede observar que los aislados $\mathrm{Ni}$ y $\mathrm{Ei}$ presentaron mayor grado de hidrólisis que los aislados provenientes de harina de grano pulido ( $\mathrm{Np}$ y Ep) al transcurrir 120

minutos del proceso. Esto nos indica que los aislados provenientes de harina integral sufrieron mayor

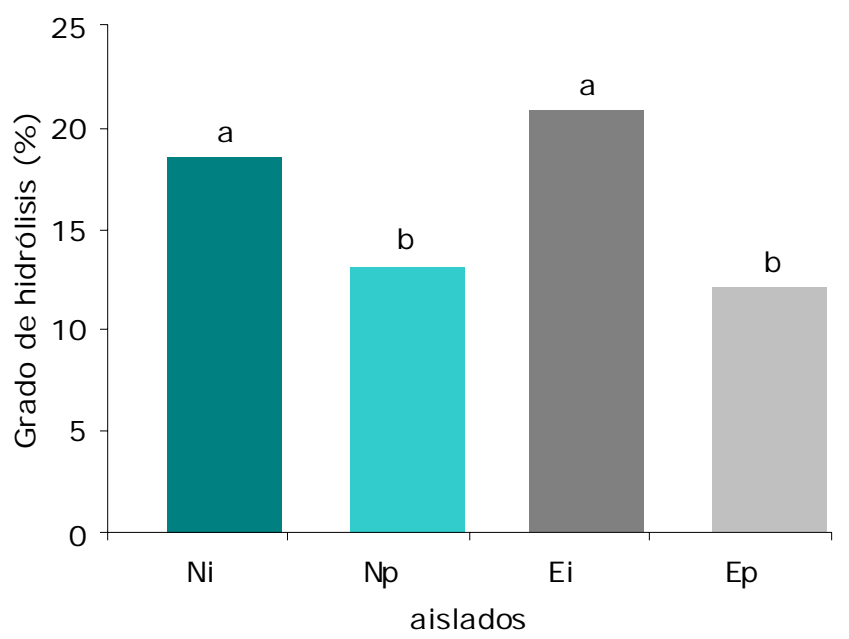

Figura 1. Grado de hidrólisis de los aislados $\mathrm{Ni}, \mathrm{Np}$, $\mathrm{Ei}$ y Ep alcanzados al finalizar la digestión gastrointestinal simulada. Letras diferentes representan diferencias significativas (LSD, $p<0,05)$.

destrucción durante la

digestión enzimática a la que fueron sometidos. El endosperma está constituido, fundamentalmente, por glutelinas de alto peso molecular y con gran cantidad de puentes disulfuro, mientras el grano integral posee mayor proporción de albúminas y globulinas que el pulido que son más fácilmente hidrolizables por enzimas como la 
pepsina y la tripsina tal como sostienen los autores Steenson and Sathe (1995). Este motivo, junto con la posibilidad de diferencias estructurales entre las proteínas provenientes de grano integral ó pulido podrían ser causales de la diferente digestibilidad.

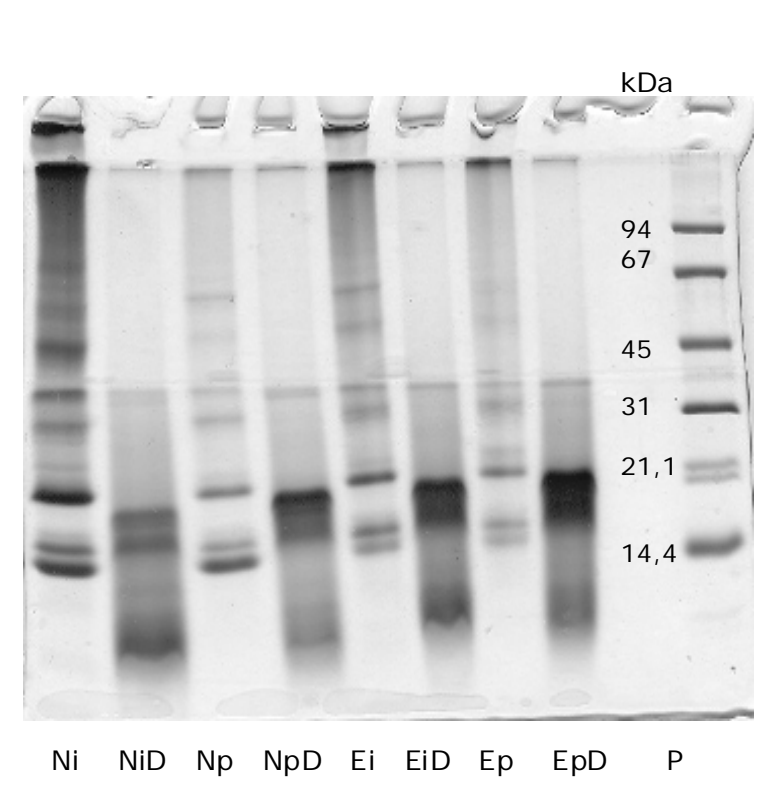

Figura 2. PAGE-tricina de los aislados proteicos sin digerir y digeridos con pepsina + pancreatina. NiD, $\mathrm{NpD}, \mathrm{EiD}$ y EpD aislados digeridos.
El análisis de la electroforesis (Figura 2) permite observar que la digestión enzimática provocó una hidrólisis de los péptidos de alto peso molecular reduciéndolos, en todos los casos, a péptidos de peso molecular inferior a 35-40 kDa sin presentar diferencias importantes entre los aislados estudiados. De acuerdo a los resultados de grado de hidrólisis las diferencias estarían en los péptidos más pequeños que no se visualizan en el gel.

\section{II.B Caracterización funcional de los aislados proteicos extraídos a pH 12}

Hasta el momento hemos observado que se presentan diferencias estructurales y nutricionales entre los diferentes aislados proteicos de arroz según sean las condiciones en que hayan sido extraídos y el tipo de harina a partir de la cual se haya realizado la preparación. Estas diferencias pueden reflejarse en las propiedades funcionales de los mismos, información que resulta en general, escasa y fragmentaria en la bibliografía existente hasta la actualidad. Es deseable que las proteínas posean propiedades funcionales tales como solubilidad, capacidad de formar espuma, entre otras, no sólo para definir la calidad del producto final, sino también para facilitar el proceso de producción. Por las razones expuestas, se hace importante evaluar las propiedades de los aislados proteicos de arroz.

En esta sección se incluyen estudios referentes a las propiedades funcionales de los aislados extraídos a pH 12, a partir de harina de grano integral y pulido de 
las variedades Nutriar y El Paso 144 ( Ni, Np, Ei y Ep). Se investigan las propiedades de hidratación como solubilidad, capacidad de retención de agua y capacidad de absorción de agua; las propiedades de superficie como capacidad de formar y estabilizar espumas y emulsiones, capacidad de absorción de aceite, y se evalúan las diferencias y relaciones que presentan entre sí.

\section{I.B.1 Propiedades de hidratación}

Dentro de esta clasificación se evaluaron, por un lado la solubilidad de los aislados proteicos a distintos $\mathrm{pH}$ y en agua destilada, y por otro las propiedades de hidratación como capacidad de imbibición de agua destilada (WIC) y capacidad de retención de agua a diferentes pHs (WHC a pHs 3, 6 y 9 y en agua pura).

\section{I.B.1a Solubilidad proteica de los aislados}

La solubilidad a diferentes pHs de la proteína de los aislados se presenta en la Figura 3. En ella podemos ver que, en términos generales, los cuatro aislados presentaron muy baja solubilidad a pHs neutros y moderados pero exhibieron mayor solubilidad a pHs extremos, lo que se corresponde con las características propias de su componente mayoritario, la fracción glutelina (Bera and Mukhejree, 1989; Anderson et al., 2001, Agboola et al., 2005). Los valores oscilaron entre 79,4 $\%$ y $0,25 \%$; ambos puntos extremos fueron registrados en el aislado $\mathrm{Ni}$ a pHs 11 y

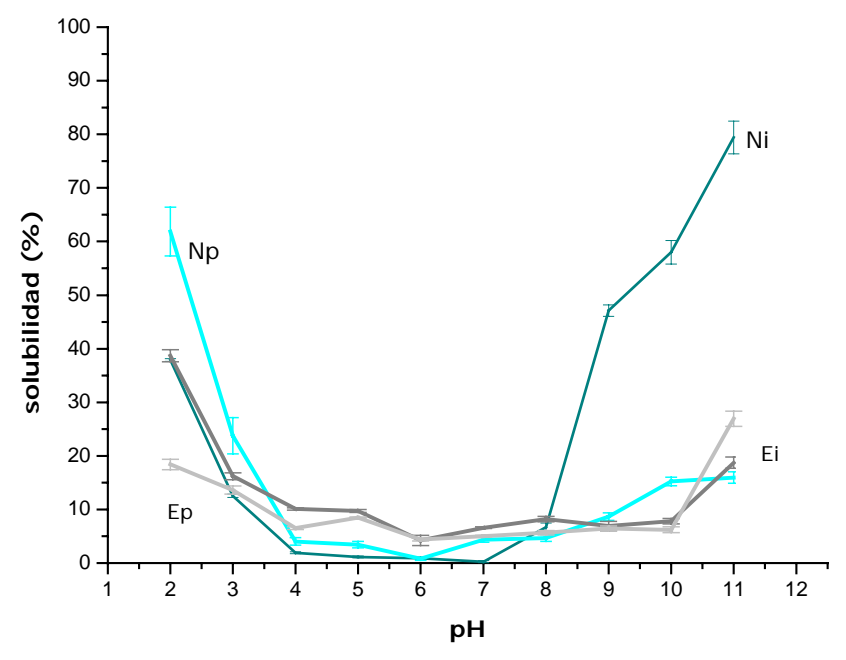

Figura 3. Solubilidad de los aislados $\mathrm{Ni}, \mathrm{Np}$, Ei y Ep a diferentes pHs ajustadas con el porcentaje proteico de cada aislado.
7 respectivamente.

Estos valores máximos fueron semejantes a los obtenidos en aislados proteicos de salvado de arroz extraídos a pH 12 (Tang et al., 2003) y a los obtenidos por extracción enzimática (Wang et al., 1999). 
Si analizamos en detalle, se muestran diferencias significativas a pHs extremos. En estas condiciones, las proteínas de los aislados de la variedad El Paso

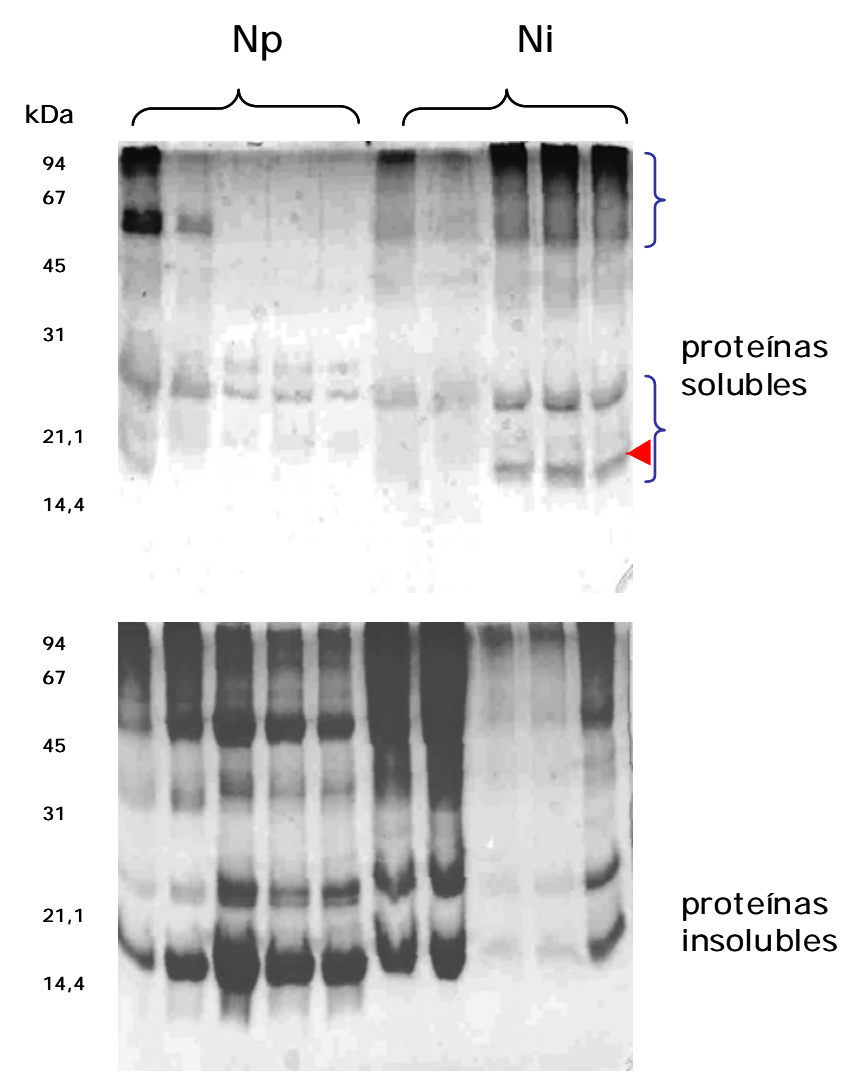

$\begin{array}{lllllllllll}\mathrm{pH} & 2 & 3 & 9 & 10 & 11 & 2 & 3 & 9 & 10 & 11\end{array}$

Figura 4. SDS-Page de proteínas solubles (gel superior) e insolubles (gel inferior) a distintos pHs. Las calles de los geles están alineadas y se corresponden. En la parte superior están indicadas las calles en las que se sembraron los asilados $\mathrm{Ni}$ y $\mathrm{Np}$ respectivamente.
144 presentaron
menor solubilidad
que las de la
variedad Nutriar.

Esto sugiere que

existen diferencias

estructurales entre

las proteínas de ambas variedades.

Considerando la

existencia de dos

subfamilias de

polipéptidos de las

glutelinas que

exhiben diferente

grado de

polimerización (GluA

y GluB) (Katsube-

Tanaka et al., 2004a), es posible que la variedad

Nutriar sea rica en la subfamilia que

presenta menor grado de polimerización (Glu A).

Asimismo se pudieron observar diferencias entre la solubilidad de los aislados de harina de grano integral y pulido. El aislado $\mathrm{Ni}$ presentó mejor solubilidad en medio alcalino ( $\mathrm{pHs}$ 9, 10 y 11), mientras que Np mostró máxima solubilidad en medio ácido ( $\mathrm{pHs} 2$ y 3 ).

A partir de esta observación se procedió a analizar mediante SDS-PAGE las proteínas solubles e insolubles de los dos aislados a distintos pHs. En la Figura 4 se muestran los respectivos perfiles. En ellos se observa que por la intensidad de las bandas, los perfiles de solubles e insolubles son complementarios y concuerdan con los valores de solubilidad de la Figura 3 (aislados $\mathrm{Ni}$ y $\mathrm{Np}$ ). Es así que los perfiles de las proteínas solubles del aislado $\mathrm{Ni}$ a pHs 9,10 y 11 y del aislado $\mathrm{Np}$ a pHs 2 y 3 muestran mayor intensidad. 
A su vez, en los perfiles, la mayoría de las bandas más intensas son similares, tanto para $\mathrm{Ni}$ como para Np (indicados con llaves azules en la Figura 4), lo que sugiere que a esos pHs se solubilizan especies proteicas semejantes. En los solubles del aislado $\mathrm{Np}$ ( $\mathrm{pH}$ ácido), la banda de $16 \mathrm{kDa}$ (señalada con una flecha roja en la Figura 4) está mucho más débil lo que indica que, en esas condiciones, dicho polipéptido es menos soluble que en $\mathrm{Ni}$ a $\mathrm{pH}$ alcalino. Los polipéptidos que se estarían solubilizando, pueden corresponder a la fracción globulina, y/o a oligómeros o polipéptidos provenientes de genes isomorfos de la fracción glutelina que, si bien tienen peso molecular similar a las globulinas, difieren en sus características de solubilidad como hemos discutido en el Capítulo I.

\section{II.B.1b Solubilidad en agua. Capacidad de retención e imbibición de agua (WHC y WIC)}

Dado que las propiedades funcionales WIC y WHC están relacionadas con la solubilidad de las proteínas en las mismas condiciones, en forma paralela se analizó la solubilidad en agua de las proteínas en estudio.

Solubilidad en agua. En la Tabla 4 podemos observar los valores medios de solubilidad de los asilados en agua. Con excepción de $\mathrm{Ni}$, que presentó muy baja solubilidad, el resto de los aislados resultaron prácticamente insolubles. Estos resultados se corresponden con las solubilidades de los mismos a pHs neutros presentados en la Figura 3 y ambos permiten corroborar con la bibliografía existente (Agboola et al., 2005; entre otros) la baja solubilidad de las proteínas de arroz debido a la abundancia de puentes disulfuro, sumado a su elevado peso molecular.

Capacidad de retención e imbibición de agua (WHC y WIC). Las propiedades de retención de agua (WHC) por parte de la proteína de arroz fueron similares en los cuatro aislados, aunque algo superiores en los aislados de harina de grano integral (Tabla 4). Posiblemente la presencia de otros componentes no proteicos como fibras, presentes en las cubiertas externas del grano influyan en alguna medida sobre la capacidad de retención de agua de los aislados estudiados.

La capacidad de imbibición (o absorción) de agua, se desdobló por un lado en la capacidad del aislado en absorber agua (WIC) y por otro el tiempo que demora el proceso en alcanzar el equilibrio (te). Los valores de WIC resultaron inferiores en la variedad El Paso 144 (Tabla 4). En valores absolutos son 
comparables con los observados por Chandi and Sogi (2007a) en concentrados proteicos de salvado de distintas variedades de arroz $(2,5$ y $5,6 \mathrm{~g} / \mathrm{g})$, superiores a los encontrados en diferentes concentrados proteicos de hojas por Aletor et al. (2002) $(2,7 \mathrm{~g} / \mathrm{g}$, ) y algo inferiores a aislados proteicos de soja $(4,3 \mathrm{~g} / \mathrm{g}$, Gandhi et al., 2000). Los valores resultan cercanos a los considerados críticos para alimentos viscosos como sopas, salsas o jugos por lo que pueden resultar ingredientes de alta calidad para alimentos de estas características (Aletor et al., 2002).

Tabla 4. Propiedades de hidratación de los aislados proteicos con respecto al agua pura

\begin{tabular}{|c|c|c|c|c|}
\hline & \multirow{2}{*}{$\begin{array}{c}\text { Solubilidad en } \\
\text { agua }\end{array}$} & \multirow{2}{*}{ WHC* } & \multicolumn{2}{|c|}{ Capacidad de imbibición de agua } \\
\hline & & & WIC* & te \\
\hline $\mathbf{N i}$ & $3,79 \pm 0,28 a$ & $7,17 \pm 0,44 a$ & $4,22 \pm 0,30 a$ & $15,0 \pm 0 a$ \\
\hline Np & $0,93 \pm 0,42 \mathrm{bc}$ & $4,45 \pm 0,36 \mathrm{bc}$ & $4,07 \pm 0,24 a$ & $1,0 \pm 0 \quad b$ \\
\hline $\mathbf{E i}$ & $1,81 \pm 0,55 b$ & $5,67 \pm 1,28 a b$ & $3,19 \pm 0,11 b$ & $1,5 \pm 0,71 b$ \\
\hline Ep & $0,35 \pm 0$ & $2,60 \pm 0,27 \mathrm{c}$ & $2,85 \pm 0,37 b$ & $1,0 \pm 0$ \\
\hline
\end{tabular}

Letras diferentes en columnas representan diferencias significativas (LSD, $p<0,05$ ); WHC: capacidad de retención agua; $* \mathrm{ml}$ de agua/g de muestra; te: tiempo que se requiere en alcanzar el equilibrio $(\min )$.

En cuanto a la forma en que se realizó la absorción o sea el tiempo requerido para alcanzar el equilibrio fue diferente: los aislados $\mathrm{Np}$, Ei y Ep la absorbieron rápidamente mientras que en $\mathrm{Ni}$, el proceso fue mucho más lento.

Considerando que $\mathrm{Ni}$ presentó elevados valores de solubilidad en agua, WHC, WIC y el tiempo mayor en alcanzar el equilibrio en el proceso de absorción de agua pura (Tabla 4), podemos corroborar la existencia de diferencias estructurales en este aislado con respecto a los demás, en este caso dichas estructuras provocarían una disminución de la velocidad de hidratación.

\section{II.B.1c Capacidad de retención de agua a pHs 3, 6 y 9 (WHC)}

Se evaluó la capacidad de retención de agua de los aislados a pHs 3, 6 y 9 Figura 5). La misma osciló entre 1,67 y 9,96 ml de agua/g de muestra, valores similares a los encontrados en aislados proteicos de amaranto (Abugoch, 2006). 


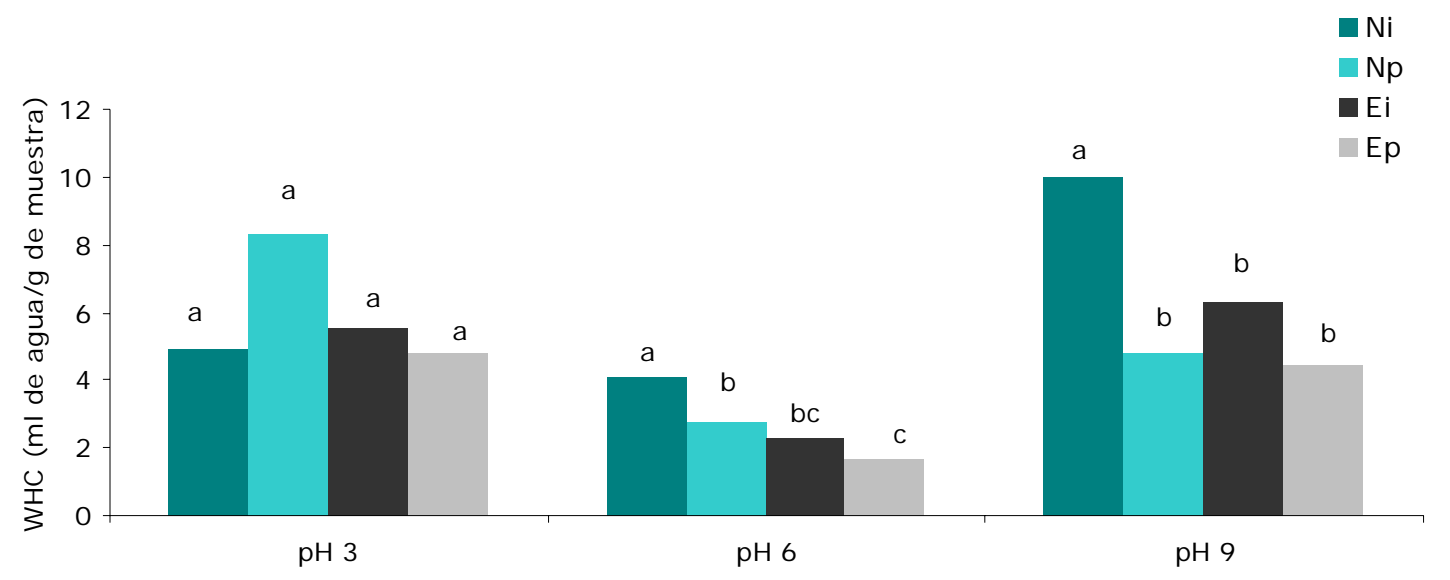

Figura 5. Capacidad de retención de agua (WHC) de los aislados Ni, Np, Ei y Ep a los pHs 3, 6 y 9. Letras diferentes representan diferencias significativas (LSD, $p<0,05$ ).

El comportamiento de los aislados fue diferente según el pH de la solución. A pH 3 no se observaron diferencias en el WHC entre aislados mientras que a pH 6 y 9, Ni se destacó del resto $(L S D, p<0,05)$ con valores mayores. Esta propiedad funcional depende, no solo del tamaño de los poros y de los capilares, sino también de las características de las moléculas proteicas. Estos resultados se correlacionan con la mayor solubilidad del aislado $\mathrm{Ni}$ en agua y a pHs alcalinos lo cual es contradictorio con la propuesta del aumento de WHC con la insolubilidad proteica. En este caso se podría explicar considerando que estas proteínas son altamente insolubles por lo cual en las condiciones estudiadas aun los mejores valores de solubilidad son bajos. La mayor solubilidad estaría entonces relacionada con una mayor capacidad de interaccionar con el agua lo cual concuerda con la capacidad de retención de agua.

\section{II.B.2 Propiedades de superficie}

Con el objeto de profundizar la investigación y analizando la solubilidad de los aislados (Figura 3) se consideró la condición menos extrema en la que los aislados pueden presentar buenas propiedades funcionales de superficie a la vez que expresen diferencias entre sí.

Conforme con este criterio, se seleccionaron los pHs 3 y 9 ( $\mu=0,2$ M) para evaluar la capacidad de los aislados de formar y estabilizar espumas y emulsiones. 


\section{II.B.2a Actividad espumante}

La capacidad de formar espumas se evaluó mediante la determinación del volumen máximo de líquido incorporado a la espuma $\left(\mathrm{V}_{\max }\right)$ y la estabilidad de las espumas expresada como el tiempo medio o sea el tiempo que tarda en drenar el $50 \%$ del volumen máximo $\left(t_{1 / 2}\right)$. En la Tabla 5 pueden observarse los parámetros que caracterizan a las espumas de los aislados estudiados.

Tabla 5. Parámetros de la capacidad de formar y estabilizar espumas de los aislados $\mathrm{Ni}, \mathrm{Np}$, Ei y $\mathrm{Ep}(\mathrm{pH} 3$ y $9, \mu=0,2 \mathrm{M})$

\begin{tabular}{|c|c|c|c|c|}
\hline & \multicolumn{2}{|c|}{ pH 3} & \multicolumn{2}{|c|}{ pH 9} \\
\hline & $V_{\max }{ }^{a}$ & $t_{1 / 2}^{b}$ & $\mathbf{V}_{\max }$ & $t_{1 / 2}$ \\
\hline $\mathbf{N i}$ & $1,80 \pm 0,02$ & $0,50 \pm 0,02$ & $4,98 \pm 0,21 a$ & $0,78 \pm 0,16 a$ \\
\hline $\mathbf{N p}$ & $4,66 \pm 0,06 a$ & $0,62 \pm 0,01 \mathrm{a}$ & $1,42 \pm 0,06 \quad b$ & $0,58 \pm 0,03 a b$ \\
\hline Ei & $2,39 \pm 0,11 \quad c$ & $0,64 \pm 0,01 a$ & $0,54 \pm 0,11 \quad c$ & $0,45 \pm 0$ \\
\hline Ep & $3,21 \pm 0,01$ & $0,58 \pm 0$ & $1,47 \pm 0,02 b$ & $0,64 \pm 0,01 a b$ \\
\hline
\end{tabular}

Letras diferentes minúsculas en columnas representan diferencias significativas (LSD, $p<0,05)$; ${ }^{a} V_{\max }$ : volumen máximo de líquido incorporado a la espuma $(\mathrm{ml})$; ${ }^{\mathrm{b}} \mathrm{t}_{1 / 2}$ : tiempo que tarda en drenar el $50 \%$ del volumen máximo (min).

Los aislados presentaron diferencias en su actividad espumante. Si analizamos, en primera instancia, los valores de Vmax vemos que a $\mathrm{pH} 3, \mathrm{~Np}$ presentó la mayor capacidad de formar espumas y Ni la menor (Tabla 5); mientras que a $\mathrm{pH}$ 9, Ni resultó el aislado con mejores espumas.

Complementariamente, si analizamos la estabilidad de las espumas vemos que a pH 3 resultó mayor en $\mathrm{Np}$ y $\mathrm{Ei}$; intermedio en $\mathrm{Ep}$ y mínimo en $\mathrm{Ni}$; mientras que a $\mathrm{pH} \mathrm{9}$, solo se diferenciaron los tiempos medios de los aislados de harina integral de las variedades Nutriar y El Paso 144 (Tabla 5). Estas diferencias no son muy relevantes ya que en todos los casos el tiempo medio fue reducido, lo que nos está determinando que las espumas resultaron inestables. Un comportamiento similar fue observado en aislados proteicos de salvado de arroz que presentaron propiedades espumantes similares a la clara de huevo pero con menor estabilidad (Wang et al., 1999). 
Las espumas de la variedad Nutriar en el aislado de grano integral a $\mathrm{pH} 9$ resultaron compactas, de burbujas pequeñas y esféricas (Figura 6B), mientras el resto de las espumas presentó burbujas poliédricas y laxas (Figura 6A). Analizando

A

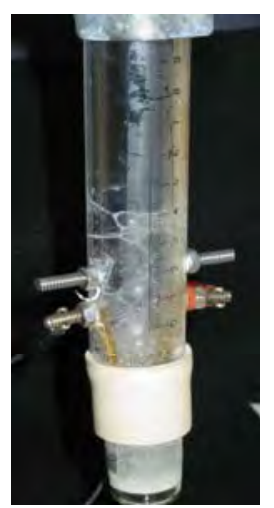

Figura 6 estabilidad. A: con burbujas poliédricas $\mathrm{B}$ : con burbujas esféricas.

(Fotografía: F. Speroni). en forma conjunta estos resultados y comparándolos con los de solubilidad, representados en la Figura 3, se puede confirmar, en esta variedad, la importancia de las proteínas solubles como principales participantes en el proceso de espumado de las proteínas.

La capacidad de formar espumas de los aislados provenientes de la variedad Nutriar resultó superior a la de los aislados proteicos de soja $\left(\mathrm{V}_{\max }=\right.$ 2,96 ml; Ventureira, comunicación personal) y superiores a los observados por Tang et al. (2003) en aislados de salvado de arroz. Cabe aclarar que estos

análisis fueron hechos en condiciones desfavorables (baja concentración proteica); posiblemente, variando las condiciones se podrían conseguir espumas más estables.

\section{I.B.2b Actividad emulsificante}

Se evaluó la actividad emulsificante de los aislados en soluciones a $\mathrm{pH} 9$ y fuerza iónica $\mu=0,2 \mathrm{M}$ a través del análisis de los perfiles del backscattering (\% BS) tanto en la zona de cremado (zona inferior del tubo de medida) como en la de coalescencia (zona superior del tubo de medida).

En una primera instancia se evaluaron los parámetros que caracterizan las emulsiones: backscattering inicial (\%BSin) y en la zona de cremado: tiempo en que el $\% \mathrm{BS}_{10-30 \mathrm{~mm}}$ decrece un $10 \%\left(\mathrm{t}_{0,1}\right)$ y constante cinética $\left(\mathrm{K}_{0,1}\right)$, valores que se presentan en la Tabla 6. 
Tabla 6. Parámetros que caracterizan las emulsiones de los aislados $\mathrm{Ni}$,

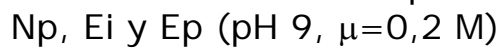

\begin{tabular}{llll} 
& \multicolumn{1}{c}{$\mathbf{B S}_{\mathbf{i n}}{ }^{\mathbf{a}}$} & \multicolumn{1}{c}{$\mathbf{t}_{\mathbf{0}, \mathbf{1}} \mathbf{b}^{\mathbf{b}}$} & \multicolumn{1}{c}{$\mathbf{K}_{\mathbf{0 , 1}} \mathbf{c}^{\mathbf{c}}$} \\
\hline $\mathbf{N i}$ & $26,47 \pm 0,47 \mathrm{a}$ & $6,03 \pm 1,25 \mathrm{a}$ & $0,39 \pm 0,09 \mathrm{~b}$ \\
$\mathbf{N p}$ & $17,71 \pm 1,96 \mathrm{~b}$ & $2,06 \pm 0,15 \mathrm{~b}$ & $1,65 \pm 0,06 \mathrm{a}$ \\
$\mathbf{E i}$ & $19,11 \pm 0,83 \mathrm{~b}$ & $3,62 \pm 0,02 \mathrm{~b}$ & $0,87 \pm 0,04 \mathrm{~b}$ \\
$\mathbf{E p}$ & $19,49 \pm 1,84 \mathrm{~b}$ & $2,11 \pm 0,35 \mathrm{~b}$ & $1,50 \pm 0,38 \mathrm{a}$ \\
\hline
\end{tabular}

Letras diferentes representan diferencias significativas (LSD, $p<0,05$ ); a \%BSin: backscattering inicial $(\%)$; ${ }^{b} \mathrm{t}_{0,1}$ : tiempo en que el $\% \mathrm{BS}_{10-30} \mathrm{~mm}$ decrece un $10 \%(\mathrm{~min})$; ${ }^{c} \mathrm{~K}_{0,1}$ : constante cinética.

El elevado valor de \%BSin del aislado $\mathrm{Ni}$ indicó que el mismo formó una emulsión más estable diferenciándose del resto de los aislados estudiados (Tabla 6). Se considera que existe una correlación lineal inversa entre el backscattering inicial y el tamaño de partícula de cada emulsión en condiciones iniciales y con la misma proporción volumétrica de aceite (Palazolo et al., 2004). En otras palabras, un valor mayor de \%BSin implica un menor tamaño de gota y, de esta manera, esta propiedad constituye una buena medida de la capacidad de la proteína de generar emulsiones.

Analizando la cinética de backscattering en esta zona de cremado, zona inferior del tubo de medida $\left(\% \mathrm{BS}_{10-30 \mathrm{~mm}}\right)$ en función del tiempo podemos determinar la estabilidad de las emulsiones (Figura 7). La mejor estabilidad de $\mathrm{Ni}$ puede observarse comparando los valores superiores de $t_{0,1}$ y algo inferiores de $K_{0,1}$ (Tabla 6). Comparando los perfiles de los cuatro aislados se nota la superioridad de Ni en la estabilidad de la emulsión. 


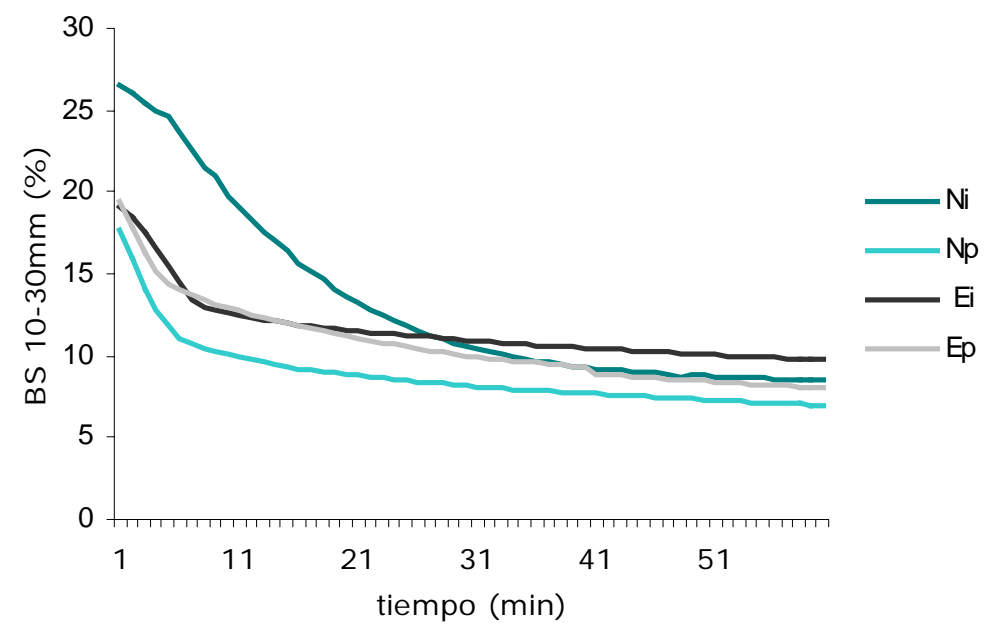

Figura 7. Porcentaje promedio de backscattering en la zona inferior del tubo de medida $\left(\% \mathrm{BS}_{10-30 \mathrm{~mm}}\right)$ a diferentes tiempos de estacionamiento de las emulsiones preparadas con los aislados $\mathrm{Ni}, \mathrm{Np}$, Ei y Ep.

En una segunda instancia estudiamos la coalescencia, ilustrada en la Figura 8 mostrando la cinética de los valores promedios de backscattering de la parte superior de tubo de medida $\left(\% \mathrm{BS}_{50-60 \mathrm{~mm}}\right)$.

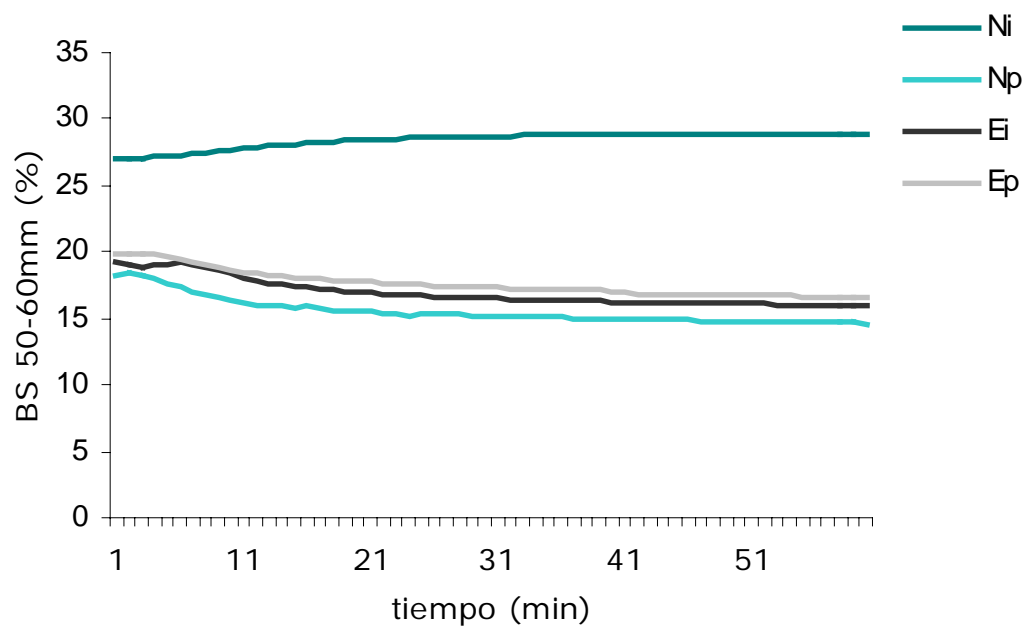

Figura 8. Porcentaje promedio de backscattering en la zona superior del tubo de medida $\left(\% \mathrm{BS}_{50-60 \mathrm{~mm}}\right)$ a diferentes tiempos de estacionamiento de las emulsiones preparadas con los aislados $\mathrm{Ni}, \mathrm{Np}, \mathrm{Ei}, \mathrm{y}$ Ep. 
El backscatering en la zona superior es la resultante de los procesos de cremado (aumento de BS) y coalescencia (disminución). La disminución de este parámetro está indicando la ocurrencia de coalescencia en los aislados $\mathrm{Np}$, Ei y Ep, especialmente teniendo en cuenta que estas emulsiones mostraron un cremado temprano (Figura 7). Mientras que los valores elevados de Ni manifiestan que la coalescencia no es un componente significativo en el proceso de desestabilización de la emulsión de este aislado.

Estos resultados nos permiten concluir que $\mathrm{Ni}$, superior en solubilidad a $\mathrm{pH}$ 9 (Figura 3), presentó mayor actividad emulsificante que el resto de los aislados.

\section{II.B.3 Absorción de aceite}

Por último, se determinó la capacidad de los aislados de absorber aceite tal como se detalla en materiales y métodos.

Los resultados presentados en Tabla 7, muestran que, si bien por el grado de precisión del método, y/o el número de repeticiones realizadas, las diferencias entre aislados encontradas no fueron estadísticamente significativas ( LSD $p<0,05$ ).

Los valores son superiores a los observados por Chandi and Sogi (2007a) en la variedad Basmati 370 y en la caseína y similares a los de la variedad Basmati 386.

Por otro lado, también resultaron semejantes a los valores obtenidos en concentrados proteicos de hojas de vegetales (Aletor et al., 2002) y en aislados proteicos de soja (Gandhi et al., 2000).

Tabla 7. Valores medios de absorción de aceite de los aislados $\mathrm{Ni}, \mathrm{Np}$, Ei y Ep (expresados en $\mathrm{g} / \mathrm{g}$ )

\begin{tabular}{l|l}
\cline { 2 - 2 } & \multicolumn{2}{c}{ Absorción de aceite } \\
\hline $\mathbf{N i}$ & $7,59 \pm 0,54$ a \\
\hline $\mathbf{N p}$ & $7,57 \pm 2,65$ a \\
\hline Ei & $8,64 \pm 2,73$ a \\
\hline Ep & $11,34 \pm 0,47$ a \\
\hline
\end{tabular}

$* \mathrm{~g} / \mathrm{g}$ de aislado. Letras diferentes representan diferencias significativas (LSD, $p<0,05$ ). 


\section{I.B.4 Correlación entre propiedades funcionales evaluadas}

Dada la existencia de bibliografía contradictoria acerca de la influencia de la solubilidad proteica sobre las propiedades funcionales de hidratación y de superficie se realizó un análisis de correlación para los parámetros estudiados a pH 9, y fuerza iónica $\mu=0,2 \mathrm{M}$ de los aislados $\mathrm{Ni}, \mathrm{Np}$, Ei y Ep (Tabla 8).

Tabla 8. Matriz de correlación entre los parámetros de las propiedades funcionales evaluadas a $\mathrm{pH} 9$ y $\mu=0,2 \mathrm{M}$

\begin{tabular}{|c|c|c|c|c|c|c|}
\hline & \multirow{2}{*}{$\begin{array}{c}\text { Solubilidad } \\
\text { proteica }\end{array}$} & \multirow{2}{*}{ WHC } & \multicolumn{2}{|c|}{$\begin{array}{l}\text { Capacidad } \\
\text { espumante }\end{array}$} & \multicolumn{2}{|c|}{$\begin{array}{l}\text { Capacidad } \\
\text { emulsificante }\end{array}$} \\
\hline & & & $V_{\max }$ & $t_{1 / 2}$ & $\%$ BSin & $t_{0,1}$ \\
\hline $\mathrm{WHC}^{\mathrm{a}}$ & $\begin{array}{c}0,9128 \\
(0,0016)\end{array}$ & & & & & \\
\hline$V_{\max }^{b}$ & $\begin{array}{c}0,9775 \\
(0,0000)\end{array}$ & $\begin{array}{c}0,8299 \\
(0,0108)\end{array}$ & & & & \\
\hline$t_{1 / 2}{ }^{c}$ & $\begin{array}{c}0,7386 \\
(0,0364)\end{array}$ & $\begin{array}{c}0,4933 \\
(0,2142)\end{array}$ & $\begin{array}{c}0,8405 \\
(0,0090)\end{array}$ & & & \\
\hline$\% \operatorname{Bsin}^{d}$ & $\begin{array}{c}0,9225 \\
(0,0011)\end{array}$ & $\begin{array}{c}0,8791 \\
(0,0040)\end{array}$ & $\begin{array}{c}0,9036 \\
(0,0021)\end{array}$ & $\begin{array}{c}0,6755 \\
(0,0660)\end{array}$ & & \\
\hline$t_{0,1}^{e}$ & $\begin{array}{c}0,8718 \\
(0,0048)\end{array}$ & $\begin{array}{c}0,9314 \\
(0,0008)\end{array}$ & $\begin{array}{c}0,7708 \\
(0,0252)\end{array}$ & $\begin{array}{c}0,3445 \\
(0,4034)\end{array}$ & $\begin{array}{c}0,8767 \\
(0,0043)\end{array}$ & \\
\hline$K_{0,1}{ }^{f}$ & $\begin{array}{l}-0,7652 \\
(0,0269)\end{array}$ & $\begin{array}{l}-0,8502 \\
(0,0075)\end{array}$ & $\begin{array}{l}-0,6441 \\
(0,0848)\end{array}$ & $\begin{array}{l}-0,2910 \\
(0,4845)\end{array}$ & $\begin{array}{l}-0,8495 \\
(0,0076)\end{array}$ & $\begin{array}{l}-0,9342 \\
(0,0007)\end{array}$ \\
\hline
\end{tabular}

Entre paréntesis figura el valor de probabilidad $(p)$ : $p<0,05=$ correlación significativa; $p<0,01=$ correlación altamente significativa, $\mathrm{p}>0,05=$ correlación no significativa; a WHC: capacidad de retención agua $(\mathrm{ml} / \mathrm{g}) ;{ }^{b} \mathrm{~V}_{\max }$ : volumen máximo de líquido incorporado a la espuma $(\mathrm{ml}) ;{ }^{\mathrm{c}} \mathrm{t}_{1 / 2}$ : tiempo que tarda en drenar el $50 \%$ del volumen máximo $(\mathrm{min}) ;{ }^{d} \% \mathrm{BSin}$ : backscattering inicial $(\%)$; ${ }^{\mathrm{e}} \mathrm{t}_{0,1}$ : tiempo en que el $\% \mathrm{BS}_{10-30 \mathrm{~mm}}$ decrece un $10 \%(\mathrm{~min}) \mathrm{y}^{f} \mathrm{~K}_{0,1}$ : constante cinética.

Se ha observado una alta correlación $(p<0,01)$ entre la solubilidad proteica y capacidad de retención de agua (WHC). En esta oportunidad, las propiedades de hidratación se relacionaron con la solubilidad de los aislados. Por su parte, Were et al. (1997) estudiando aislados proteicos de soja, encontraron relación directa entre WHC y solubilidad. Asimismo, la capacidad de retención de agua se correlacionó con la capacidad de formar espumas y de formar y estabilizar emulsiones.

La capacidad de formar espumas se correlacionó en forma altamente significativa con la solubilidad $(p<0,01)$, mientras la capacidad de estabilización lo 
hizo en forma significativa $(p<0,05)$. Varios autores han encontrado que al aumentar la solubilidad de las moléculas, se incrementa la capacidad de formar espumas entre ellos Anderson et al. (2001) estudiando hidrolizados de glutelinas de arroz y Agboola et al. (2005) corroborando esta relación directa a diferentes pHs.

Se ha observado una fuerte relación entre los parámetros que caracterizan la emulsión y la solubilidad. Tanto el \%BSin, como el $t_{0,1}$ presentaron una correlación altamente significativa con la solubilidad, mientras que el $K_{0,1}$ se correlacionó en forma significativa y negativa dada la relación inversa entre este parámetro y la capacidad de estabilizar una emulsión. Existen posiciones encontradas en cuanto a la relación entre la solubilidad y la capacidad para formar y estabilizar emulsiones. Varios autores han encontrado una correlación positiva (Crenwelge et al., 1974; Volkert and Klein, 1979; McWatters and Holmes, 1979; Voutinas et al., 1983; Bera and Mukherjee, 1989; Qi et al., 1997; entre otros); mientras que otros mencionan que ambas propiedades no están necesariamente relacionadas (Wang and Kinsella, 1976; Aoki et al., 1980, Voutinas et al., 1983).

Por otro lado, se ha observado que la capacidad de estabilizar la espuma $\left(t_{1 / 2}\right)$ y los parámetros de la emulsión no se correlacionan en forma significativa $(p>0,05)$, mientras y como es de esperar, los que caracterizan a la emulsión están altamente correlacionados entre sí (Tabla 8).

Bera and Mukherjee (1989) estudiando concentrados proteicos de salvado de arroz encontraron una fuerte influencia del $\mathrm{pH}$ y la concentración salina sobre la solubilidad del nitrógeno y la capacidad de formar espumas y emulsiones. Al aumentar la concentración de sales decrecen la solubilidad, y la capacidad de formar espumas y emulsiones siendo inverso el comportamiento con la variación de $\mathrm{pH}$.

\section{II.C Conclusiones}

De acuerdo a los resultados obtenidos, la variedad Nutriar, se caracterizó por su mayor contenido proteico tanto en grano integral como en pulido y con valores del aminoácido esencial lisina algo superiores.

$\mathrm{Si}$ bien todos los aislados presentaron baja solubilidad a pHs neutros, con moderada a alta solubilidad a pHs extremos la variedad Nutriar se destacó por su mayor solubilidad tanto a pHs ácidos ( $\mathrm{Np}$ ) como a pHs alcalinos ( $\mathrm{Ni}$ ), características diferenciales que se vieron expresadas en sus propiedades funcionales. 
Los aislados de esta variedad presentaron mejores propiedades de hidratación, expresadas en elevados valores de WHC en agua. Por otro lado el aislado Ni presentó mejor capacidad de formar y estabilizar espumas y emulsiones.

Entre grano integral y pulido las diferencias se manifestaron en su digestibilidad, así como en sus valores de solubilidad y de WHC en agua siendo en todos los casos superior en aquellos aislados provenientes de grano integral. En cuanto a las propiedades de superficie, también se observaron diferencias entre aislados de grano pulido e integral; mientras los aislados de grano pulido presentaron mayor capacidad espumante en medio ácido, los de grano integral mostraron mejores propiedades en medio alcalino.

Estas características permiten diferentes aplicaciones de los productos y coproductos de la elaboración del grano de arroz. Los aislados, preparados a partir del quebrado (pulido) pueden ser buenos ingredientes para incluirlos en formulaciones alimenticias ácidas, mientras los aislados preparados a partir del grano completo incluyendo embrión y cubiertas externas le confieren características fisicoquímicas y nutricionales diferenciales. Las condiciones de $\mathrm{pH}$ en que estos aislados presentan sus propiedades de superficie óptimas constituyen una limitación para su utilización como ingrediente alimentario. Sin embargo las correlaciones analizadas especialmente a pH 9 y las observadas en el resto de los solventes utilizados permitieron reconocer una alta relación de la funcionalidad con la solubilidad de las proteínas de arroz. De esta manera, esta fuerte relación hace suponer que posibles modificaciones en la molécula proteica (como hidrólisis o acilación) que provoquen un incremento en su solubilidad permitirían la utilización de aislados proteicos de arroz como potenciales ingredientes para la industria. 
4 CONCLUSIONES GENERALES 


\section{4 / CONCLUSI ONES GENERALES}

Los resultados del presente trabajo permiten destacar al arroz de la variedad Nutriar con ventajas desde el punto de vista alimentario frente al arroz tradicional.

Su caracterización ha permitido concluir que:

- Esta variedad, de alto contenido proteico, posee una superioridad en la fracción glutelina, incremento que está localizado fundamentalmente, en los tegumentos externos del grano o salvado.

- Sus proteínas presentaron mayor solubilidad en la mayoría de las condiciones estudiadas. Posiblemente la existencia, en la fracción glutelina, de subunidades provenientes de diferentes subfamilias genéticas con mayor o menor grado de polimerización le confieran propiedades fisicoquímicas que se traducen después en propiedades funcionales diferenciales.

- Esta mayor solubilidad les permitió expresar mejor funcionalidad presentando a sus aislados proteicos como ingredientes alimentarios de elección. A su vez la mayor solubilidad y extractabilidad permitirían mayores rendimientos en la obtención de aislados a nivel industrial y con un mayor contenido proteico.

Se han encontrado diferencias entre proteínas de esta variedad provenientes de grano pulido e integral. Estas diferencias permiten proponer variadas aplicaciones.

- Mientras que las proteínas provenientes del grano pulido presentaron una mayor solubilidad, extractabilidad y funcionalidad a pHs ácidos las provenientes de grano integral se mostraron superiores en medio alcalino. 
Este interesante comportamiento se observó en las dos variedades estudiadas y no se ha podido explicar desde el punto de vista molecular.

- En especial el aislado de harina integral, se destacó en sus valores de capacidad de retención de agua (WHC) y a pHs 6 y 9, en su capacidad de absorción de agua (WIC), así como en su capacidad de formar y estabilizar espumas y emulsiones.

- La capacidad de estos aislados de absorber y retener agua jugaría un importante papel en la textura de diversos alimentos y podrían utilizarse especialmente en la elaboración de quesos, masas dulces y variados productos; mientras que por sus propiedades de superficie los aislados de grano pulido serían buenos agentes espumantes a pHs ácidos y los de integral a pHs alcalinos.

- Los aislados de grano integral en ambas variedades presentaron mayor digestibilidad que los correspondientes a grano pulido lo que sería destacable en formulaciones infantiles.

- La elevada correlación entre solubilidad y funcionalidad observada en las proteínas de arroz estudiadas, permiten suponer que posibles modificaciones químicas en la molécula proteica, como hidrólisis o acilación mejorarían la solubilidad de la proteína y posibilitarían la utilización de aislados proteicos como potenciales ingredientes para la industria alimentaria.

- Asimismo podría determinarse la funcionalidad de estos aislados proteicos en la formación de geles lo que abriría aun más el abanico de posibilidades de su utilización como ingrediente, recurso valioso, disponible y económico, posible de ser utilizado en la elaboración de alimentos. 
REFERENCIAS BIBLIOGRÁFICAS 


\section{REFERENCI AS BI BLI OGRÁFI CAS}

A.O.A.C. 1970. Association of Official Analytical Chemists Inc. Official Methods of Analysis of AOAC International. 11th ed., AOAC International. Gaithersburg, M.D. p. 858.

Abugoch, L. E.; Martínez, E. N. and Añon, M. C. 2003. Influence of the extracting solvent upon the structural properties of amaranth (Amaranthus hypochondriacus) glutelin. Journal of Agricultural Food Chemistry; 51: 40604065.

Abugoch, L. E. 2006. Relación estructura-funcionalidad de glutelinas y aislados proteicos de amaranto (Amaranthus hypchondriacus). Tesis doctoral. Universidad Nacional de La Plata, Facultad de Ciencias Exactas, Centro de Investigación y Desarrollo de Alimentos, CIDCA; 151p.

Adler-Nissen, J. 1979. Determination of the degree of hydrolysis of food protein hydrolysates by trinitrobenzenosulfonic acid. Journal of Agricultural and Food Chemistry, 27: 1256.

Agboola, S.; Darren, N. and Mills, D. 2005. Characterization and functional properties of Australian rice protein isolates. Journal of Cereal Science, 41: 283-290.

Ahmedna, M.; Prinyawiwatkul, W. and Rao, R. M. 1999. Solubilized wheat protein isolate: functional properties and potential food applications. Journal of Agricultural Food Chemistry; 47: 1340-1345.

Aletor, O.; Oshodi, A. A. and Ipinmoroti, K. 2002. Chemical composition of common leaf vegetables and functional properties of their leaf protein concentrates. Food Chemistry; 78: 63-68.

Anderson, A. K. and Guraya, H. S. 2001. Extractability of protein in physically processed rice bran Journal of American Oil Chemistry Society; 78 (9): 969972.

Anderson, A.; Hettiarachchy, N. and Ju, Z. Y. 2001. Physicochemical properties of pronase-treated rice glutelin. Journal of the American Oil Chemists' Society; 78: 1-6.

Ansharullah, J.; Hourigan, A.; Chesterman, C. F. 1997. Application of Carbohydrases in Extracting Protein from Rice Bran. Journal of the Science of Food and Agriculture; 74 (2): 141-146.

Aoki, H.; Taneyama, O. and Inami, M. 1980. Emulsifying properties of soy protein: Characteristics of 7S and 11S proteins. Journal of Food Science; 45: 534.

Apostolatos, G. 1984. Protein isolate rich in methionine from the edible dry bean (Phaseolus vulgaris L.). Journal Food Technology; 19: 233-237. 
Baldi, G.; Fossati, G. and Fantone, G. C. 1776. By-products of rice. II-Protein fractions and amino acid composition. Riso (Italian); 25: 347-356.

Bandyopadhyay, K.; Misra G. and Ghosh, S. 2008. Preparation and characterization of protein hydrolysates from indian defatted rice bran meal. Journal of Oleo Science; 57 (1): 47-52.

Barber, S. and Barber, C. B. 1974. Basic and applied research needs for utilization of rice bran as food and feed. Proceedings of the International Conference Rice-byProducts Utilization, Sept.29-Oct.2. Spain.

Baumann, H. 1967. Apparatur nach Baumann zur testimmung der flussigkeitsaufnahme von pulvrigen substanzen. Glas-und instrumenten-technik. Fachzeistschrift für das laboratorium; 11: 540-548.

Bera, M. B. and Mukherjee, R. K. 1989. Solubility, emulsifying and foaming properties of rice bran protein concentrates. Journal of Food Science; 54 (1): 142-145.

Betschart, A. A.; Fong, R. Y. and Saunders, R. M. 1977. Rice by products, Comparative extraction and precipitation of nitrogen from U. S. and Spanish bran and germ. J ournal of Food Science; 42: 1088.

Bezus, R.; Vidal, A. A. y Asenjo, C. 2002. Nuevo genotipo de alto potencial de rendimiento y contenido proteico. I Congresso da Cadeia Produtiva de Arroz. Anais, ISSN 1516-7518; p.47

Bourgeois, C. and Le Roux, P. 1986. Proteínas animales. 1 ed. Editorial El Manual Moderno. México.

Cagampang, G. B.; Cruz, L. J.; Espiritu, S. G.; Santiago, R.G and Juliano, B.O. 1966. Studies on the extraction and composition of rice proteins. Cereal Chemistry; 43: 145-155.

Cagampang, G. B.; Perdon, A. A. and Juliano, B.O. 1976. Changes in salt-soluble proteins of rice during grain development. Phytochemistry; 15: 1425-1430.

Chandi, G. K. and Sogi, D. S. 2007a. Functional properties of rice bran protein concentrates. Journal of Food Engineering; 79: 592-597.

Chandi, G. K. and Sogi, D. S. 2007b. Biochemical characterization of rice protein fraction. International J ournal of Food Science and Technology; 42: 1357-1362.

Chavan, J. K. and Duggal, S. K. 1978. Studies on the essential amino acid composition protein fractions and biological value (BV) of some new varieties of rice. Journal of the Science of Food and Agriculture; 29: 29-233.

Cheftel, J.; Cuq, J. and Lorient, D. 1989. Proteínas alimentarias. Editorial Acribia, Zaragoza, España. Cap. 4: 49-100.

Cheftel, J.; Cuq, J. y Lorient, D. 1993. Aminoácidos, péptidos y proteínas. En Química de los Alimentos. Director O. Fennema. Acribia; 275-414. 
Chen, L. and Houston, D. F. 1970. Solubilization and recovery of protein from defatted rice bran. Cereal Chemistry; 47: 72.

Chou, D. and C.U. Morr, 1979. Protein-water interactions and functional properties. J ournal of the American Oil Chemist Society; 56: 53-58.

Connor, M. A.; Saunders, R. M.; Kohler, G. O. 1976. Rice bran protein concentrates obtained by wet alkaline extraction. Cereal Chemistry; 53 (4): 488-496.

Crenwelge, D. D.; Dill, C. W.; Tybor, P. T. and Landmann, W. A. 1974. A comparison of the emulsification capacities of some protein concentrate. Journal of Food Science; 39: 175.

Damondaran, S. 1997. Protein-stabilised foams and emulsions. In: S. Damondaran, \& A. Paraf Eds., Food proteins and their applications, New Corp., Marcel Dekker, Cap. 3: 57-110.

Delseny, M. and Raynal, M. 1999. In: Shewry, P. and Casey, R. Seed proteins, Kluwer Academic Publishers, Netherlands; 427-475.

Desikachar, H. S. R. and Parpia, H. A. B. 1970. Processing and utilization of rice bran with special reference to its possibility for human food. Proceedings of $5^{\text {th }}$ World Cereal and Bread Congress, G.D.R.

Drzewiecki, J. 2001. Similarities and differences between Amaranthus species and cultivars and estimation of outcrossing rate on the basis of electrophoretic separations of urea-soluble seeds proteins. Euphytica; 119: 279-287.

FAO. 2004. http://www.fao.org/rice2004/es/f-sheet/hoja3.pdf. Fecha de consulta: 28/9/09.

FAO. 2008. http://www.fao.org/docrep/t0567e/T0567E08.htm. Fecha de consulta: 12-1208.

FAO/WHO. 1973. Ad Hoc Expert Committee. Energy and Protein Requirements. Tech. Report Series 522; FAO Nutrition Meetings Report Series No. 52. WHO, Geneva, FAO, Rome.

FAO/WHO/UNU. 1985. Energy and Protein Requirements. Technical Report Series No. 724; WHO: Geneva.

Fukushima, D. 1991. Recent Progress of Soybean Protein Foods: Chemistry, Technology, and Nutrition. Food Reviews International; 7: 323-351.

Furukawa, S.; Mizuma, T.; Kiyokawa, Y.; Masumura, T.; Tanaka, K. and Wakai, Y. 2003. Distribution of storage proteins in Low-glutelin rice seed determined using a fluorescent antibody. Journal of Bioscience and Bioengineering; 96 (5): 467-473.

Galili, G. and Herman, E. M. 1997. Protein Bodies: Storage Vacuoles in Seeds. Adv. Bot. Res.; 25: 113-140. 
Gandhi, A. P; Khare, S. K. and Jha, K. 2000. Preparation and characterization of protein isolates from soymeal. Journal of Food Science and Technology; 37: 624-626.

Gnanasambandam, R. and Hettiarachchy, N. S. 1995. Journal of Food Science; 60: 1066-1069, 1074.

Halling, P. J. 1981. Protein-stabilized foams and emulsions. CRC Critical Reviews in Food Science \& Nutrition; 12: 155-203.

Hamada, J. S. 1999. Use of proteases to enhance solubilization of rice bran proteins. Journal of Food Biochemistry; 23: 307-321.

Hamada, J. S. 2000. Characterization and functional properties rice bran proteins modified by commercial exoproteases and endoproteases. Journal of Food Science; 65 (2): 305-310.

Hardy, J.; Scher, J. and Banon, S. 2002. Review: Water activity and hydration of dairy powders. Lait; 82:441-452.

Hettiarachchy, N. S., Griffin, V. K. and Gnanasambandam, R. 1996. Preparation and functional properties of a protein isolate from defatted wheat germ. Cereal Chemistry; 73: 364-367.

Ju, Z. Y.; Hettiartachchy, N. S. and Bath, N. 2001. Extraction, denaturation and hydrophobic properties of rice flour proteins. Journal of Food Science; 66 (2): 229-232.

Juliano, B. O. 1972. The rice caryopsis and its composition. P: 16-74. In: Rice: Chemistry and Technology. $1^{\text {st }}$ ed. DF Houston, ed. American Associated of Cereal Chemists, St. Paul, Minnesota.

Juliano, B. O. 1980. Cap X. Properties of rice caryopsis, pp.403-438. In: Luh B. S. Rice production and utilization. Ed AVI Publishing Company, Inc. 924p.

Juliano, B. O. 1985. Rice Chemistry and Technology. 2nd Edition (edited by B.O. Juliano). American Association of Cereal Chemists, Inc. St. Paul, Minnesota, USA; $774 \mathrm{p}$.

Juliano, B. O. 1994. Polysaccharides, proteins, and lipids of rice. In: Rice: Chemistry and Technology Ed. St. Paul, Minnesota, American Associated of Cereal Chemists; 98-141.

Katsube-Tanaka, T.; Duldulao, J. B. A.; Kimura Y.; Iida S.; Yamaguchi T.; Nakano, J. and Utsumi, S. 2004a. The two subfamilies of rice glutelin differ in both primary and higher-order structures. Biochimica et Biophysica; Acta 1699; 95-102.

Katsube-Tanaka, T.; Endo, T.; Iida, S.; Yamaguchi, T. and Nakano, J. 2004b. Quality assessment of rice seed protein using the capillary electrophoresis method. Actas del 4 International Crop Science Congress, I.C.S.C., 1-5. 
Kinsella, J. E. 1981. Functional properties of protein: Possible relationships between structure and function in foams. Cereal Chemistry; $7: 273-288$.

Kneifel, W.; Paquin, P.; Abert, T. and Richard, J. P. 1991 Dairy foods. Water-holding capacity of proteins with special regard to milk proteins and methodological aspects - A Review. Journal of Dairy Science; 74: 2027-2041.

Komatsu, S. and Hirano, H. 1992. Rice seed globulin: A protein similar to wheat seed glutenin Phytochemistry; 31 (10): 3455-3459.

Krishnan, H. B.; White, J. A. and Pueppke, S. G. 1992. Characterization and localization of rice (Oryza sativa L.) seed globulins. Plant Science; 81: 1-11.

Krishnan, H. B. and White, J. A. 1997. Protein body formation and immunocytochemical localization of globulins and glutelins in developing rice (Oryza sativa L.) embryos. Crop Science; 37: 932-939.

Kumagai, T.; Kawamura, H.; Fuse, T.; Watanabe, T.; Saito, Y.; Masumura, T.; Watanabe, R. and Kadowaki, M. 2006. Production of rice protein by alkaline extraction improves its digestibility. Nutrition Science Vitaminol; 52: 467-472.

Kung, L.; Chen, H. and Sung, H. J. 1987. Chinese Agricultural Chemical Society; 25: 299-307.

Laemmli, U. K. 1970. Cleavage of structural proteins during the assembly of the head of bacteriophage T4. Nature; 227: 680-685.

Lew, E. J. L.; Hauston, D.F. and Feller, D. A. 1975. A note on protein concentrate from full-fat rice bran. Cereal Chemistry; 52:748.

Libore, A. B. 2006. Cultivares de arroz (pp. 95-110). In: El Arroz. Su cultivo y sustentabilidad en Entre Ríos. Ed. Universidad Nacional de Entre Ríos (UNER) y Universidad Nacional del Litoral (UNL); 1: 314p.

Lin, C. S., and Zayas, J. F. (1987). Functionality of defatted corn germ proteins in a model system: fat binding capacity and water retention. Journal of Food Science; 52: 1308-1311.

Loisel, W.; Guéguen, J. and Popineau, Y. 1993. In: Food Proteins. Structure and functionality. K. D. Schwenke and R. Mothes, Eds. VCH Weinheim. Germany; 320-323.

Lowry, O. H.; Rosebrough, N. J.; Farr, A. L. and Randall, R. J. 1951. Protein measurement with the folin phenol reagent. Journal of Biological Chemistry; 193: $265-275$.

Lynn, L. 1969. Edible rice bran foods. In: Protein-enriched cereal food for World Needs. Ed. Milner, M. American Association of Cereal Chemists Inc. St. Paul, MN. 154 p.

MacRitchie, F. 1998. In: Proteins at liquid interfaces; Moebius, D., Miller, R., Eds.; Elsevier: Amsterdam; 149p. 
Mahajan, A. and Dua, S. 1995. Functional properties of rapeseed protein isolates. Journal of Food Science Technology; 32:162-165.

Maki, Z. and Misao, T. 1983. Nutritional significance of rice bran protein concentrate with trypsin inhibitor activity. Journal of Nutritional Science Vitaminology; 29: 293.

Mandac, B. E. and Juliano, B. O. 1978. Properties of prolamin of mature and developing rice grain. Phytochemistry; 17: 611-614.

Martínez, E. N. and Añón, M. C. 1996. Composition and structural characterization of Amaranthus protein isolates. An electrophoretic and calorimetric study. Journal of Agricultural Food Chemistry; 44:, 2523-2530.

McWatters, A. and Holmes, M. 1979. Influence of moist heat on solubility and emusification properties of soy and peanut flours. Journal of Food Science; 44, 774-7765.

Mitra, G. N. and Das, B. 1975. Nutritive value of some rice varieties grown in Orissa. I. Protein content and composition of protein. J. Res. Orissa University of Agriculture and Technology; 5:51-57.

Mooney, B. P. and Thelen, J. J. 2004. High-throughput peptide mass fingerprinting of soybean seed proteins. Automated workflow and utility of UniGene expressed sequence tag databases for protein identification. Phytochemistry; 65: 17331744.

Morita, T. and Kiryama, S. 1993. Mass production method for rice protein isolate and nutritional evaluation. Journal of Food Science; 58: 1393-1396, 1406.

Nakano, T.; Shimatani, M.; Murakami, Y; Sato, N. and Idota, T. 1994. Digestibility and absorption of enzymatically hydrolized whey protein. Journal of Japanese Society of Nutrition and Food Sciences; 47: 203-208.

Nelina, A. y Ruíz, F. 2005. Efectos beneficiosos de una dieta rica en granos enteros. Revista Chilena de Nutrición; 32 (3): 191-199.

Nishimura, M.; Morita, R. and Kusaba, M. 2009. Review: Utilization and molecular characterization of seed protein composition mutants in rice plants. Japan Agricultural Research Quarterly; 43 (1): 1-5 http://www.jircas.affrc.go.jp.

Osborne, T. 1924. In: The Vegetable Proteins. 2da. Edición. Ed. Longmans and Green, Nueva York.

Padhye, V. W. and Salunkhe, D. K. 1979. Extraction and characterization of rice proteins Cereal Chemistry; 56 (5): 389-393.

Palazolo, G. G.; Sorgentini, D. A. and Wagner, J. R. 2004. Emulsifying properties and surface behavior of whey soy proteins in comparison other proteins. Creaming 
stability of oil-in water emulsions. Journal of the American Oil Chemists' Society; 81:625-632.

Pan, L. G.; Tomas, M. C. and Añon, M. C. 2002. Effect of sunflower lecithin on the stability o water-in-oil and oil-in-water emulsions. Journal of surfactants and detergentes; 5: 135-143.

Paranam, L.; Hettiarachchy, N. S.: Schaefer, C. and Beck, M. I. 2007. Hydrophobicity, solubility and emulsifying properties of enzyme-modified rice endosperm protein. Cereal Chemistry; 84 (4):343-349.

Petruccelli, S. and Añón, M. C. 1994. Relationship between the method of obtention and the structural and functional properties of soy protein isolates. 1. Structural and hydration properties. Journal of Agricultural and Food Chemistry; 42: 21612169.

Pilosof, A. M. R. 2000. Cap I. Propiedades de Hidratación. In: Pilosof A. M. R. y Bartholomai G.B. Caracterización funcional y estructural de proteínas Ed. CYTED-EUDEBA; 17-29.

Pomeranz, Y. and Ory, R. L. 1982. Rice processing and utilization. In CRC Handbook of Processing and Utilization in Agriculture; Wolff, I. A., Ed.; CRC Press: Boca Raton, FL; Vol. II, 139-186.

Prakash, J. and Ramanatham, G. 1995. Effect of stabilisation treatment of rice bran on nutritional quality of protein concentrates. International Journal of Food Sciences and Nutrition; 46 (2): 177-184.

Qi, M.; Hettiarachchy, N. S. and Kalapathy, U. 1997. Solubility and emulsifying properties of soy protein isolates modified by pancreatin. Journal of Food Science; 62 (6): 1110-111.

Qu, L.; Satoh, H.; Ogawa, M. and Wei, X. 2001. Improved eletrophoretical analyses for rice seed storage protein. Acta Genetica Sinica; 28 (8): 730-737.

Quinn, J. R. and Paton, D. 1979. A practical measurement of water hydration capacity of protein materials. Cereal Chemistry; 56: 38-40.

Quiroga, A. V.; Martínez, E. N. and Añón, M. C. 2007. Amaranth globulin polypeptide heterogeneity. The Protein J ournal; 26 (5): 327-333.

Robert, L. S.; Nozolillo, C. and Altosaar, I. 1985. Homology between rice glutelin and oat 125 globulin. Biochimica et Biophysica Acta; 829: 19-26.

Saeed, M. and Cheryan, M. 1988. Sunflower protein concentrates and isolates low in polyphenols and phytate. Journal of Food Science; 53: 1127-1131.

SAGPyA.

http://www.sagpya.mecon.gov.ar/new/00/agricultura/otros/granos/arroz0405.p hp, pagina web de la Secretaria de Agricultura, Ganadería, Pesca y Alimentos. Fecha de consulta: el 7/10/2008. 
Sánchez-Vioque, R.; Clemente, A.; Vioque, J.; Bautista, J. and Millán, F. 1999. Protein isolates from chickpea (Cicer arietinum L.): chemical composition, functional properties and protein characterization. Food Chemistry; 64: 237-243.

Sawai, H. and Morita, Y. 1970. Studies of $\gamma$ globulin of rice embryo. Part II. Separation of three components of $\gamma$ globulin by ion exchange chromatography. Agricultural Biology and Chemistry; 34:53.

Schägger, H. and von Jagow, G. 1987. Tricine-Sodium Dodecyl Sulfate-Polyacrylamide gel electrophoresis for the separation of poprteins in the range from 1 to 100kDa. Analytical Biochemistry; 166: 368-379.

Schwenke, K. D. 2001. Reflections about the functional potential of legume proteins. Nahrung; 45: 377-381.

Shih, F. F. and Daigle, K. W. 1997. Use of enzymes for the separation of protein from rice flour. Cereal Chemistry; 74 (4): 437-441.

Shih, F. F. and Daigle, K. W. 2000. Preparation and characterization of rice protein isolates. Journal of the American Oil Chemists' Society; 77, 8:885-889.

Shih, F. F. 2003. Review: An update on the processing of high-protein rice products. Nahrung/Food; 47 (6): 420-424.

Shotwell, M. A. and Larkins, B. A. 1989. The biochemistry and molecular biology of seed storage proteins. En: The biochemistry of plants, a comprehensive treatise. Ed. Marcus, A. New York: Academic Press; 297-345.

Shyur, L.; Wen, T. and Chen, C. H. 1994. Purification and characterization of rice prolamins. Botanical Bulletin of Academia Sinica; 35: 65-71.

Silingo, A. 2000. Propiedades estructurales y funcionales de aislados proteicos de soja modificados. Efecto de la presencia de calcio. Tesis doctoral. Universidad Nacional de La Plata, Facultad de Ciencias Exactas, Departamento de Ciencias Biológicas; 193p.

Steenson, D. F. and Sathe, S.K. 1995. Characterization and digestibility of Basmati rice (Oryza sativa L. var. Dehraduni) storage proteins. Cereal Chemistry; 72(3): 275-280.

Tang, S.; Hettiarachchy, N. S.; Ju, Z., and Cnossen, A. 2002. Surface hydrophobicity and protein cross-linking in rice subjected to varying drying and tempering condition. Journal of Food Science; 67(8): 2930-2933.

Tang, S.; Hettiarachchy, N. S.; Horax, R. and Eswaranandam, S. 2003. Physicochemical properties and functionality of rice bran protein hydrolyzate prepared from heat-stabilized defatted rice bran with the aid of enzymes. Journal of Food Science; 68 (1): 152-157. 
Tecson E. M. S.; Esmama B. V.; Lontok, L. P. and Juliano, B. O. 1971. Studies on the extraction and composition of rice endosperm glutelin and prolamin. Cereal Chemistry; 48 (2): 168-181.

Torgensen, H. and Toledo, R. T. 1977. Physical properties of protein preparations related to their functional characteristics in comminuted meat systems. J ournal of Food Science; 42 (6): 1615-1618.

Udaka, J.; Koga, T.; Tsuji, H.; Kimoto, M. and Takumi, K. 2000. Efficient extraction and some properties of storage proteins (prolamin and glutelin) in ancient rice cultivars. J ournal of Nutritional Science and Vitaminology; 42 (2): 84-90.

Utsumi, S. 1992. Plant food protein engineering. In: J. E. Kinsella (Ed) Advances in Food Nutrition Research, Academic Press, San Diego CA; 36: 89-208.

Villarreal, R. M. and Juliano, O. B. 1978. Properties of glutelin of mature and developing rice grain. Phytochemistry; 17: 177-182.

Vioque, J.; Sánchez-Vioque, R.; Pedroche, J.; Yust, M. y Millán, F. 2001. Obtención y aplicaciones de concentrados y aislados proteicos. Grasas y Aceites; 52 (2): 127-131.

Volkert, M. A. and Klein, B. P. 1979. Protein dispersibility and emulsion characteristics of flour soy products. Journal of Food Science; 44: 93.

Voutinas, L. P.; Cheung, E. and Nakai, S. 1983. Relationships of hydrophobicity to emulsifying properties of heat denatured protein. Journal of Food Science; 48: 26-32.

Wagner, J. R.; Sorgentini, D. A. and Añón, M. C. 1996. Thermal electrophoretic behavior, hydrophobicity, and some functional properties of acid-treated soy isolates. Journal of Agricultural and Food Chemistry; 44:1881-1889.

Wagner, J. R. 2000. Capítulo III. Propiedades superficiales. In: Pilosof A. M. R. y Bartholomai G.B. Caracterización funcional y estructural de proteínas. Ed. CYTED-EUDEBA: 41-74.

Wang, J. C. and Kinsella, J. E. 1976. Functional properties of novel proteins: alfalfa leaf proteins. Journal of Food Science; 41: 286.

Wang, M.; Hettiarachchy, N. S.; Qi M.; Burks, W. and Siebenmorgen, T. 1999. Preparation and functional properties of rice bran protein isolate. Journal of Agricultural and Food Chemistry; 47: 411-416.

Wen, T. N. and Luthe, D. S. 1985. Biochemical characterization of rice glutelin. Plant Physiology; 78: 172-177.

Were, L.; Hettiarachchy, N. S. and Kalapathy, U. 1997. Modified soy proteins with improved foaming and water hydration properties. Journal of Food Science; 62 (4): $821-823$ y 850. 
Wieser, H.; Seilmeier, W. and Belitz, H. D. 1980. Vergleichende untersuchungen über partielle aminosäuresequezen von prolaminen und glutelinen verschiedener getreidearten. I Protein fraktionierung nach Osborne. Z. Lebensm. Unters. Forsch; 170: 17-26.

Wijerante, W. B. 2005. Propiedades funcionales de las proteínas de soya en un sistema de alimentos. Alimentaria Ed. Alfa editores. Noviembre- diciembre 2005.http: //www.alfa editores.com/alimentaria/Noviembre\% 20Diciembre\%2005/TECNOLOGIA. Fecha de consulta: 23/09/09.

Wilde, P. and Clark, D. 1996. Methods of testing protein functionality. Cap.V. Foam formation and stability. Edited by G. Hall Blackie Academic y Professional. Primera edición; 111-148.

Yamagata, H.; Sugimoto, T.; Tanaka, K. and Kasai, Z. 1982. Biosynthesis of storage proteins in developing rice seeds. Plant Physiology; 70: 1094.

Zhai, C. K.; Lu, C. M.; Zhang, X. Q.; Sun, G. J. and Lorenz, K. J. 2001. Comparative study on nutritional value of Chinese and North American wild rice. Journal of Food Composition and Analysis; 14: 371-382.

Zhou, Z.; Robards, K.; Helliwell, S. and Blanchard, C. 2002. Review: Composition and functional properties of rice. International Journal of Food Science and Technology; 37:849-868. 